



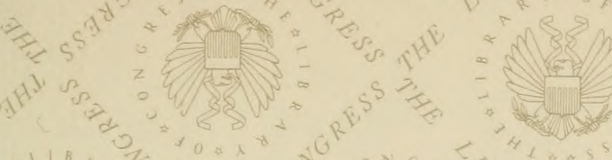

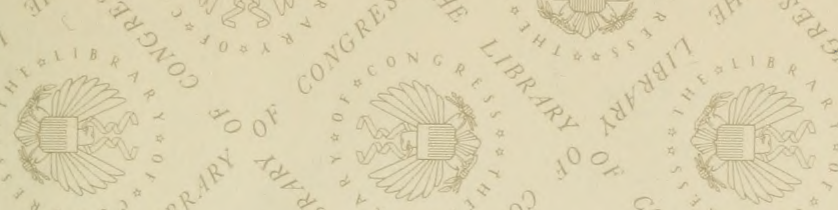

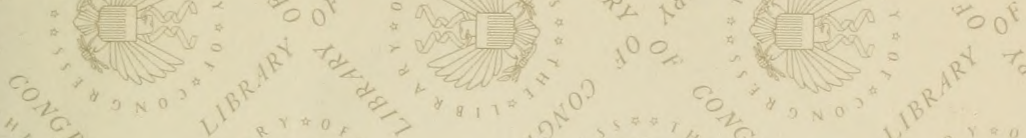

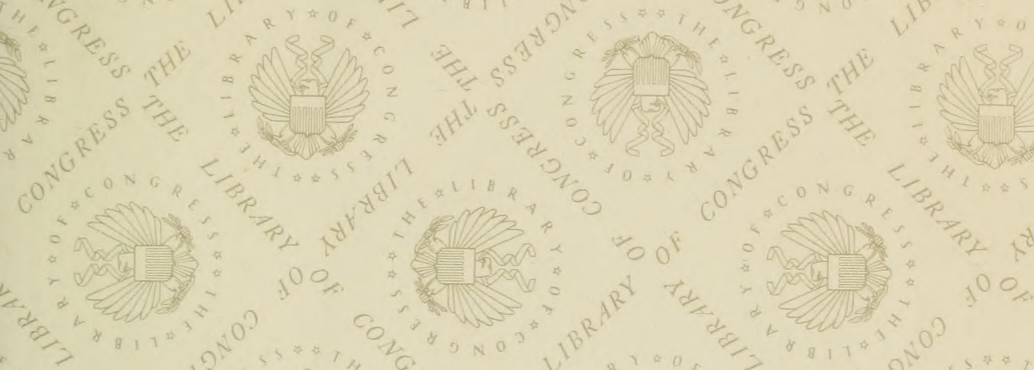
(1)

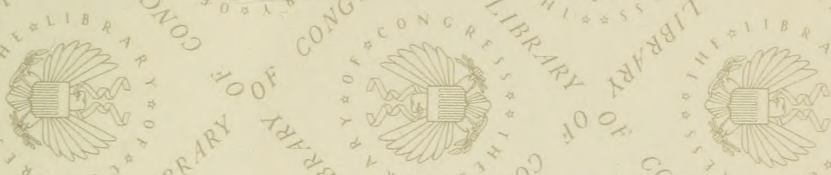

8

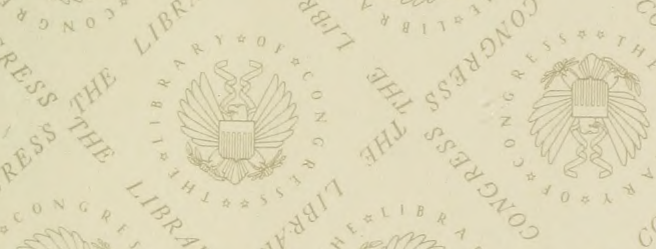

and $=0$

$\mathrm{C}^{\circ} \mathrm{s}$

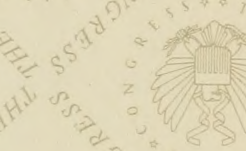


N. 


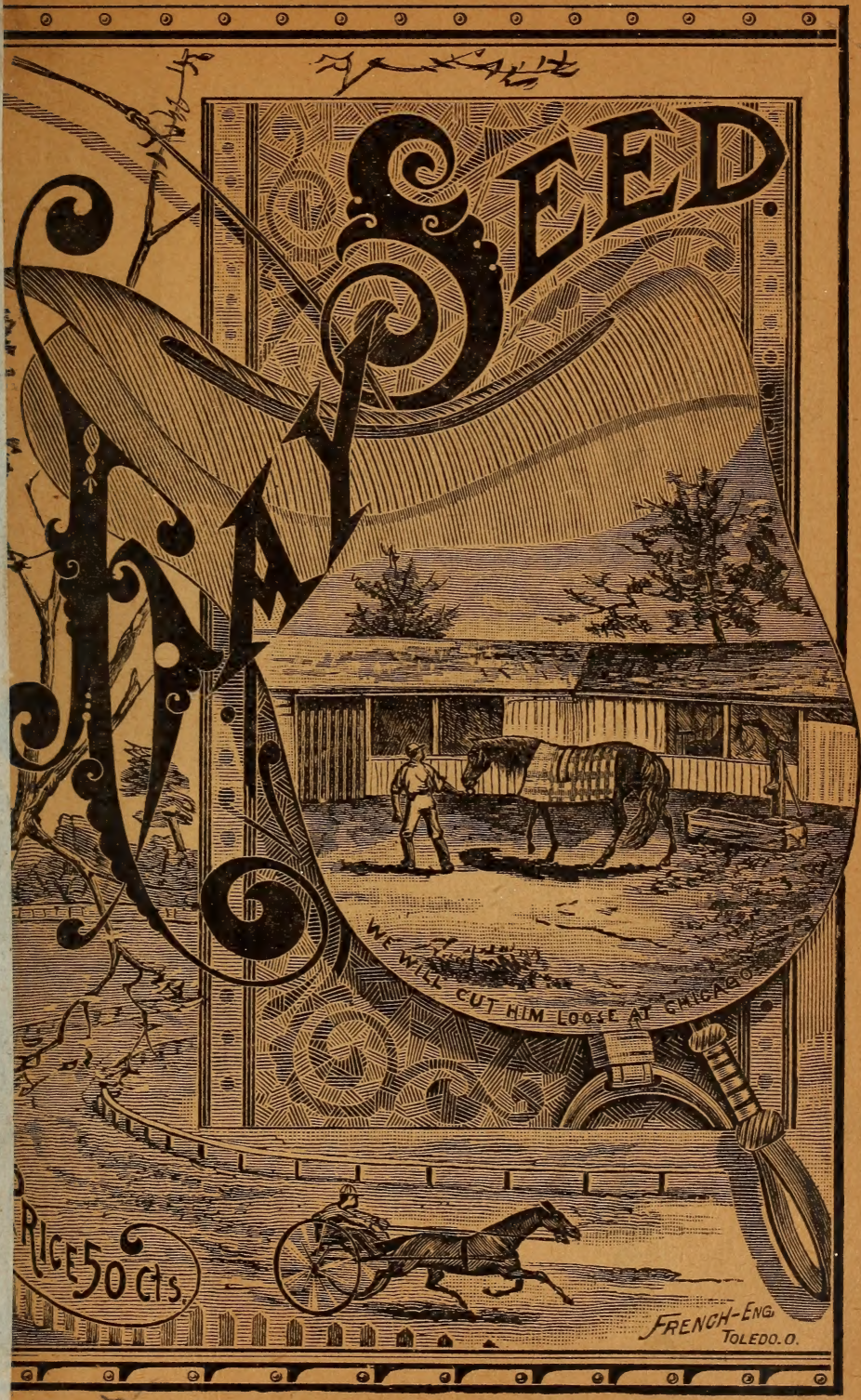





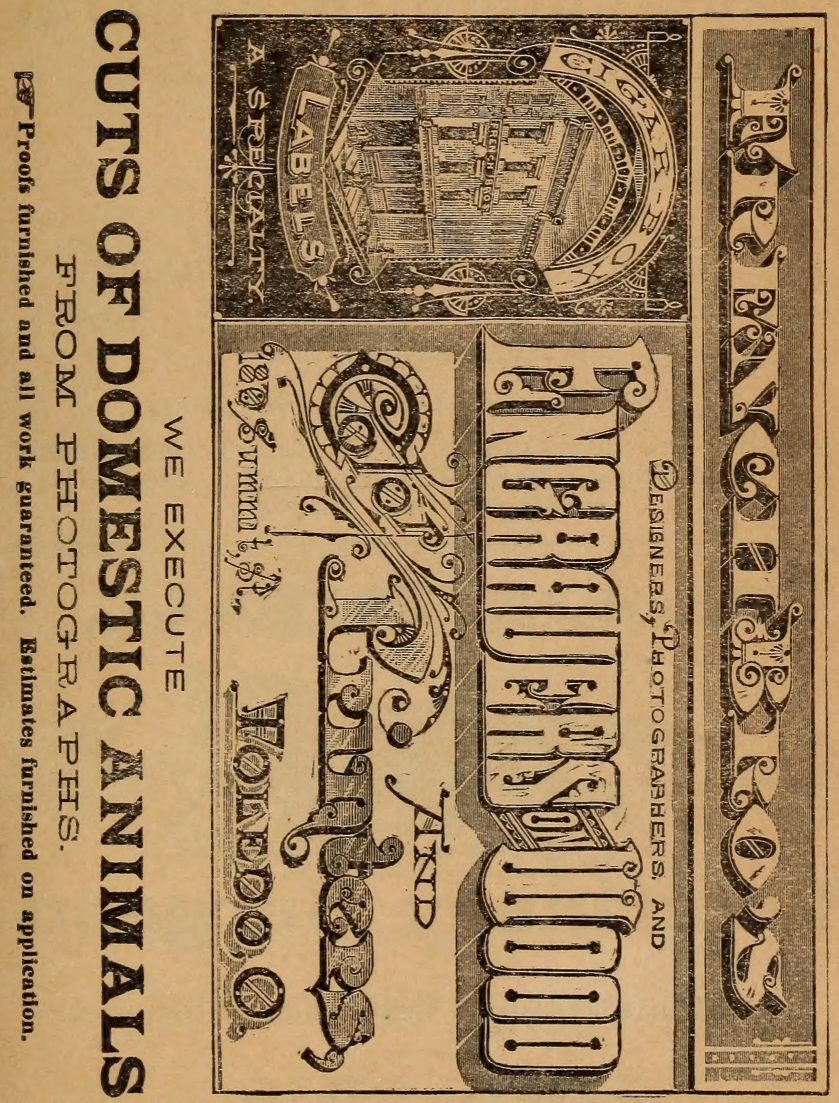




\section{MOLONY,}

Manufacturer of Cigars,

INO. 59 MONIEOM Ex",

TOLEDO, 0.

BRANDS

CHIEF JUSTICE, BOARD OF TRADE,

LA CAROLINA, CUNARD,

LEONA,

WHITE SWAN, \&c.

PRIVATE BRANDS TO ORDER.

None but the Best Quality of Havana Tobacco from the Vueta Abajo, District of Cuba, used in our our Best Goods.

Dr. A. N. SMEAII,

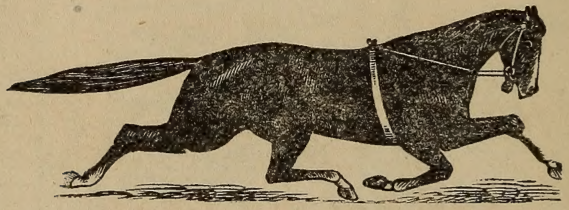

Veterinary Surgeon

(Graduate Ontario Veterinary College),

$$
\text { IIMA, OEIO. }
$$

Calls by Telegraph promptly attended to. 


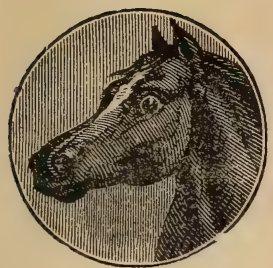

Has the following Stallions in Stud:

WINFIELD BOY,

By Edward Everett.

MAMBRINO

PATCHEN, Jr.

By DeHerr's Mambrino Patchen.

HENGIS,

Imp. Percheron. 299 St, Clair Street, Toledo, 0. LORD LORNE,

Imp. Clyde.
.V. NEWTON,

Surgeon,

(Graduate Ontario Veterinary College.)
Veterinary

MEDICINE FOR HORSES \& CATTLE

ALWAYS ON HAND.

Calls to Country by Mail or Telegram promptly attended to.

Office, Infirmary, Boarding and Sale Stable

Residence, 2 lst and Jefferson Sts.

\section{J. H. WAGNER}

Manufacturer of and Dealer in

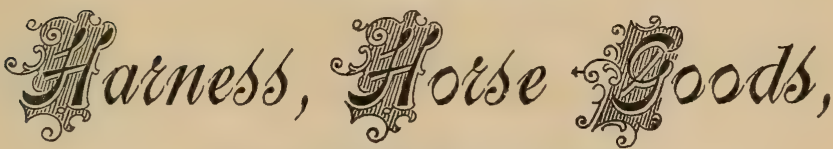

AND RACING CEAR

I Make a Specialty of Single Strap

TRACK HARNESS, FORב̨\$30, Guaranteed.

Goods Sent O. O. D. by Express to all parts of the U.S.

\section{J. H. WAGNER,}

117 Superior Street, TOLFDO, OHIO. 


\section{CONTENTS.}

PAGE.

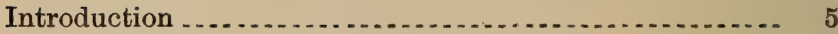

Shoeing, Feeding and Watering ..................... 7

Teeth............................ 9

Clothing, Harness, Bits, etc. ........................ 13

Shoeing, Boots, Care After Work ................... 16

Faster Work, Repeats, etc........................... 19

Sweating Scrapes, Their Effects and Reasons for........ 22

The Sweat......................................... 27

Treatment After the Sweat ...................... 30

Watchfulness now the Order of the Day ............... 32

Financial Matters Discussed a Little.................... 34

How to Develop a Horse.............................. 36

Win if you Can .................................... 39

Toe Weights Changing the Way of Going .............. 41

Management Before and in the Race.................... 43

Value of Trotters Compared with Pacers................ 46

Wintering a Trotter or Pacer........................ 48

Developing a Pacer................................. 50

Harnessing and Driving Horses........................ 54

Buying a Horse.................................... 57

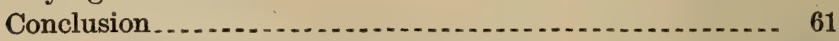

Rules National Trotting Association............... 63-92

Betting Rules_............... 93-99

List of 2:30 Trotteirs .

List of $2: 30$ Pacers. ............................... 135-141 


\title{
HAY SEED:
}

—or-

\section{HOW TO DEVELOP SPEED}

\author{
$-\mathrm{IN}-$ \\ TROTTERS AND PACERS,
}

$\longrightarrow \mathrm{AND}-$

STEER THEM IN A RACE.

Also, the Rules of the National Trotting Association, and the names of all Horses with Records of 2:30 or better, Trotting or Pacing, down to the close of 1883 .

TOLEDO:

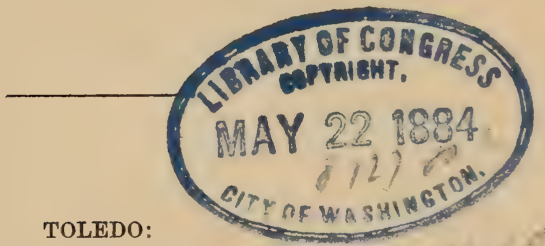

Blade Printing and Paphr Co. 1884. 


\section{$S T=11$}

Entered according to Act of Congress,

In the Office of the Librarian of Congress, at Washington, D. C., by

J, E. WATSON,

In the yeás of our Lord, 1884.

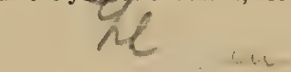




\section{PREFACE.}

$\mathrm{HE}$ author and compiler of this work has endeavored to condense and crystalize, in as brief a manner as possible, the great fundamental principles of developing speed in Horses, and believes that by a careful reading and attention to the contents of this work, any man with horse sense and a natural love for this noblest of all animals, coupled with a patient dispositiona man who can "wait and win,"-can become a successful trainer and driver. The work is peculiarly adapted to amateurs and farmer boys, who can readily understand every word contained in the work without reference to the dictionary. The author has confidence the work will be appreciated, from the fact that it is the only brief treatise of its kind in English literature that embodies all the information the amateur needs. And there is no doubt that in the future, when interviewing the great Knights of the Ribbons rivaling the fame of Bither, Johnson, Turner, Mace, Splan, Frank Van Ness, Jack Phillips, and other present great lights of the trotting turf, the reporter will be informed that their fame is indebted in no small degree to

Hay Seed. 



\section{HAY SEED.}

\section{CHAPTER I. \\ INTRODUCTORY.}

It is my intention to give in this work a few short and sensible hints as a guide to the horsemen who seek to handle their own horses, who have had little or no experience in the art of developing speed. There is no legerdemain or slight of hand business about developing a trotter ; the business was formerly, say twenty-five years ago, shrouded in mystery, and a trainer of trotting horses was looked upon as a walking epitome of knowledge, when at the same time nine out of ten of these same men were comparatively amateurs. The whole business of developing speed in horses is based upon common sense and the knowledge of the laws of health as applied to the equine race. Now, to begin with, don't ever fool your time away with a dunghill or culd-blooded animal, one that will be looking for a place to lie down before he gets to the half-mile pole. But don't understand me that a horse of whose breeding nothing is known is necessarily a dunghill. A well bred horse, if he doesn't look it, will show it in his miles, and there is where breeding is of the most value and satisfaction. But an exceptionally well bred animal will never be overlooked by a horseman, though he may have no pedigree that anybody knows of.

We will take it for granted that your horse is broken or has been driven in harness; if your colt has never been driven he may be worth more than if he had been handled by some of the self-styled horse breakers. In the first place, don't do anything to the young horse to shake his confidence in mankind, but try and cultivate his confidence and respect. As good a way as I know of to 
gentle green colts - three, or even four years old-is to tie them in a stall in a barn with other horses and treat them just the same, viz: feed, water, bed, groom and go through the whole business with them until they become accustomed to the noise, and having people around. They will in a couple of weeks become perfectly docile. I have found that the less fuss that was made about hitching up a green colt the better. If you have got a good driving pole horse, hitch the colt in with him, to some light running vehicle, having first had a harness on him a few times and a bit in his mouth, and if he has had the proper kind of treatment around the stable it is a hundred to one he will go off readily, and by the time he has been driven a mile he will act like a horse ; don't drive him too far, two or three miles is far enough the first time. Keep driving him every day carefully. But if you have not got a good driving pole horse, hitch the colt to a skeleton wagon or sulky and get up behind him just as though he had been driven before. Make him think he is a horse, and above all don't fight him, and don't try to pull his head up too high unless you know he is going to kick. Get him to do what he does cheerfully and you will have a better broken horse in two weeks than half the old ones are. 


\section{CHAPTER II.}

\section{SHOEING, FEEDING AND WATERING.}

The colt should be shod if worked on dirt roads, and if snow or ice prevail shoe him all around sharp, so he can stand up. Don't shoe him too heavy, a twelve or thirteen ounce shoe in front and an eight ounce shoe behind is heavy enough. If you don't know how to have him shod, go to the best and most intelligent blacksmith you know and tell him you want him shod just as well as he would shoe a trotter, and pay him what he asks, if he is a man of judgment and experience in this kind of shoeing. I ain not going to write a work on shoeing horses; there are too many of that kind of publications now, and the more a man reads-the greater part of them-the less he knows.

In regard to feeding, which is a very important part of our undertaking, I will say: A three-year-old ought to have at least ten quarts of oats a day and what hay he will eat up in an hour, say at night. If you are going to make a practice of driving him early in the morning, give him two quarts of oats and a little water before you hitch him up; it will stay his stomach and he will feel more like going out. But if you don't work him until late in the forenoon, give him his full feed, four quarts, about six o'clock in the morning, and a little hay. In respect to feeding hay, or grain either, no man can lay down any rule as to how much any horse should consume in $\mathbf{2 4}$ hours. They want what they need to supply the natural waste of the body and keep them in strength and flesh and growing every day. Here is where judgment comes in play. A colt doesn't want drawing so as to make him look gaunt like an old campaigner, neither do you want to stuff him. In aged horses hay at night only will ordinarily suffice if the horse is a hearty 
feeder, and again some horses will not eat any more than they need if they have it by them all day. Colts, like boys, ordinarily have good appetites, and want enough to keep them growing.

Give the horse all the water he wants at night, unless he has a race or trial on hand for the morrow, when it would not be advisable. In the morning a horse, if he is in good health and is accustomed to have what water he wants at night after he has finished his hay, will not exhibit much thirst, unless he is a glutton and has gorged himself with his bedding, which habit ought to be curtailed at once, for no horse can be gotten into condition or kept so, if he eats all the litter he can reach. In short, water should not be given a horse in quantity when it is going to interfere with the performance of his daily work. Give him a couple of swallows in the morning before he eats his feed. Never give him over one-half a bucket at once except at night, when he may have a reasonable allowance. Rain, river and spring water are the kinds ordinarily in use for horses in training, well water being too cold, drawn directly from the well, to give horses with safety. A sudden change of localities, as a campaign necessitates, sometimes compels a change of water from hard to soft, or vice versa, and is attended always with some danger of relaxation of the bowels, but by adding a small handful of linseed meal to a bucket of water and gradually decreasing the quantity, the use of it can be discontinued in two or three days, and your horse will have become accustomed to the water. Water is better to stand in the sun and air long enough to approach the temperature of the atmosphere before using it if it is well or cistern water. If a horse is a light and delicate feeder, the more water you can get him to drink the more he will consume of feed. Dainty feeders are nearly always light drinkers. The lise of water for such horses with just enough cream tartar in it to assidulate it slightly has been found beneficial. If a horse is inclined to drink too much put only as much in the bucket as you want him to drink at one time. Other horses 
want a pailful set down for them so they can drink it unobserved.

In checking a horse up you need a check bit independent of the driving bit. Some horses will check with an old-fashioned check rein and check bit with the gag runners sewed or hooked high on the crown piece of the headstall, but nearly all the trotters and pacers are checked with an overdraw check running over the top of the head and buckling into the small check bit. You want a set of bandages, a couple of scrapers and plenty of rubbers made from linen salt sacks; you want a dozen for each horse; you want a couple of soaking tubs; take a kerosene oil barrel and saw off each end with a depth of six or eight inches, fit some boards inside of the chime and screw them to the head, so your horse will not push the bottom out when he steps his weight onto them. Wire spring skewers are essential; and you also want a good muzzle, but be careful how you use it. You will need a rubbing out headstall, merely a strap over the top of the head, each end buckling into the ring of a bit; you want a foot and a tooth rasp, and numerous other articles as your wants will suggest. Toe weights are very useful in some instances, and occasionally indispensable, but never use a weight that you have to fasten to the foot with screws screwed into the horn. I have seen inflammation set up in the foot from the screws pressing into the laminæ of the foot, and severe lameness result from their use.

TEETH.

The teeth in horses are receiving more attention than formerly, as it is a well settled fact that their teeth are subject to decay, ulceration, irregular growth etc., same as in the human family, though not perhaps, in the same degree. A horse in his three or four year old forms is most liable to suffer, as the three-year-old cuts four front teeth and eight back teeth, and in their fourth year they cut four front, eight back, and four tushes, and considerable irritation and fever often attend the cutting of these teeth. 
Attention should be directed to the shedding of the molars in the three-year-old, the roots becoming absorbed, the crowns of the teeth get loose and hang to the gums, and should be removed as they will cut the cheek and make the mouth sore. Many horses I am satisfied suffer from toothache with decayed teeth, and when a decayed tooth is discovered it ought to be removed immediately, upon its first attempt to ache. The presence of decayed teeth may be detected by such symptoms, as improperly masticated food passing the bowels undigested, tossing the head, discharge from one nostril, irritable disposition pulling or driving on one rein, and pulling at the bit or refusal to take hold of the bit. The remedy for decayed teeth is removal. You will need the assistance of some one skilled in Veterinary dentistry, to remove a decayed molar tooth The upper jaw being wider than the under one, the outer margin of the upper grinders become sharp, and unless this over-growth is removed with a tooth-rasp, the cheek, coming in contact with the sharp edges of the grinders, gets sore, and checking a horse aggravates him, as it presses the cheek against the teeth with greater force. The inside margins of the lower grinders get sharp in the same way, and hurt the tongue, and no horse can be made to trot or pace fast, that has teeth that hurt or aggravate him, and as a trainer, you should always keep a tooth-rasp handy, they cost little, and you can remove the sharp edges of teeth as well as any one, but for the extraction of a grinder, you had better employ a Veterinary dentist, as it is quite an undertaking. The reason a horse cannot go fast with teeth - that hurt him is, that if he carries his head one sided, as he will invariably do if he is driving on one rein, he can't go square, and is bound to tangle in his gait, and of course cannot speed fast. I have seen horses in a race in scoring, that carried their heads one sided, and pulled on one rein; these horses were suffering from imperfect teeth or effects of same. These horses knowing how to go, would finally take hold of the bit and go fast, but this was game in its triumph over infirmity, the horse having 
acquired the proper way of going, in his course of training, and possessing the spirit to do or die, he takes hold of the bit, though it may be ever so painful, and tries to get there. Horses possessing this valuable inheritance, known as game, (which is by the way imparted from one generation to the other), are very dangerous competitors in a race. 


\section{CHAPTER III.}

CLOTHING, HARNESS, BITS, ETC.

There are different opinions about blankets and covering for horses in the stable. I don't believe a horse needs anything more than to make him comfortable. No horse ought to sweat under the blankets in the stable, and he should be provided with changes, so he can be made comfortable in any change of the temperature. In winter, if he is clipped, he must be provided with extra clothing, unless the stable is heated artificially, and for out door use the blanket for clipped horses should be large enough to cover them well down toward their feet, and the shed ought to be a very warm one, or they ought not to be left under it at all if it is a cold day. A single strap rubber trimmed harness with a good, substantial, three inch saddle and flat lines, all made from Maffot's leather, is good enough for anybody and looks as well as any harness that was ever made. Horses ordinarily act as well in a headstall with winkers as any, although some flighty, nervous horses, and shyers, act better in an open bridle. Experiment will teach you which kind of headstall to adopt. There are a thousand styles of bits, but the ordinary jointed bit, known as the Dexter trotting snaffle, is as good as any. Sume horses act better with a plain bar bit than any other, but use the one your horses appear to like best. Don't make a puller of him by driving him on a bit he is continually fighting against. 


\section{CHAPTER IV.}

OBJECT OF WORKING HORSES-WORK FOR AGED HORSES.

It is important for the amateur to understand why he is working his horse. What is the object of it? Why, to develop his speed, of course. But not one man in ten can give you an intelligent answer to your questions as why do you do so and so. Now no horse can go any faster than he has got power to carry him. If the speed is not in him, no man can make him show it.

Speed is the physical capacity or power to get over the ground at a rapid rate. A horse may have apparently the physical capacity to go fast, but does not and can not; he may be proportioned correctly and fill all the dimensions of the tape line trotter and look like a trotter, but can't go on-and here is where those knowing men get left in trying to pick out a trotter with a tape line and references to the stud books. A horse without the inborn disposition to go on and get there is no good, no matter how he is bred, how he is formed, or how he is gaited. You get him in a tight place where it is necessary for him to extend himself and he will shut up like a jack knife, and quit without any apparent reason, only that he don't seem to want to do it. If a horse is strong and has the disposition to go on, if he is not quite perfectly gaited, he will oftener surprise you by his rapid improvement than would a finely gaited one, and just as strong and sound, that don't care whether he gets there or not.

We will assume that you have got a horse sound and five years old, that has a gait that is pure enough to carry him a mile in 2:30, when in condition to go a mile; and this horse has never had an attempt made to develop the speed he is supposed to possess. We will also assume that it is early spring, the roads are in condition to 
drive upon, and you are situated so you can give this horse all the attention he needs to develop the latent speed he is expected in the near future to exhibit. I will say a few words respecting the quarters you give the horse to occupy. A box stall twelve by fourteen feet, with a plank floor not too tight to prevent the urine from running through, will answer, and the floor should be far enough from the ground not to be damp. Arrangements should be made to properly drain the grounds in the vicinity of barns and stabling, as horses are, in my judgment, susceptible to malarial disorders, as well as the human family. I do not like an underground barn with stalls for horses over the basement, as there is always a draft through any aperture there may be in the floor, and horses' feet dry up when kept in such a place, and require a great deal of attention. A clay or earth floor is not desirable for horses doing fast work and sweating considerably, as they are liable to contract colds, coughs and rheumatic troubles from lying on these ground floors with nothing but straw between them and the earth. Don't let your horse lie on the ground if you are working him for speed.

It is understood by you, of course, that proper ventilation is desirable, as is also light. The windows for ventilating the stable should be about six feet from the floor, so that any draft through these windows will not strike the horse. We will suppose this horse as yet has not shown any disposition to interfere or cut himself anywhere; this being the case, you have not got to worry yourself about the shoeing, a very great relief, I assure you. Now you want to make a firm resolve not to speed this horse, either for your own or any other person's gratification or amusement, until he has had some work and got strong, and has learned something about going along-if you expect to make a trotter out of him. Walking exercise has been found not absolutely necessary, as formerly indulged in. Old time trainers used to begin by giving horses walking exercise in the spring for two or three weeks before they even thought of driving them in 
harness; but I believe that a horse is safer in the hands of the trainer, hooked to a light wagon or sulky, than he is in the care of a boy doing his walking work out of sight of the barn. You may commence by jogging and walking a little, say five or six miles (in the forenoon is the best time) for the first week or ten days. Ten quarts of oats in three feeds, of four quarts in the morning, two at noon, and four again at night, with some hay, ought to be enough for him, and you ought to see him begin to improve in the way he does his work as well as in appearance. By this time he will be in shape to send along a little, and you ought to increase his work a little, and likewise the amount of oats, say to twelve quarts per day; but if you observe that he don't like the increased amount of work, wait a week more. By this time the muscles must have tone enough in them to carry him along on a good road a ten-mile-an-hour clip, for four or five miles, without much apparent fatigue. But don't begin to brush him yet; he wants to be able to jog his ten miles out in an hour easy before you commence to call on him. If he is the horse we think he is, he will soon commence to do his brushing himself. And here is where you want to use judgment; right here is where one-half the good horses are ruined. If he now commences to take hold of the bit and go away at a rapid clip, steady him carefully, and take him back before he commences to tangle or tire. The chances are at this time, if you let him go on and trot over himself and go into a break, he will hit himself somewhere, and it will set him back in his training weeks, and perhaps spoil him. Don't let him go to a break; trotters nowadays don't leave their feet often when they beat 2:20; they don't have time. 


\section{CHAPTER V.}

SHOEING, BOOTS, CARE AFTER WORK, ETC.

Up to this time, perhaps, youl have seen no occasion to change his shoeing, except to have them removed and reset, which ought to be done once in three weeks at the longest. You now want to observe closely how he carries his legs, and if he is brushing himself anywhere. Young horses often exhibit a propensity to shove the hind foot under the front foot and brush the hoof up at the coronet, which is called "scalping." If your horse does this, get a pair of scalping boots the first thing you do, and wear them on him in this work. Horses do this scalping while jogging, but it gets them into the habit of single footing, and when they get this habit it takes a long time to restore their confidence so they will go square again. All horses, or nearly all that can go fast, go with their hind feet outside of their forward ones. You also want to observe if this horse brushes his hind pasterns with the outside of the shoes of the front feet; this is called speedy cutting. If your horse, in your judgment, can show indications of a three minute clip or better, look out for this speedy cutting business. If you are working him on a half mile track he will probably brush himself here while making the turns, which will have the effect to scare him and make him unsteady and break. Now if your horse ever goes to a break when he is moving within his speed, he has hit himself somewhere, and you should get right out and see about it at once. If, upon examination, you find he has hit himself, don't start him up again until he is protected. If he is shod all right don't expect to remedy the difficulty by changing shoes unless the trouble is apparent. Clinches some times work out by the head of the nail striking a stone and driving it up: to avoid this have the shoer 
file the heads of the nails down even with the shoe, then the clinches will not work out to bother you. And here is scmething I want you to recollect about shoeing for interfering or knee knocking. Don't ever take any portion of the wall of the foot away in any case. All you take off the inside of the feet just so much nearer together the horse's feet will be whether in motion or standing, and you spoil the shape of the foot and weaken it. Horses sometimes interfere and hit themselves without any fault of the shoer. Perhaps the animal has not learned to travel, is weak, or a dozen other causes no blacksmith is responsible for.

In bringing your horse in from a drive after he has acquired some strength, let him come home in shape, so you can scrape a little sweat out of him after he has stood with a woolen sheet on him a few minutes, or while you are hanging up his harness. If he breaks out in perspiration strip off the sheet and scrape him out as dry as possible and throw the sheet over his back and loins, and commence and rub out his head and ears and neck, and finally his whole body Don't put him in the stall until he is cooled off, so he will not break out again. It may take three-quarters of an hour, probably; you need not rub all the time. Pin the sheet on him and walk him around in the sun and out of a draft, and before you get done with him wash out his feet clean and brush him all over; brush out his mane and foretop and tail, but don't tear out any hair. If it is time to feed now, give him a suck of water and his dinner, and go and get your own. The best rubbers I have ever seen are Ashton salt sacks cut into four pieces. Always have plenty of clean, dry rubbers on hand; you can't dry out a horse with a dirty, damp rubber. There is considerable work about training one horse if you do all the work yourself. But your ingenuity will devise some way to get along with the work. I have never seen a man yet who liked to ride behind a good horse and do the driving, but who would manage some way to have some body around the barn when he got back to help do up the trotter. 
Don't be afraid to give your horse some grass. Let him pick it himself in the latter part of the afternoon if you work him in the forenoon, and if he at any time is constipated give him a big bran mash at night with some salt in it. Keep his bowels open unless he is of a washy constitution and inclined to scour; you must use judgment. A horse that scours (or in other words exhibits an unnatural looseness of the bowels) is out of shape some where, and is probably the result of indigestion or derangement of the stomach and bowels. If you live near a good veterinary surgeon, consult him; it will be cheaper in the end. However, I have corrected this trouble more than once by giving a tablespoonful of powdered charcoal three times a day in the feed.

The feet and legs must be looked after now; don't soak your horse out too much in hot or any other water, because you have seen some other trainer do it. It might have been necessary in the case, of an old ringer that had to be scalded every day to keep him on earth. Jack Phillips has probably won more races with hot water than any other man in this country. He knows when to use it. If you don't detect any fever in the legs, or inclination to swell over night, your horse is all right, and a good walk in the grass in the morning when the dew is on is as good a poultice as the feet can have. Don't oil or anoint the feet, or stuff them, if they don't need it. Blue clay or moss wet in water is the best stuffing, and oils are a detriment, I think. 


\section{CHAPTER VI.}

FASTER WORK, REPEATS, ETC.

About four weeks must have elapsed by this time, and you can now begin to call on the horse for a brush occasionally in his work. Don't brush him over a quarter yet at a time, and not too often, and never up to the full measure of his speed. Some horses will take more work than others, but an ordinary well-bred horse ought to jog out ten or twelve miles a day to a wagon in about an hour without falling off any in appearance, condition or feelings. After you commence to brush the horse along in his daily work, your judgment ought to guide you as to whether you are overworking him or not.

I suppose you think you ought to give him a big scrape now. Perhaps it is not necessary; a neck sweat and hood may reduce the throat and neck enough, and perhaps he don't want any scrape of the body more than he gets every day in his work yet a while. I will, further on in the work, give you a scientific explanation of a scrape, how to do it and what to do it for. It is about time this horse had a half mile trial. If you have any suspicion he will hit his knees, protect him. The night before you give him the trial, give him about half the amount of hay he ordinarily has and about two-thirds the usual quantity of water; in the morning give him two quarts of oats at the usual time of feeding (we assume you have been giving him his breakfast in one feed up to this time) and no hay of any account. Give him a couple or quarts of water when you go to the stable in the morning, and after he has eaten his oats and a very little hay let him have two or three swallows more. Hook him up about ten o'clock, the food having had time to assimilate, and jog him out five miles; then give him a swallow of water, and give him a half mile, commencing 
to call on him as you approach the half mile pole and send him for all he is worth till you get to the win, without letting him leave his feet. Have some friend you can rely on to hold the watch that can catch the time correctly, and that won't lie to you. If your horse has shown a half in $1: 25$, you have got a quite promising young horse that has only been worked four weeks. This is a 50 clip, and lots of them can't do it that have been worked all summer. Now jog your horse to the stable and do him up in good shape. The first thing you do, put a set of linen bandages wet in warm water on his legs, all round, and let them stay on till they get dry or the horse has cooled out, then take them off, hand rub the legs a little, and if you don't see any swelling or heat in the legs they are all right and he has done well. Work him now just the same as you have all along; in a week give him a trial a mile out. If he has improved he ought to show you a mile in $2: 45$. If he should chance to be one of those phenomenal trotters of the period, he might go so fast your hair would turn gray in the mile. Soberly speaking, the speed shown at the present day by horses with comparatively little training, and in the hands of amateurs in some cases, is truly marvelous. They break out at different places, hundreds of miles apart, but almost without exception upon investigation it is discovered that these horses are bred to go fast and stay the distance. You will, by observing how your horse finishes his first mile, be able to determine to a great extent what kind of a horse you have. If he finishes his mile as though he had another mile in him, and trots the last half a couple of seconds the fastest, and does not show much distress in breathing, and his legs tremble but slightly if any, you may conclude you have got quite a horse, providing, of course, he has done his mile in as good time as you have reason to expect of him. You ought not to have driven him to a break in either of these trials. He had better have a little speed left in him than to have gone to a break. In ten days, if he is improving, give him another trial, a mile and repeat. Don't try to 
drive all the speed out of him the first heat, and if he acts as though he had plenty more in him, give him the second mile with an interval of twenty minutes or half an hour between the heats. As soon as you have finished the first heat, unhook him from the sulky, pull off his harness and throw a sheet on him; give him two or three swallows of water, and in three or four minutes, while you are walking him around, he will break out in a profuse perspiration. (Don't get in a draft with him.) Commence and scrape out his neck and shoulders and finally his whole body; have a couple of boys who can help rub him up, and in course of twenty minutes he will be sufficiently recovered to harness again and prepare for the next heat. If he has worn any boots in the first trial, remove them as soon as he is unharnessed and see that they have not chafed him, and put them back on the last thing before you hitch him in the sulky for the last heat. Jog him a mile or two, and, remember, always to jog your horses the reverse way of the track, and if any other party is driving the right way of the track and you meet them, give them the pole, or pass to the left, they passing you on your right. In working a horse the reverse way of the track, and only turning him when you want to speed him, he acquires the habit of getting away rapidly. A very important thing for a trotter to know is how to score well; it frequently wins a race. Up to this time, I have counciled extreme caution, which every trainer will tell you is safer that to rush business. 


\section{CHAPTER VII.}

SWEATING SCRAPES, THEIR EFFECT AND REASONS FOR.

I have promised to give you a chapter on sweating, and I will quote from that eminent authority on the subject, Joseph Carn Simpson:

The natural outlets of the body are the skin, bowels and kidneys. With their aid we get rid of what the old trainers called the waste and spare. We can increase the action of them all by articles given as food or medicine. The evacuations through the numerous pores of the skin are what we call sweating, the effects of whichwhen properly used-being to bring a horse into such a state, called condition, that he can do without injury, what would be an impossibility for him to perform without its aid. I have signified my objections to stimulating the bowels and kidneys by cathartics and diuretics as aids of training, and I must necessarily show that condition can be acquired without their help. Sweating has two distinct things to perform : the first, to give freedom to the respiratory organs and the action of the heart, which we may call internal relief; the second, to promote the strength and activity of the muscles and lighten the load to be carried, which, with the same propriety, may be termed external relief. The organs of respiration are the lungs, bronchial tubes, trachea or wind-pipe, glottis or valve, at the extremity of the trachea, nasal passages and nostrils. It requires study to understand the workings of the organs of circulation and breathing, and I must confess that I am not capable of understanding any of the treatises that I have read on the subject sufficiently to explain them, or to make them as intelligible to you as they are to me, though the deductions drazen from 
the statements I am going to make I know to be correct. They have been demonstrated by my practice, and since I have followed my present plan of sweating I have never had a horse become baked or feverish, which was frequently the case when I sweated them without thinking of the causes why it should be done, or was aware of the results that might be expected to follow.

The action of the heart is so closely identified with the lungs that both have to be taken into consideration. Quicken the motion of the one and you accelerate the other, but not in the same proportion. For instance, when a horse is breathing tranquilly the respirations are from four to eight in a minute, and the pulsations thirty-six to forty. As you increase the motion of the lungs by fast work, the respirations will be multiplied till the ratio will be as one to two, possibly two to three. Suppose that, in driving your horse, you keep up the rate of speed until he becomes distressed; the respirations would probably be forty to forty-five times in a minute, with the pulsations at seventy-five to eighty. The inspirations at times would be a good deal longer than the expirations, frequently sighing and "blowing out " suddenly. This arises from the amount of adipose matter interfering with the heart and lungs, restricting the first and enfeebling the others, and it would be a long time before he would recover and the circulation and breathing be restored to their natural condition. You get rid of the superfluities, and drive him until he exhibits great fatigue, having gone perhaps two or three miles, the respirations have increased to two-thirds that of the heart. Still the expirations and inspirations are nearly equal, and there is very little if any sighing. He blows out freely and forcibly, recovering the natural breathing in much less time than before. In the first case he would have been "dead beat;" in the second, by taking a pull he would "come again" and make another struggle. This shows that rapid respiration and arterial action can be kept up if the organs are in a proper state. The main muscle acting on the lungs and assisting in respiration is 
the diaphragm. In forcible expiration the abdominal muscles act with great power. It will be useless to take much time to show that if an excessive deposit of fat exists their aid will be much diminished. Fat within the chest is laid in layers beneath the serous coating, and about the base of the heart. It materially affects the breathing by encroaching on the pulmonary chamber, and interfering with the expansion of the lungs, so that the minute air cells can not be filled to the extent of their capacity as they can when freed from this obstruction. If the heart is healthy, there is room within the pericardium for all its motions, contraction and expansion not being greatly restricted by the outside coating of fat. But this coating does affect the equalization or rythm of the pulsations when the action is hurried, so it becomes necessary to remove the obstruction here as elsewhere. The change in the blood, from the time it leaves the heart by the arteries till it is returned by the veins, after having been aerated in the lungs, is a wonderful provision of nature for it to obtain properties from the atmosphere essential to the existence of life.

The passage of the blood to the extremities of the vessels that convey it, is accompanied in sweating by another phenomenon, viz: the forcing the moisture through the pores of the skin, which we call sweat. In the evacuations from the bowels and kidneys there is never a particle of fat, and the emaciation following purging or excessive stalling is not due to fat being carried from the body directly, but to causes resulting therefrom. In exudation, however, the oily part of the biood is got rid of as well as the watery fluid that accompanies it. You will perceive, when a horse takes his first sweats, the moisture is of a thick, unctious nature, forming a lather like soap when it meets with friction from the clothes or harness. As the horse's body becomes freed from impurities, the sweat becomes thinner and cleaner, finally having the appearance of clean water as it trickles down his legs. The skin, then appears to be the most direct way of getting rid of the fat, and not only the most direct but 
the most natural. The fat, in the first place, being deposited by the blood, the loss of the oily portion in sweating is replaced by the absorbants working on the surplus in store, removing it from where the original deposit was made, and, as the sweatings are continued, exhausting all that we desire to get rid of. There are other changes, probably, that take place in the blood, one being a greater fluidity, perhaps occasioned by an increase of heat. It would appear that the abstraction of the watery particles would have a contrary effect, yet I am satisfied that this is counteracted by an opposing force, which I cannot explain, rendering the arteries and veins less liable to engorgement than when the circulating fluid had properties which made it more difficult to propel through them. From the relief afforded by copious and repeated sweatings, we might infer that the abstraction of the fatty globules in the blood was the means of lessening the labor of the heart, which is of the greatest importance when the blood is sent bounding along more than twice as fast as when the animal is at rest. The theory that the pulsation keeps time to the step is, I believe, correct when the action is much hurried. Hence, when a horse is making a fraction more than two bounds in a second, the work of the heart is greatly increased, and the labor of that vital force-pump would be much lessened by the blood being easier to urge through the tubing of the veins as fast as the accelerated pace required that it should be. It will be readily seen that nearly all the inside fat will have to be got away before the respiratory organs are capable of performing their functions in a manner that will endure fast work. The heart is also facilitated in its operations by the removal, and the diaphragm and abdominal muscles can act with far greater force. The whole internal economy is in a measure changed, the muscles of the stomach are strengthened, and digestion is better and more rapid. The gastric juices are more intimately blended with the contents of the stomach, and the waste for the bowels to carry off is less acrid and easier expelled. We will also find that the same process will get rid of the 
external fat, and while the load is lightened for the horse to carry, and the muscular system is brought to a higher state of vigor, it also assists in the expansion of the chest. The intercostal muscles, or the muscles between the ribs, have a good deal to do with respiration, and the reduction of the neck removes the unnecessary load of fat which surrounds the wind-pipe, giving more room for it to convey the air to the bronchial tubes, and through them to the lungs. I have just said that the same process gets rid of fat whenever it is deposited either among the internal vicera or where it surrounds the muscles. This is so, yet we can so modify it in practice that the effect will be greater in absorbing the interior than the exterior deposit. Thus you will frequently see an animal in racing condition with a fair covering of hard flesh over the general exterior of the body. Till we remove from the lungs and heart the adipose deposit that hinders their working, we cannot give exercise to be of much benefit to the muscles of locomotion. The first sweats, then, will have to be given independent of speed, which these organs are yet unable to endure. The questions attending sweating for the outward formation are not so complicated. The muscles are masses of elastic fibers, terminated by the tendons on which they act by contraction and relaxation.

Thus, while one set exert their force in one direction by contraction, the opposite are lengthened so not to interfere with the power applied. Some run parallel with the tendons, others cross these in an oblique direction, and still others at nearly right angles from the first. The fat is deposited where they overlap each other, filling up the interstices and giving prominence to the muscles by pushing the outside one out. In a very fat horse there is a further deposit of adipose matter between the skin and body, sometimes covering the muscles of the ribs to quite a depth. This is entirely useless, while that in the interstices has a duty to perform of great importance, viz.: lubricating the fibers so that the friction at the points of attrition is much lessened. The muscles become harder and more tendonous as they are made to perform active duty. This change takes place as the result of exercise, 
as does not the removal of fat, when that removal is dependent on other agencies than muscular exertion. Exercise is the only means of effecting this change of the muscular system, and the amount of work best adapted to effect this end is varied in almost every animal that has to undergo the conditioning process. As the fat is wasted, there ought to be a proportional increase of muscle, and which will invariably ensue if the training has been properly attended to.

Sweating under clothes has also a local effect. This is an advantage which no other system of depletion can boast of, and the benefits of which can hardly be over estimated. If it were otherwise, we would be compelled to bring one part of the horse's body much lower than we would like it in order that some other part might be in a condition to stand the requirements of fast work.

There is nothing like the danger of over-sweating the neck that there is in the chest, which will bear a great deal of reduction. We may reduce the muscles that cover the shoulder-blade too much, but the intercostal and abdominal muscles will bear some reduction if it is necessary to get rid of any fat in the immediate vicinity. There is a vast difference between young and matured horses, both as to the necessity and effects of sweating, and the treatment given some aged horses would ruin a colt. The reason is, that young horses are not so fat inside as older ones, and reducing them inside would be accompanied by the wasting of the muscles. Till colts can go fast enough to tire themselves, there is ordinarily no necessity for sweating them under clothes more than enough to cleanse the skin. They will sweat enough in their work to answer all purposes.

THE SWEAT.

The night before you sweat your horse, give him a bran mash in lieu of his regular feed of grain, and only half the ordinary allowance of water, and half his usual allowance of hay, and if a gross feeder muzzle him. In the morning, give him not over two quarts of oats when 
you feed your other horses, and no water, and as soon as he has eaten the grain muzzle him, groom him as usual, and about eight o'clock give him a walk for half an hour. By the time he has been walked the bran mash will have performed its office, and he will be emptied out and ready to prepare for the sweat. Take him into the stable, take a long, soft woolen blanket and double it together so it will be full length and half the width, throw it over his back and bring the end under his belly; be careful to have it straight and free from wrinkles-it ought to lap a foot or more-fasten it with safety skewers, or, what is better, four strings sewed onto the side of the blanket a little below where it crosses the back bone, and the same number on the end that you bring between the fore and hind legs; then it can be fastened without any danger of wounding the skin. Take a little lighter blanket and double it in the same way, and fold it as many times around the neck, enveloping it from the shoulders to the ears; now take another blanket, but smaller, and cover the horse all over with it, tying it under the tail and around the breast. A hood large enough to cover the shoulders, without ear pieces. A Kersey suit over this, buckled at the flank; hood with ear pieces, and his costume is complete. Let out your harness to accommodate the extra amount of clothing, and hitch him into the sulky. (Have a drink made for him of oat meal and water, which make a little above blood heat by adding hot water.) Walk him and jog a couple of miles, when the perspiration will begin to start some, and you can give him a drink of the warm gruel, a few swallows (two or three), which will facilitate the flow. Then give him a couple of miles more jogging, fast enough to start the moisture, and go to the stable, unhitch him, but throw immediately onto him a couple of extra blankets to retain all the heat. He will labor in breathing, but give him another swallow of the warm drink, when the perspiration will begin to run down his legs and ooze through the blankets. Don't be alarmed at the profuse flow; you will see that he doesn't breathe as hard as before, and the arteries will become more 
elastic and the pulsations less rapid. Have your scrapers and rubbers ready, unbuckle the hood and outside blanket, throw the hood across his loin and turn back the clothes so as to expose his chest, throw the neck wrapper to one side and scrape him out carefully. Have help enough to rub him gently around the head and ears while you, after covering the neck and chest, scrape his back, sides and quarters; be careful not to irritate him. His neck will now scrape again; go all over him again, and then throw off all the wet clothes; rub him briskly, but gently, all over with dry, clean rubbers, and get some dry, clean clothes -blanket and hood-and smooth his hair down the right way, put on the blanket and hood and put a light blanket over this, outside the tail, and have him walked for fifteen minutes, when you can finish doing him up by drying him up slowly, occasionally removing the clothes and substituting lighter ones all the time. Wash his feet and get the tubs and put his feet into them, and wash his legs from the knees and hocks down with warm water. When this is done, dip the bandages in hot water and do up his legs from the knee and hock to the coronet. Fix up his bedding, give him two quarts of drink previously prepared by putting a tablespoonful of pure cream tartar into ten quarts of water, which is all he ought to have until the next morning. Pour out about two quarts of the ascedulated drink at a time, so not to tantalize him by showing him more water than you want him to drink at one time. Give him two quarts of oats and three or four pounds of hay, and when he has eaten it, muzzle him, and leave him undisturbed till the next feed. The object of restricting him in the amount of water, is that the absorbents will take hold of the fat, which they would not do if you give him an unlimited supply of fluids. A good clear warm day should always be taken advantage of to give a horse a sweat, and you should be careful not to get into a draft of air in the cooling out process. His next feed will be his regular evening meal of oats and hay, which ought to be curtailed about one-third in amount, but the morning following feed him as usual, and give water likewise. 


\section{CHAPTER VIII.}

TREATMENT AFTER THE SWEAT.

Hitch up your horse the morning after his sweat and jog him three or four miles slowly, but don't give him any fast work until the day after. If you have not overdone the sweating, your horse will act and step out as light as a feather, and his eye will be clear and bright. You can't fail to see if your horse don't feel as well as common. You will, the second day after the sweat, give him some fast work, but not up to his limit of speed, as this should never be done except in a trial, and I don't think half mile trials amount to much, only to teach the horse to quit after he has gone to the half mile pole. In the early part of the horse's preparation a half mile heat is well enough to gauge the speed he has, but I would not persist in half mile trials. I will say a little more about walking. In the early part of the horse's training, walking exercise in the morning should be given when the dew is on the grass, and walk him so he can have the benefit of it on his legs and feet. A walk towards evening of an hour, with the privilege of picking grass, will be enjoyed by the animal and his appetite and constitution benefited. In training horses a man must get up in the morning. A horse in training ought to be fed at five o'clock in the morning, after having a few swallows of water, two quarts of oats, his bed shaken up and stall cleaned of manure and wet straw. After you have had your breakfast, clean his coat and feet and give him a little walk in the dew, hitch him into the sulky and give him his work, after which he can be fed two quarts more oats and some hay, and watered. Now fix up his bed and leave him to himself till three o'clock in the af- 
ternoon, when you can feed him two quarts more oats, and when they are eaten give him some more water, after which you can give him his afternoun or evening walk, when is your opportunity to let him eat some grass, and after he has been returned to the stable, hand rub his legs a little, see if he has cuffed himself anywhere, pick and wash out his feet, have his bed fixed up a little and return him to his stall till seven o'clock, when you can give him his feed of four quarts of oats and his full allowance of water, and what hay he needs. Some horses need a little corn to keep up their flesh and stamina, and some very ravenous feeders, by mixing a little shelled corn in the oats, will be rompelled to eat slower and masticate the grain properly. You ought always to have nn hand, ears of corn, good, sound oats and wheat bran, the coarser and lighter in weight to the bushel the better, to be used for bran mashes. You want salt handy, also. 


\section{CHAPTER IX.}

WATCHFULNESS NOW THE ORDER OF THE DAY.

Your trotter now being on the high road to the object of your ambition, viz, to beat 2:30, you want to see that he gains in speed and style of going, and if you are training in the vicinity of a track you will have opportunities to see how he likes company, and you should try and get him used to it. You want to take care he doesn't take on too much flesh, if he is a hardy horse, and also you don't want to over-work him. By reference to the article on sweating, you will learn by noticing the inspirations and expirations of air to and from his lungs when pulled up after fast work, and how he does it; how he is progressing in his training in respect to his internal organs. If he "blowes out" forcibly after fast work and fatiguing exercise, and recovers rapidly, it is fair to assume that he is doing well. As a horse approaches racing condition, the quicker and more completely does he recover from exhaustion in a short space of time. Your judgment must continually guide you now; once a week is often enough, ordinarily, for a horse to have fast work. You had better save him some and let him trot himself into condition than to have him right on edge the first race you start in.

If you contemplate giving your horse only nne race and then laying him out of work, that is a different affair from trotting through half a dozen meetings, and in that case should be on edge if you expect him to distinguish himself, for it is exceedingly rare for a green horse and a green driver to win their first race, unless they lay over the rest of the entries in speed by several seconds, and then, if you have the most speed, some man may out drive you. 
But your horse should have five repeats before you start him to win a race, and one of them should be of three heats; the others just mile and repeat. But never give your horse a repeat within five days of a race, or after you start into a campaign. If he trots one race each week, he will not need any repeating, and, while I think of it, I wish to state that there is not a horse that ever marked the earth that can not be made to quit, by overwork. And here is where many horses not possessing the the stamina afforded by thoroughbred crosses have gone wrong, the trainer not having the judgment to tell him when to let up in the work. Always work your horse in the forenoon, when he can get the benefit of the sun. A horse worked only in the cool of the day will wilt like a mushroom when started in a race in the heat of the afternoon. 


\section{CHAPTER $\mathrm{X}$.}

FINANCIAL MATTERS DISCUSSED A LITTLE.

It takes a smarter man to campaign a trotter or string of them and come out in the Fall with enough money to pay him for his time, risk and amount of capital invested, even if he has a winner to handle, than it does to do any other kind of business. You may inquire, how can this be; that a man controlling a winner, viz., one that is an average horse in his class, and not make anything out of it? It is this way: these men ordinarily beat themselves. They get into some job to work the pool box, and the first they know they are left. James Wade, formerly owner of Red Cloud (now dead), can tell you how it works. He entertained the writer last summer one afternoon with his experience with a trotter who, by the way, was a winner. The business left a lasting impression upon Mr. Wade's mind. He went into the campaign inexperienced, but he knows all about the business nowno little job to let somebody else win will ever capture him now-not if he can win. If you are going to handle one horse to develop him, you might as well have two or three. It would use up mnre of the time and not be so monotonous. You could help pay the expenses by handling a couple of others besides your own horse, and afford to hire a GOOD man to rub and take care. When you hire a rubber you had better give him double pay and get a good man than to have a bummer do your work for nothing. Good horses cost money and are worth money, and no class of property requires as faithful, sober men to take care of it as property invested in race horses. Still, fifty per cent. of the rubbers in charge of good horses representing a large outlay of 
capital you would not trust to watch a lumber pile. But owners are requiring better men than formerly, to do work around trotters and pacers, and will not have men addicted to drunkenness and dissipation, and it is right. You want a man whom you can trust to sleep in the barn, and take care of the horses and premises, and back bone enough to clean out all bummers and tramps who ordinarily infest training grounds and not have them sleeping and loafing around the premises at night.

If it is your first experience try and manage it so you can relate during the hours spent around the stove in the winter coming, some of your experience in the charmed circle, with that feeling of satisfaction which is afforded by the fact that you got there. 


\section{CHAPTER XI.}

A FAST TROTTER OR PACER IS ONE THING, BUT A RACEHORSE IS ANOTHER : AND NOTHING MAKES RACE-HORSES BUT RACES. - NECESSITY OF RACES TO THOROUGHLY DEVELOP A HORSE AND FIND OUT WHAT THERE IS IN HIM.

You will never be satisfied as to the capacity of your horse until you have had him in a race. So you will naturally look around and see where you had better enter him. You will probably select the three minute and two forty classes as the proper place to give him a chance to distinguish himself, although there is more danger at the present time of getting a record for your horse, that you would rather not have in the three minute, than in the "two forty class," as nearly all the fliers make their debut in the slower classes. But make your entries where you think you will have a fair chance given you to win, if you can, and I would select a meeting where the track belunged to the National Association, for such organizations are responsible, and in case you are not satisfied with the treatment you get, you stand a chance to get some satisfaction if you are really in the right, by an appeal. Make your entry according to the conditions published and send the money to pay the entrance fee, you will have to pay it any way, and you might as well do it first as last.

If possible get to the track in time to secure good stabling for your horses, and get an extra stall for a feed room, to put your hay and feed in, as well as the rest of your traps. You want above all things a good sulky, made by one of the reliable makers, of which there are a number, which vary in price from one hundred to a 
hundred and fifty dollars. A well built fifty or fifty-five pound sulky, will carry you around any turn at any rate of speed if you know how to sit in it, with perfect safety, and will tear down any ordinary buggy if you should run into it. These well built sulkies may bend, but very rarely break, so patronize a builder of known reputation. You want plenty of sheets, woolen and linen. Your woolen blankets which are not in use will come in play to hang on lines around the stalls to keep the air from blowing through the cracks in the stable, as at some places you can throw a cat through the cracks. Take plenty of rubbers, a couple of lanterns, curry combs, brushes, sponges, pails, foot tub, foot picks, boots, bandages, and hooks with screw eye and screw staples, are very handy to put on doors while you stay, and when you pack up take them away again. You want an oat seive and a two quart measure, a Marine clock with an alarm, a half gallon of leg wash of some kind, Castile soap, hammer or hatchet, foot rasp, a pair of pinchers and small saw. You can have a chest or large trunk that you can pack all these things into except the foot tub. You will need all the articles I have enumerated and many more, and it is not a convenient place to borrow things at a race track. A couple of camp stools and a hammock are articles of convenience and don't take up much room. But the most important thing I have omitted, and that is money enough to carry you as far as you want to go, if you don't win a cent. It con tributes so largely to a man's peace of mind, and is, I believe, a powerful nervine, and will assist you immensely by its influence when you get up to drive the race. You will meet the gang when you get there, probably, or some of them ; they will size you up right away as a "tender foot," let them enjoy their convictions, and talk about anything but your horses and what you know about the business, they will find out all you want them to know, without you informing them. After getting located to suit you, get plenty of straw, and if your stall has no board or plank floor get some boards and put down before you make up 
the beds, if you have to buy the lumber; then fix up the things you have brought in their respective places; you want a clothesline to go around the stalls to hang the blankets on. You will have no trouble about buying what feed you want, nearly all the tracks now furnish hay and straw free. If you have shipped by rail (which is always the way to move, if you don't go more than twenty-five miles, unless you go with the horse yourself), don't hook up your horse until the next morning; you may give him his regular evening walk and let him get all the rest he can. Do not change the feeding time or manner of feeding or kind of feed from what you have been using all the time, and observe what the character of the water is and how it varies from the water at home, and govern your actions accordingly. Get a place to board as near as possible to your horses, so that you can go to your meals and leave your man or men in charge of the stable till you get back; never leave your horses alone, even if you lock the stalls; there is no necessity for doing it if you have men you can rely upon, and if you have not, get different ones. You are out to make a dollar if you can with your horses and you will need to attend strictly to business. Don't try to drink up all the "Conversation Water" that comes in your way; that has been tried by some very hardy individuals of my acquaintance, and no man ever lived to accomplish it. In short, conduct yourself just as well as though you had your wife along with you, and set a good example for your men, it will have its effect and accrue to your benefit invariably. 


\section{CHAPTER XII.}

\section{GENERAL VIEWS ABOUT WINNING IF YOU CAN.}

Some men are continually contriving to save a record. I never saw one of these men have a horse that could get a record that would be fast enough to hurt him. You never can win either, by staying behind, you have got to get up in front to win. It is a very rare thing for any horse to be fast longer than two seasons in succession, There are some exceptions to this rule, however, as instanced in the case of Goldsmith Maid, Dexter, Rarus, and Driver, and that is about all I think of now. So if you have got the speed and staying qualities, you had better make use of them; you can not tell how long you will have either. Horse flesh is a very uncertain commodity.

A man having a horse in a race and driving him himself, has a great percentage in his favor over any outside bettor. He can not help but know whether he can win or not, and he will know if there is any "fixing" going on. Where a strange field of norses come together, every body is at sea when contemplating the relative chances of the starters. Occasionally there is a horse that cannot win a race, but can brush and speed so fast that if the driver is as astute as a number of men I could mention, he will be approached by some backer of a horse who desires to win the race, and an offer of a divide will be made in advance of the start, which arrangement is ordinarily effected. It is very amusing to observe the tangle these fixers sometimes get themselves into, by leaving out of the arrangement the wrong horse, or the one that proves to be able to win the race in spite of all the ingenuity of the opposition. The pacing race at 
Chicago, in 1883 , where the Missouri pacer, Richball, downed them all, when he had been bringing but ten dollars in a hundred and twenty in the pools, is an instance where the discovery was made too late, and the "posted division " met their "Waterloo."

No business sharpens a man's perceptive faculties like managing race horses, or awakens him to the fact that he may be operating out of his proper sphere. I never could see the odds that we often see one horse bring over the "field," when there is a large field of good horses to start, and all of them good ones and known to be by previous performances nearly matched in point of speed and staying qualities. In a race where such a field of starters show up. I want the short end to begin with, for it very frequently occurs that before the race is won, the hot favorite is selling in the field; and you can get both ends of the race and go out and set down and see them fight it out, as you will be ahead whoever wins. A man under these circumstances can view the race with a calmness that is truly blissful. 


\section{CHAPTER XIII.}

TOE WEIGHTS CHANGING THE WAY OF GOING.

Toe weights have played an important part in developing the speed and steadiness in way of going in trotters, and are of recent discovery, comparatively. As near as I can ascertain, they were first used by James Wilson, of Rushville, Ind., who was the owner of that phenominal sire of trotters, Old Blue Bull, and who now leads all others in the number of his get that have obtained records of $2-30$ and better in many a hotly contested race. Many of Blue Bull's get were either pacing or mixed gaited horses, and by the judicious use of toe weights, they were easily converted to the trotting gait of the purest character, and nearly every converted pacer, that possessed a sufficient amount of "hard bottom" blood, have proved themselves horses of no ordinary capacity in their day and time. But I think many good horses have been injured by wearing more weight than was absolutely necessary, which has had the effect of straining the muscles and tendons, and by injuring the feet, by bringing them in contact with the ground with greater force than the feet were calculated to stand without serious results. After a horse has been converted, I think the weights should be decreased in ounces gradually, to the lowest point possible, and more reliance be placed upon skillful driving, to keep the horse level in his gait. Many horses that are pure gaited trotters can trot faster, and without detriment to themselves, by wearing a reasonable amount of weight on each fore foot, as the weight at the apex of the toe has the effect to straigthen out the fore leg wher extended, and thus gain in length of stride, whereby they can trot 
the mile out from 2 to 5 seconds faster than they could without them. There are a dozen different styles of toe weights that have, as claimed by their respective inventors, their advantages, and of their usefulness in many cases there is no question, and I might add that they are indispensable as part of your outfit as a trotting horse trainer. In the development of speed in horses that are mixed gaited, by this I mean horses that cannot either pace or trot squarely, weights will always have to be resorted to, if you desire to square them and save time in doing so. The application of a 4 or 6 ounce weight to each hind foot, on the outside, has the effect of opening their gait behind and thereby improving the way of going.

A trotter that puts one hind foot past his front foot on the outside, but carries the other hind foot in line with the front one on the same side is something very annoying to a trainer. The foot that does not go out where it ought to is ordinarily shod with a shoe twice as heavy on the outside as on the inside, and sometimes a side weight is used, and there are cases where the reverse has been resorted to with success This is accounted for by some men as sympathetic. The mare Adelaide by Phil Sheridan, placed one hind foot between her front ones instead of going outside with both hind feet. She could go very fast and got a record of $2-193 / 4$ this way of going, but these examples are rare. Many experiments will have to be resorted to in order to gait some horses pruperly, while others are the poetry or motion. If you have a horse that uses one hind leg properly and swings the other in line with his front foot, if a side weight or a shoe with the weight in the outside half doesn't have the desired effect, reverse the matter and shoe that foot light, with an ordinary shoe, and shoe the foot that is carried properly, same as you have previously shod the other, and use a side weight also. This has had the effect in some cases, of inducing the horse to carry both legs properly. Many experiments have to be resorted to, in order to get some horses to go square. 


\section{CHAPTER XIV.}

\section{MANAGEMENT BEFORE AND IN THE RACE.}

We will assume now that your horse is good enough to keep the starters company in the race, as far as speed is concerned, but never having been in a race, you can not tell how he will act in scoring among a half dozen starters, some up in the air, and some in front, some behind, the crowd in the ampitheatre and along the inside railing to the track all excited and more or less noise, is all calculated to somewhat excite a green trotter, and a green driver as well. If you are going to start your horse in a race to-morrow, you should observe some of the hints before spoken of, as to the curtailment of hay and water, to-night. In the morning give the horse his regular feed of oats at the regular time, and a little hay, and probably walking exercise will be all he will require; and at ten o'clock give him two more quarts of oats and a few swallows of water. He will not want any thing more until an hour before you start, you can give him a pint of oats; it doesn't amount to much but satisfies the animal, and he will not miss his afternoon feed so much if the race should be prolonged by broken heats. Get everything ready and have boots, if you wear boots on the horse, that will protect him; they should be made to fit. You will need quarter bonts any way, and probably knee boots, and hind leg, shin and pass boots; at all events give him what protection he needs, and own them yourself; don't borrow or depend on borrowing; have bandages, sponges, pail of water, etc., handy. If you go to the stable to rub out you will only have to take a pail of water and sponges to the quarter stretch to sponge out with. If you do not weigh 150 pounds have your extra weight to make that in the cushion to your sulky. Hitch up about fifteen minutes before you will be called, and proceed to warm up for the heat, and accustom the horse to the crowd and the music (if there is any), and the 
general surroundings, but don't unnecessarily excite him. When the judges have drawn the positions for each horse the bell will call you all up, and you will proceed to weigh, get your colors and position. When you are all ready to score for a start, you will go to the distance stand, or where you think best, watching the rest closely, and turn as soon as any of them and come down to the wire in the position assigned to you. You will never get the word the first attempt, but if it is not a "go" you will be signaled by the bell to come back, where as if it is a "go" the judges will say "go," in which case go on. If you have the pole and can keep it, do so, and don't "shrink" or "cringe" if some chap comes close to you. Never let anybody drive you into the fence nor carry you out on the turns; stay where you are and keep your horse level. If any of them can out trot you they will be entitled to the pole, but never have any fear at this point; remember if they run into you, you can hurt them as much as they do you, and if you don't flinch they will not try it again. Drivers do not ordinarily drive into a man known to be resolute and game; when they do it is owing to being mistaken in the man. If your horse happens to leave his feet don't snatch him, but let him take one, two or three jumps, steady him, and by a little skillful management you will be able to land him on his feet without slackening his pace, as a steady pull to land him in a trot is the proper thing. It is all wrong to teach a trotter when he leaves his feet to come almost to a standstill before you catch him, as you will lose so much grourd you will not be able to regain it, and thereby lose the heat. If it is evident that you can win the heat and you want to do so, go on; but there is no use in winning with a dozen lengths to spare. You will save getting a lower mark for your horse by winning by a length, and it will answer all purposes. After you have won the heat, or finished it, slacken the gait and jog back to the stand, where your rubber should be to take the horse, while you dismount, by permission of the judges, and weigh, which by consulting the rules of the National 
Trotting Association, you will find is one of the requirements. You will now attend to the wants of your horse. Slip him out of the sulky, slip off the harness, and cover him up so as to insure a scrape; pull off the boots and have a set of wet bandages (not cold) and do up his legs immediately. Shower some water, with a sponge, on his poll and forehead, sponge out his mouth and move him until you get a scrape, when you can proceed to dry him out some with the rubbers. You will have ample time without any need of hurry or confusion, to get your horse ready for the next heat, as you will have twenty minutes any way, and if two races are sandwiched, you will have half an hour. A few sweet apples are the finest thing you can have to give him while he is walking-two or three between the heats-and a little wisp of hay. You can give him a couple of swallows of water and sponge out his mouth the last thing after having hitched up for the next heat.

You must pay attention to his legs and see that the boots have not chafed him. The wash you have must be used on his legs, and can be used over his shoulders and loins when you strip those parts to scrape him. You will cool out in the open air, and in the warm season of the year there is very little danger of his getting chilly; the sun will not hurt him unless he is very much fatigued, in which case you may walk in the shade

This is the general way of conducting a race, and you will by this time have accumulated considerable experience of your own. If your horse is strong in his legs and not very much fatigued by the heat he has trotted, there may be no real necessity for bandages, but they will do no harm, are put on in a moment, and may be of service; and if weak in any of his legs they are positively necessary. Before you put the boots back onto him brush all the sand out of them and scrape off with a knife any accumulation of sweat that will come in contact with the skin. A boot that chafes a horse may make him unsteady and flighty, and practically defeat every other effort you have made to win the race. 


\section{CHAPTER XV.}

\section{VALUE OF TROTTERS AS COMPARED WITH THAT OF PACERS.}

Individual trotters of the first-class have as yet sold for more money than any pacer. But allow me to predict, (and I am not interested in any pacer or sire of pacers), that the time will come when a first-class pacer will bring as much as a trotter of the same degree of merit. There is a reason at present existing that is manifest, why a pacer is not as valuable in dollars for racing purposes, as a trotter. This is it: There are a thousand fast trotters where there are ten pacers, and consequently, trotting associations that are composed of men largely interested in breeding trotters, and as trotters predominate in such a degree, more money by far is offered by such associations to be competed for by trotters; and until within two years, there was no show anywhere for a pacer if he was not a "Whirlwind" in point of speed, and for this reason, men who wanted to invest money in racing stock bought trotters because there was a greater number of chances to win out their investment in races. But the pacer can no longer be ignored, he is bound to come to the front, the public demand it. You over-hear men talking now a days about attending a meeting. many of whom cannot leave their business more than one day perhaps, and nine out of ten of this class, will ask what day do the pacers go ? "I want to see the "Sidewheelers." Any day at a race meeting where a large field of pacers are advertised to start, there will be a good attendance; it is the attraction of the day and meeting, as a race among a fair field of pacers of any class, has been invariably worth seeing, they have in the past invariably "gone for blood," 
and the receipts at the gate and pool-box, have been very satisfactory. There have been more genuine sur prises in the pacing races of the last two years, than in any other, and that element of uncertainty which lends its charm to racing of any kind, is intensified. The general verdict is "no man can pick a winner in the pacing race," and in conclusion I will say, I had rather own a fast pacer than be President of the United States, in so far as fun and money are concerned. It is gratifying and interesting to contemplate the fact that the American people can produce almost anything there is a demand for, in an incredible short space of time, and the pacer is a case in point, in proof of this assertion, as until quite recently, fast pacers were very scarce, now I can name a number who can almost break a watch with their speed, and a number yet to hear from not yet distinguished. Any gentleman desiring information concerning pacers, their pedigrees, location of birth, and general history, should correspond with Mr. N. A.. Randall, of Indianapolis, froprietor of the Western Sportsman, who knows more about the pacing element in Indiana, Kentucky, and Illinois, than any man I have met. 


\section{CHAPTER XVI.}

WINTERING A TROTTER OR PACER WITH THE VIEW OF CAMPAIGNING HIM THE FOLLOWING SEASON.

Unless a horse has some infirmity at the close of the season when it is intended to devote his powers to racing the following season, there is no good reason as I can see, for a complete let-up in his training. But if he is weak in his legs, and it is evident that comparative rest will not renew his accustomed strength and stoutness, he will have to have a let-up, and a course of blistering or firing resorted to, and before you do it, if you are not a competent judge yourself of what is necessary to be done in the case, consult some Veterenarian of standing in his profession, and follow his directions in the matter. But if on the contrary, the horse is all plumb on his legs, a season of comparative rest and good care, will take him through the Winter, and bring him out in the Spring in fine fettle, and eager again to renew the contest which will be ever ready to welcome him, providing he is not a "ringer." After you get him home, give him a chance to eat all the fresh grass he wants, and let him up in his work, jogging him short distances about every other day, and if there have been any inflammatory symptoms about his legs or elsewhere, they will shortly disappear. You can have his shoes removed and replace them with a set of tips, which will answer all purposes for him to do his jogging in, and will give his feet a chance to expand by allowing the heels to come in contact with the ground, but don't stop feeding him a reasonable amount of oats daily. When icy roads have taken the place of soft dirt roads, you will need to have him shod sharp with caulks, and give him work enough to keep him in health and 
bodily strength, and unless you are very anxious to sleighride and brush with the boys, you have no need to clip him. I would not indulge in speeding him at all during the Winter, as he will have all the fast work he wants when Springtime comes. A hurse wintered in the manner I have indicated, can be made "June fast," if you need the speed thus early. While you are passing the Winter months, subscribe for one or more of the Weekly Journals of the country, of which there are a number, towit: Turf, Field and Farm, Spirit of the Times, of New York, or the Western Sportsman, of Indianapolis, or the Chicago Horseman and Dunton's Spirit of the Turf, published in Chicago, all of which are interesting reading, and devoted to the interests of Horsemen throughout the World. No Horseman can read either of these papers without learning something of value to him, beside entertaining him during the leisure hours at home. Any question you may desire to ask of any of the foregoing journals respecting the treatment for various complaints that horses, as well as other domestic animals, are subject to, will be answered through their columns by a competent Veterinarian employed for that purpose, free of charge, which many times is very convenient, especially if you reside at a point remote from a Veterinary Surgeon's place of business, and also a saving in expense. No trotter or pacer should be allowed to lay on a superabundance of fat in Winter, as it will have to be removed, and this must be accomplished at the expense of the legs, largely. But a horse can be allowed to lay on some fat, it helps him to keep warm, and when time comes to shed his coat in Spring, the fat will be there to assist nature in the reproduction of the new coat. I should never clip a horse designed to be campaigned the following season. 


\section{CHAPTER XVII.}

\section{DEVELOPING A PACER.}

Many of the trotting-horse trainers and drivers, even of the present day, have had but limited experience in this department, if any. I think that Indiana has at present more talent in the line of developing pacers than any other State, and as it is the home of the pacer it is not to be wondered at. A pacer probably will give evidence, if he is going to show any remarkable speed, sooner, and with less trouble, in the hands of a competent man, than a trotter. The lateral movements of a pacer in action at once demonstrates that there should be less trouble, by odds in developing him, than would be ordinarily with a trotter. A pacer moves a side at a time, or the fore and hind legs of each side of the animal move simultaneously; now all that is necessary is, to have a level head, and a disposition to "go on," (without which no horse is worth a dollar as a race horse,) together with the requisite strength bodily, to carry him along, and the condition to continue those exertions, and you have a pacer. If you have a pacing bred horse, with hard bottomed crosses in his pedigree, and he shows an aptitude for pacing, you would, I assume, be foolish to try and convert him, and make a trotter of him, it can be done as a rule, but the chances are that you would have but an indifferent trotter, where you might have had a "whirlwind" in the form of a pacer. I will enumerate some of the requisities you will need in developing a pacer. In the first place a pacing horse should be shod as light in front, with steel shoes, as possible, and have a shoe (not a plate) on; and if you have any suspicion he will touch his knees, you want the most approved style of knee boot 
you can find, for when a pacing horse hits his knee, squarely, with the other fore foot moving at speed, and without boots, you will have a cripple for some time, and you therefore never should take any chances. Knee and quarter boots are ordinarily all the boots you will need; they are at all events the most important, any others that may be needed will suggest themselves as time progresses. A pacer can move rapidly with his head elevated by the check pretty high, with greater ease to himself than can a trotter. You will notice by close attention that nearly every pacer that can go fast, goes with his head in a peculiar position, nearly all higher than you would expect to see them carry their heads if they were trotting. There are some exceptions to this rule, it is true, but in teaching a pacer to go, you will want his head pretty well up, and you can gauge the matter as the requirements indicate. In five weeks from the time you take a green pacer in hand you will be able to judge pretty accurately whether you have got any natural speed or not. For the horse should-if he was in good plight, as regards flesh and soundness when you took him in handhave shown you he has some speed, if there is any in him-in four or five weeks. It is the theory of some good trainers, that a pacer tires in his legs before he does any where else, as evidenced by the fact, that when a pacer does leave his feet, he generally makes a wild losing break, and is rarely a good breaker. The lateral movements of the pacing gait will, I think, help to establish this theory, as the power applied to move the body along at the rapid pace, is not distributed as in the the trotter, and he consequently tires sooner. The long distant matches of earlier times substantiates this theory ; notably, the ten mile races between Kentucky Prince and Hero, the pacer, in 1853 , for $\$ 5,000$ a side, each race; in the first Hero was stopped in the seventh mile and in the last he struggled on and quit in the tenth mile. Although Hero had a world of speed and had shown a mile in $2-18 \frac{1}{2}$, he tired, and in the last race, nine miles in a trifle less than twenty-five minutes, was the best he could do. 
Kentucky Prince winning both races easily, driven by the veteran, Hiram Woodruff, while Hero was driven by George Spicer, a worthy contemporary of Hiram's. Therefore assuming the theory to be correct, that a pacer tires in his legs sooner than a trotter, it stands the trainer in hand to season the pacers legs thoroughly. The pacing gait is not as trying to the legs as the trotting gait, and consequently the pacer can, and does stand more fast work in his preparation for a campaign, or in the course of his development than you would subject the average trotter to. All the rules of health, feed, care and management in his sweats and races are identical to those in vogue respecting the management of trotters. The pacing mare Gurgle, now owned by J. I. Case, Esq., of Racine, Wis., is a noticeable example of how near you can come to spoiling a pacer of the first magnitude by endeavoring to make an indifferent trotter. Pat Dickerson, of North Vernon, Ind., bought her of his brother in the Spring of 1883 , for six or seven hundred dollars, as a trotter, but she demonstrated to her owner's satisfaction in the first race he had her in, that he had more"of a pacer than trotter, and acting upon the impulse, changed her shoes, and at the Chicago meeting she distinguished herself in the great pacing contest, wherein Johnson was the winner, by finishing a good second in 2-I 3 , and was sold then and there to J. I. Case, for, I think, $\$ 7,000$. This was a happy change. Gurgle was sired by the pacing stallion Pocahontas Boy, sire of Buffalo Girl, J. H. Clark, of Scio, Alleghany County, New York, is owner of Pocahontas Boy. Pacers before they get balanced in their gait will often hit the inside of one front foot against the inside of the hind foot of the opposite side and sometimes "scalp" the inside of the hind pastern, in which case a pair of scalping or toe boots would be necessary; but a pair of very light toe weights from two to four ounces, ordinarily corrects the habit, and, once over it, by continued proper attention to shoeing and driving, it rarely returns. I believe a light steel bar shoe, not to exceed twelve ounces in weight, for front 
feet, will suit a pacer better than any other, and I will add, that no shoe for any horse is as good as a bar shoe properly set. There should be a space between the frog and the bar of the shoe, when first applied, so you can readily slip a silver quarter of a dollar between. By using a bar shoe, the horse gets a natural frog pressure and keeps the frog pressed up into the sole where it belongs, and the foot will stay sound longer at fast work, with a bar shoe properly applied than with any other. In driving a pacer, a different position in the sulky may be assumed than in driving trotters; a pacer needs more weight on his back than a trotter,and the position intended to throw as much weight on the horse's back as possible should be assumed. In catching a pacer when he makes a break, swing him a little sidewise, first one way then the other, he has got to catch a side at a time and this motion will do it quicker than a pull you would take on a trotter to recover him from a break.

There is a family that belong in Southern Indiana, named Stewart, who are natural born handlers of pacers. They brought out Flora Bell, Greeley, and a number of others, not so distinguished, but fast. I have heard them state that a pacer could be made to go as fast as he ever would in sixty days. No horse designed to become a fas $t$ pacer should ever be allowed to trot; make him either pace or walk. A double gaited pacer is a fraud and a delusion. 


\section{CHAPTER XVIII.}

\section{HARNESSING AND DRIVING HORSES.}

In "hitching a horse," as it is termed among horsemen, many men are deficient, otherwise good horsemen. A horse with a harness on that does not fit him, is in about the same frame of mind as his driver would be with a shirt on that is an uncomfortable fit. See that your headstall fits his head, and that the hair in his mane and foretop is not doubled up under the crown piece of the headstall, the saddle should be set at the right point, back of withers, and the back strap should be the right length to keep the check-rein from pulling the saddle forward onto the withers. The girths should be buckled snugly and the breeching should be loose enough to give the quarters plenty of room, and tight enough not to allow the wagon to run on to the horse, should you be obliged to take a pull on him. Make a point to see that everything about the harness and vehicle is strong, and properly hitched; attention to this particular often saves many an accident, and in some cases, loss of life and property. Martingales should be long enough, ordinarily, to allow the reins to draw straight from the bit to turrets, and in many cases can be dispensed with entirely. The use of headstalls with winkers, can also, in many cases be dispensed with.

In trotting and pacing horses for racing purposes, I think an open bridle is preferable. But in road horses that are inclined to be slack drivers I think winkers are an advantage, as without them a lazy horse is watching you and will slacken his gait if he can see you are not prepared to give him a cut with the whip. 
In driving, the whip is an important auxiliary, and you should never get in behind a horse without one, but an indiscriminate use of the whip will produce unsatisfactory results with horses, as well as with the growing generation of men. Never use it unless it is necessary, then let the horse know that it is no plaything. In driving horses, insist upon an even rate of speed when you start them up, and don't pull at the bit, only steady the horse, he will as he improves in strength and gait, take hold of the bit hard enough to suit you. Horses learn to go themselves if they are not interfered with and have the capacity to go. A horse in a horseman's hands may in a short time learn to go a clip that will carry a man ten or twelve miles an hour, without any persuasion, and do it cheerfully, and passing into another man's hands, get in a short time so that he will have to be clubbed to get him ten miles in an hour, or else he will graduate into a chronic puller; now this is all in the treatment and driving. I have seen some ladies who were exceptionally good drivers of road horses and exhibited a judgment and discretion found in but few of the sterner sex. For horses that shy, and are afraid of objects they are unacquainted with, of course you must be on the look out for. But the fear in the horse is oftener intensified by the timid driver, than a catastrophe is averted by such a driver's exertions. Watch your horse but don't communicate to him through the medium of the reins and bit, that you anticipate any unruly exhibition from him. There is a magnetism existing which I cannot account for, that is communicated from the driver to the horse and from the horse to the man through the medium of the reins and bit. Any man having had much experience in riding and driving horses, can attest to this statement. You may go out to drive, not feeling first rate, on a fine morning; if the horse possesses a superabundance of animal spirits, you will shortly begin to feel better and exhilerated by the association. Some may say it is only the air and exercise, and constant and rapid change of scenery. but I know better, you get into a street car, and ride, 
eight or ten miles at the same rate as behind the horse and you will be able to appreciate the difference. I would not give a cent to ride behind a horse if I couldn't drive him. I have no doubt many men have experienced the difference between riding with a friend, he doing the driving, and driving themselves.

In recovering a horse from a break, some horses acquire the habit of catching their gait by a pull upon the left rein, some will only catch with the right, which habit is formed by the driver to whom they owe their education. A horse should not be snatched from side to side but steady him until he knows what he is about, and ordinarily by a slight shake of the bit he will recover his trot readily. Never allow a horse to slacken his rate of speed if it is possible to catch him without doing so. There is occasionally a horse that will leave his feet and make a couple of jumps, when a steady pull will seemingly catch him in the air and he will land in a square trot and apparently glorying in his accomplishment. Horses that leave their feet without cause, like interfering, brushing themselves, etc., and are moving entirely within their limit of speed, a little whalebone does a world of good, and you can make them understand by its use, that you will put up with no such foolishness. But before you use the whip be sure that the horse is not brushing himself anywhere, in which case you would commit an unpardonable mistake by whipping him, and a horse may be guilty of the offense of leaving his feet in a playful manner without being able seemingly to control his animal spirits. Work is the remedy to be applied in this case instead of the whip. 


\section{CHAPTER XIX.}

BUYING A HORSE.

In buying a horse that is supposed to possess speed, insist upon seeing him harnessed and driven, if he is broken to harness. Never buy a "lot trotter" unless you know to a dead certainty that he will not "shut up "when you hitch him in harness. The writer has seen horses that in the field, could show you a gait that would seem to indicate a capacity to wipe out all previous records, and when harnessed could not go fast enough to keep warm. Of course, a thorough horseman can judge something of the claims to merit a horse or colt may have in respect to speed, by observing their action in the field, being able by reasnn of their experience and observation to discriminate between a high "tail over the back" gait, and genuine trotting action, he would take into consideration the conformation of the animal in general, and also his near ancestry, or pedigree upon which the writer places. considerable reliance. I had rather have a green colt out of sire and dam who were performers, than out of a sire and dam not performers, whose offspring is untried; other things being equal. If a man comes to you and says: "I have got a horse that can show a mile in ' 25 , he is sound and all right and no record, and I'll sell him for a thousand dollars!" If he will agree to show you 2-25 and take off fifty dollars per second for every second he falls short of the mark, the probability is, if you can nail him to this agreement, he will have to give you the horse and odds besides. Men always over-rate the speed their horses possess, when negotiating a sale. If you are not a judge of speed, there is no sure test for you to apply but a watch, it will generally beat any trotter. There 
are many men whose experience has made them excellent judges of speed, and will readily depend upon their judgment in estimating the speed of a horse under negotiation.

Any unsoundness of limbs, feet or wind, in a trotter or pacer renders the animal practically of little value, there are some exceptions however. The loss of an eye would not incapacitate a horse for turf or road purposes, and horses with a bone spavin on each leg, are frequently of considerable value, but any infirmity of the locomotive or breathing powers will result in great disappointment to the owner nine times out of ten; so, if you value your peace of mind, don't buy a cripple. Size in horses men may differ about more than either of my foregoing observations, respecting speed and soundness. Horses both big and little, have been not only great performers but great lasters as well. From fifteen to sixteen hands seems by experience to be about the range that first-class performers cover in respect to height. A sixteen hand horse is large enough and a fifteen hand horse is small enough for turf purposes. Length of body is quite as important as height. A horse "long on the ground" has an advantage over a horse much shorter; some horses fifteen and a half hands high, frequently are longer than other horses sixteen hands, in which case other things being equal, the smaller horse I would prefer for a race horse. Limbs, feet, respiratory and digestive organs in a sound and healthy condition, we must admit, contribute largely in the make up of a horse, but a horse without a well balanced head is of no earthly account as a race or road horse of the first order. The brain is the seat of nervous energy, and this is what is absolutely essential in a performer of the first magnitude. Were this not a fact, how can the superiority of Maud S., Jay Eye See, St. Julian, Richball and Johnson, be accounted for, as compared with others of the equine family. Thousands of horses all over the United States, trained and untrained, possesses as fine muscular development, just as good bone, from the same families, been educated and 
handled by just as good men, and have not lacked in opportunities to distinguish themselves. If the brain is not the fountain of speed in the trotter and pacer, will not some Solon of the present day enlighten us? The existence of this brain power in the requisite degree to impell the animal at the rate of a mile in 2-10 is not apparent to the observation, and it remains to be seen whether the horse has this requisite or not. All horses exhibit in their countenance and eyes, any index of their general disposition. If you will judge them in the same manner you would estimate a man's character, providing you are a good physiognnmist, you will come as near the right estimate as any body. I have seen men who placed great stress upon a high tempered boisterously disposed colt, some kicker or runaway animal, that did it out of pure "cussedness." I have seen men go and buy one of this kind, and unbeknown to any neighbor work at his purchase for a month or six weeks, felicitousiy awaiting for the time to arrive for him to astonish and paralyze his friends and acquaintances with his newly acquired treasure, but I have never known a man made happy by the purchase of such an animal. We prefer a mild mannered sensibly disposed horse to any hot headed kicker or runaway animal, both for a road or a race horse, or in any other capacity. In respect to breeding, a well bred horse will not be overlooked on account of the absence of known pedigree. The breeding is apparent in the animal whether good or bad. In selecting a trotter that is undeveloped from among a number of unbroken colts, the pedigree and performances of his immediate ancestors should not be overlooked, although one colt from the sire and dam of a number of colts and fillies may be a phenomenal trotter or pacer, while the others, full brothers and sisters, are of no particular account. The Bruno and Brunette family was remarkable for their all being trotters of no mean capacity. Bruno and Brunette trotted a trial in double harness, in $2-25 \frac{1}{2}$. Young Bruno's record 2-22 $1 / 2$, Breeze 2-24, Daniel Boone, record 2-3I, trial 2-26, Carl Burr, trial 2-243/4 and Jack Archol, the 
youngest of Old Kate's foals, won a race in $\mathbf{I} 880$, in $\mathbf{2 - 2 9}$ and Bona Fide has no record, but is a trotter; all these colts by Rysdyks Hambletonian, and Old Kate, of whose breeding nothing is known. Some men we hear speak very regretfully on account of the deaths of such sires as Rysdyks Hambletonian, Blue Bull, Ethan Allen, George Wilkes, etc., as though there would never be another sire capable of producing a first-class trotter, but I believe that to-day there are ten stallions calculated and capable of siring as fast and game trotters as any of the dead heroes proved themselves capable of doing, to where there was one such sire fifteen years ago. All there is necessary to prove this assertion is time and opportunity. We would not detract from the fame of the dead heroes above alluded to, if we could. At the same time, I believe in according to the living and vigorous representatives now in the stud, the opportunity they deserve, believing that the time is not far distant, when some trotter or pacer will do a mile in two minutes, and moreover, I believe that there will appear upon the trotting and pacing horizon within the next three years, a double team that will wipe out all previous records, any way of going, and both horses go the same gait, or in other words, no running mate will be employed. 


\section{CHAPTER XX.}

\section{CONCLUSION.}

When a horse has come to his speed, do not dog the speed out of him by long tedious slow jogging, for when his limbs are seasoned to go a mile in good time, say $2-30$, or a little better, his further improvement in speed will result from short jogs and sharp brushes of speed in his work, not too extended, together with close attention to the conditioning process, with a repeat once a week or ten days, if you are not trotting him in races, and if you are, he will not need a repeat. Don't over work him; two-thirds of the "quitters" are horses that have had too much work; and bear in mind another important truth, different horses will require different treatment in respect both to feeding, water and work, and if you should have a dozen horses in charge, probably not more than two of them would require the same treatment, and your judgment must guide you as to feed, water, work, shoeing and hitching. No man has ever attained a desirable reputation as a trainer and driver of trotting horses without possessing the elements in his make up, that would have made him successful in any other department of life wherein judgment, perseverance and a level head, would be required to insure success. As to the general integrity of the profession I will say, that I believe they have exhibited as much fidelity to the trusts reposed in them as any other class of men; bank officials and treasurers of trust funds not excepted. One thing is certain, you need never expect anfy man to serve you unflinchingly, unless you make it an object for him to do so. Very little complaint is ever heard from men who employ first-class trainers and drivers, and pay them what their services are worth. And further, no horseman on earth can take a natural born "duffer" and make a race horse of him, and still you hear men every day condemned and ma- 
ligned for not making a winner out of some animal utterly destitute of the first element of a race horse (except in the mind of his owner). If you set out to develop a trotter, your object, I presume, will be the dollars and cents that will accrue as speed is acquired by the horse. If you have not that object in view you will never make a trotter. I have never known a first-class trotter or race horse of any description, brought out by a trainer, just for the fun of the thing; amusement is not a sufficient incentive. As I observed at the outset, do not trot or pace your horse for any one's amusement, or your own even, if he don't need speeding; great harm has befallen horses in showing them to people who had no interest in seeing them go, but idle curiosity.

I have endeavored in the foregoing pages, to give the information the amateur horseman would naturally crave upon the subject of developing speed, at the outset of his career as a trainer. Perhaps there will never be a man read this book but what knows, or thinks he knows more than the writer, but that is nothing, there is no subject that the average man, and woman even, think they are as competent to grapple with as The Horse, and if you desire to arouse a man's antagonism, tell him he doesn't know anything about a horse. If I have succeeded in interesting you, reader, to the extent, that you will seek to upset any of the theories or practices laid down in this work, I am satisfied. There is a great amount of pleasure and satisfaction in the companionship of horses if they are good ones, but if you possess the knowledge and deservement that will enable you, not only to select a good one from among ten thousand, but to develop him in speed and money value also, you combine pleasure with profit. Many a horse to-day is performing menial service that had he in his youth been taken in hand by a thorough horseman, would have had his name enrolled in the 2-30 list. No horse can ever distinguish himself without an opportunity and the assistance of a competent trainer, and knowledge is the pre-requisite of the trainer's qualifications. 


\section{RULES AND REGULATIONS} $-\mathrm{OF}-$

\section{"The National Trotting Association." \\ [TO GOVERN ALL ENGAGEMENTS AND PERFORMANCES OVER THE ASSOCIATED COURSES.]}

Enacted by the National Trotting Association at the Congress held in the City of New York February 13, 1884.

RULE I.-MANDATE.

Section I. All trotting and pacing engagements and performances over the several courses which are, or shall be, represented by membership in "THE NATIONAL TrotTing Association," and each and every person who shall in any way be concerned or employed therein, as well as all associations and proprietors themselves who are or shall become members of said National Association, shall be governed by the following rules from and after February 13, I884. [See also Articles I2 and I3 of By-Laws.]

RUle 2.-ENTRIES.

Section r. All entries must be made in writing, signed by the person making the same or by some one authorized in his behalf; and, within the time appointed for closing, they must be addressed and forwarded according to the published conditions, or deposited with the Secretary or other person authorized to receive them

SEC. 2. All entries not actually received by the member as aforesaid, at the hour of closing, shall be ineligible, except entries by letter bearing postmark not later than the day of closing, or entries notified by telegram, the telegram to be actually received at the 
office of sending at or before the hour of closing, such telegram to state the color, sex, and name of the horse, and the class to be entered, also to give the name and residence of the party making the entry.

SEC. 3. The hour for closing the entries for all purses or premiums offered by any of the associated courses shall be I o'clock P. M., except for stakes and purses for horses to be named at the post, the entries to which shall close at the hour fixed for the race.

SEC. 4. Nominations for sweepstakes shall not be privileged to compete unless the payments have been made as required by the conditions. And nominations for premiums may be rejected when not accompanied by the entrance money.

SEC. 5. It shall be the duty of the Secretary, or other person authorized, to prepare the list of entries for publication, comprising all information necessary for the enlightenment of the general public and parties to the race.

\section{Rule 3.-Entrance-Fee.}

Section I. The entrance-fee shall be ro per cent of the purse, unless otherwise specified; and any person failing to pay his entrance dues, or in stake races his declaration, forfeit, or entrance, may, together with his horse or horses, be suspended until they are paid in full, which shall be with addition of Io per cent. penalty, and interest at 7 per cent. per annum until paid-the penalty to go to the National Association. [See Rule 50; also Rule 5 I, Sec. 7; and Rule 52, Sec. 3.]

SEC. 2 No suspension for non-payments of dues as aforesaid shall be lawful unless ordered within one week of the close of the meeting, and no suspension shall be imposed for non-payment of such dues contracted in a class wherein the horse was permitted to start, or in any case when the member has applied for membership subsequent to the closing of its entries.

SEC. 3. All entries shall be governed by the published conditions, and shall be bound for the entrance fee 
regardiess of any proposed deviation from such published condition, and any member who shall make a collusive arrangement to allow a nominator privileges differing from those allowed by the terms of the race to other entries in the same class, shall upon satisfactory evidence therof produced to the Board of Review to be held to forfeit to the National Association, the amount of the purse in which such collusive arrangement was made, one-half of such forfeit to go to the informant upon recovery of the same, and the member, upon a second conviction of like character, shall be expelled.

\section{Rule 4. - How Many to Enter.}

Section I. In all purses three or more entries are required, and two to start, unless otherwise specified.

\section{Rule 5.-Horses to be Eligible when Entries CLose.}

Section I. A horse shall not be eligible to start in any race that has beaten the advertised time prior to the closing of the entries for the race in which he is entered, unless otherwise specified in the published conditions. Fractions of a second shall be considered in determining the time made, and shall be entered in the record, but they shall not operate as a bar in making entries; that is, a horse gaining a record of $2.29 \frac{1}{2}$ shall remain eligible in the 2.30 class.

SEC. 2. A horse shall not be eligible if the time specified has been beaten by him at a greater distance; that is, a horse having made two miles in five minutes shall take a record of 2.30 and be eligible for a 2.30 race, but not for a race limited to horses of a slower class than that.

Rule 6.-Description and Name of. Each Horse REQUIRED.

SECTION I. An accurate and sufficient description of each entry will be required; such as shall identify the ani$\mathrm{mal}$, and shall embrace the following particulars, to wit: 


\section{[COLOR.]}

Sec. 2. The color shall always be given, and when necessary to identification, the marks shall be stated.

[SEx.]

SEC. 3. It shall be distinctly stated whether the entry be a stallion, mare or gelding, and the names of the sire and dam if known shall be given in all cases, and when unknown it shall be so stated in the entry. If this requirement as to pedigree is not complied with the entry may be rejected; and when the pedigree is given, it shall be stated by the member with the publication of the entry, and if the pedigree or record of a horse be falsely stated, for the purpose of deception, the guilty party may be fined, suspended, or expelled, by order of the Board of Review.

[NAME OF HORSE.]

SEC. 4. Every horse shall be named, and the name correctly and plainly written in the entry; and after entering or trotting in a public race such name shall not be changed without procuring a record thereof to be made in the office of the Secretary of the National Trotting Association, for which there shall be paid a recording fee of $\$ 50$, the fee to go to said National Association. For each violation of this requirement a fine of $\$ 100$ shall be imposed, together with suspension of the horse until paid, and no horse shall be thus recorded by a name that has been recorded for another horse.

Sec. 5. If a horse has ever trotted in a public race, the last name under which he or she trotted shall be given with the entry; and if the name has been changed within two years, each name he or she has borne during that time must be given; and if any horse without a name has ever trotted in a public race, mention must be made in the entry of a sufficient number of his or her most recent performances, to enable interested parties to identify the animal: provided, that it shall not be necessary to furnish any one association or proprietor with the same record of performance the second time during one season. 
SEC. 6. In entries and nominations made after 1875 , the words "no name" shall not be received as a name; neither shall such descriptive words as "bay horse," "gray mare," "unknown," etc., be allowed as name, under a penalty of a fine not to exceed the entrance-fee, to be imposed on the member who violates this restriction. But this restriction shall not apply to any horse having obtained a record previous to 1876 under the name of "Unknown."

SEC. 7. A horse having once been named, shall not afterwards start in a race on any association course, without a name, or under a different name, unless the foregoing requirements have been complied with.

[DOUBLE TEAMS.]

SEC. 8. In all double-team races the entry must contain the name and description of each horse, in the manner provided for entry of single horses.

\section{Rule 7.-Identification.}

Section r. The residence and post-office address, in full, of the person or persons in whose name an entry is made must always be given, and if the name or residence be falsely stated, for the purpose of deception, the entry shall be disqualified from winning, and the offender shall be punished by a fine not or exceed $\$ 100$, or by suspension or expulsion.

SEC. 2. If the nominator is not the owner, then the name and residence of the owner or owners must also be stated with the nomination.

SEC. 3. Whenever the nominator is personally unknown to the officers of the course, if required, or if his entry is protested, he shall establish his identity, and that of his horse, by sufficient references or evidence; and if the Judges are not satisfied in regard to said identity, before or after the start, all pools and bets on said horse may be declared off, and if so declared off it shall be publicly announced from the stand; and if the identity of the horse shall not be established within twenty-one days be 
barred from wianing, and any premium which might be awarded said horse which is not distributable under the rules to another horse in the race shall revert to the National Trotting Association. [See Rule I6, Sec. 8.]

Rule 8.-Entries that Cannot Start.

Section I. As many horses may be entered by one party, or as many horses trained in the same stables as may be desired, but only one that has been owned or controlled wholly or partly by the same person or persons, or trained in the same stable within ten days preceding the race, can start in any race of heats.

\section{RULE 9.}

Section I. No purse will be awarded for a "walk over," but in cases where only one of the horses entered for a purse shall appear on the course, he shall be entitled to his own entrance money and to one-half of the entrance money received from the other entries for said purse. The restriction herein as to "walk over," shall not apply to stakes or forfeits.

Rule 10.-In Case of Death, Enagements Void.

SECTION $\mathbf{r}$. All engagements, including obligations for entrance fees, shall be void upon the decease of either party or horse, so far as they shall effect the deceased party or horse; but forfeits, also matches made, "play or pay," shall not be affected by the death of a horse.

\section{RULE II.-Match Races.}

SECtion I. In all match races these rules shall govern, unless the contrary be expressly stipulated and assented to by the club, association, or proprietor of the course over which the race is to come off.

Rule 12.-When Matches Become "Play or Pay."

Section r. In ali matches made to come off over any of the associate courses, the parties shall place the amount of the match in the hands of the stakeholder one day before the event (omitting Sunday) is to come off, at such time and place as the club, association, or proprietor, upon application, may determine, and the race shall then become "play or pay." 
Rule 13.-Purse or Stake Wrongfully Obtained.

SECTION I. A person obtaining a purse or stake through fraud or error, shall return it to the Treasurer of The National Trotting Association, if demanded within one year, by the member or by the President or Secretary of this Association, or by order of the Board of Appeals, or he shall be punished, as follows: He together with the parties implicated in the wrong. and the horse or horses, shall be suspended until such demand is complied with and such purse or stake shall be awarded to the party justly entitled to the same.

Rule 14-Fraudulent Entries or Meddling with HORSES.

Section I. Any person found guilty of dosing or tampering with any horse, or of making a fraudulent entry of any horse, or of disguising a horse with intent to conceal his identity, or being in any way concerned in such a transaction, shall be expelled.

SE.C. 2. Any horse that shall have been painted or disguised, to represent another or a different horse, or shall have been entered in a purse in which he does not belong, shall forfeit the entrance money and be expelled.

\section{RULE I5.-ReWARD.}

Section I. A reward of $\$ 50$ will be paid to any person who shall first give information leading to the detection and conviction of any fraudulent entry and of the parties thereto, to be paid out of the funds of The National Trotting Association by the Treasurer, upon the decision and order of the Board of Review: provided, that this shall not be construed to extend protection to courses outside of this Association.

Rule i6.-Protest.

Section 1. Protests may he made verbally before or during a race, and shall be reduced to writing, and shall contain at least one specific charge, and when required, a statement of the nature of the evidence upon which they are based, and they shall be filed with the 
judges, association, or proprietor, before the close of the meeting; and the protesting party shall be allowed to file additional charges with evidence. [See Rule 7, Sec. 3.]

SEC. 2. The Judges shall in every case of protest demand that the rider or driver, and the owner or owners, if present, shall immediately testify under oath in the manner hereinafter provided; and in case of their refusal to do so, the horse shall not be allowed thereupon to start or continue in that race, but shall be considered and declared ruled out, with forfeit of entrance money.

SEC. 3. But if the parties do comply, and take the oath as herein required, unless the Judges find conclusive evidence to warrant excluding the horse, they shall allow him to start or continue in the race under protest, and the premium, if any is won by that horse, shall be retained a sufficient length of time (say three weeks) to allow the parties interested a chance to sustain the allegations of the protest, or to furnish information which shall warrant an investigation of the matter by the associate member, or the Board of Appeals: provided, that where no action as aforesaid has been taken to sustain a protest, or to furnish information, during three weeks, the associate member may proceed as if such protest had not been made.

SEC. 4. In any heat such protested horse shall win, the Judges shall waive the application of a distance as to all other horses, except for "fouls" defined in rule 48 .

SEC. 5. When a protest is presented before or during a race, and the parties refuse to make the prescribed oath, if the Judges believe the refusal is designed to favor a fraud, they may require the horse under protest to start or continue in the race.

SEC. 6. Any person found guilty of protesting a horse falsely and without cause, or merely with intent to embarrass a race, shall be punished by a fine not exceeding $\$ 100$, or by suspension or expulsion.

SEC. 7. When a protest has been duly made, or any information lodged with the Judges in support of a protest, 
alleging an improper entry or any act prohibited or punishable under these rules, the same shall not be with. drawn or surrendered before the expiration of three weeks, without the approbation of the association or proprietor of the course upon which such protest or information was produced; and if any association or proprietor shall permit such a withdrawal of protest or information, with a corrupt motive to favor any party who shall be affected by the same, the assaciation or proprietor so permitting, if convicted thereof by the Board of Appeals, shall be expelled from all connection with the National Trotting Association. [See By-Laws, Art. 7, Sec. 9.]

SEC. 8. Associations or proprietors shall be warranted in withholding the premium of any horse, during the time herein mentioned, without any formal protest, if before it is paid they shall receive information in their judgment tending to establish fraud. Premiums withheld under this rule to be forthwith sent to the Treasurer of said National Association and by him be retained, awaiting the result of an investigation by the member or by the Board of Appeals. [See Rule 7, Sec. 3.]

SEc. 9. The oath required in answer to protest shall be in the following form, to wit:

I...................... of the County

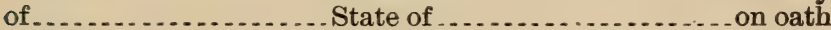
depose and say that $I$ am the called................................... same entered in a purse for horses that have never trotted better than minutes and...................... seconds, to be trotted this day on this course, and the same that has been protested, and to which protest this affidavit is in answer, hereby declare and affirm that to the best of my knowledge and belief said before-mentioned horse is eligible to start or compete in the race aforesaid; and that I fully believe all the provisions and conditions required in the rules and regulations for the goverment of trials of speed over this course were fully and honestly complied with in making the entry aforesaid.

Given under my hand at day of A. D. 188 this

Subscribed and sworn to before me, this day of ............. A. D. 188 . 
[Note.-In the absence of a Justice of the Peace, if this oath be administered by an officer of the association, or one of the Judges of the race, it will be considered sufficient for the purposes of the National Association.]

Rule 17.-When Horses Shall Not be Drawn.

Section $\dot{i}$. No horse shall be drawn except by permission of the Judges of the race, unless at or before seven o'clock P. M. of the day preceding the race (omitting Sunday), the proper party shall have lodged with the President, Secretary or proprietor of t'se course a written notice or notice by telegraph, of his intention not to start, after which notice the horse so drawn shall be ineligible to start in the race. For a violation of the requirement herein, a fine not to exceed $\$ 100$, or suspension or expul sion shall be imposed, the penalty to apply to both the horse and party who violates the regulation.

SEC. 2. Parties having two or more entries in one shall elect which they will not start, and notify their decision at the same time, in the same manner and under the same penalty as provided above. This rule shall not be construed to relieve nominators from payment for entries that are drawn.

\section{Rule 18.-Power of Postponement.}

SECTION I. In cases of unfavorable weather, or other unavoidable cause, each association or proprietor shall have power to postpone to the next fair day and good track (omitting Sunday) all purses or sweepstakes, or any race to which they have contributed money, upon giving notice thereof; and they may exercise this power before or after the race has commenced. [See also Rule 19.]

\section{Rule I9.-No Trotting after Dark.}

Section I. No heat shall be trotted when it is so dark that the gait of the horses cannot be plainly seen by the Judges from the stand, but all such races shall be continued by the Judges the next fair day (omitting Sunday), at such hour as they may designate. 
- Sec. 2. In all purses, matches, and stakes, the above rule shall govern, unless otherwise especially agreed between the parties and the association or proprietors.

\section{Rule 20.-Weights and Weighing.}

SECtion I. Every horse starting for purse, sweepstake, or match, in any trotting or pacing race, shall carry, if to wagon or sulky, $\mathbf{1}_{5} \mathrm{l}$ lbs., exclusive of harness; and if under the saddle, I $45 \mathrm{lbs}$., the saddle and whip only to be weighed with the rider.

SEC. 2. Riders and drivers shall weigh in the presence of one or more of the Judges previous to starting for any race, and after each heat shall come to the starting stand, and not dismount or leave their vehicles without permission of the Judges, and those who are deficient in bodily weight shall be re-weighed after each heat. Any rider or driver not bringing in his required weight shall be distanced, unless such decision shall be deemed to favor a fraud. But a rider or driver thrown or taken by force from his horse or vehicle, after having passed the winning-post, shall not be considered as having dismounted without permission of the Judges. and, if disabled, may be carried to the Judges stand to be weighed, and the Judge may take the circumstances into consideration and decide accordingly, and the riders or drivers who shall carry during the heat and bring home with them the weights which have been approved or announced correct and proper by the Judges, shall be subject to no penalty for light weight in that heat: provided, the Judges are satisfied the mistake or fault was their own, and that there has been no deception on the part of the rider or driver who shall be deficient in weight, but all parties shall thereafter carry the required weight.

Rule 2I.-Handicaps and Miscellaneous Weights.

SECTION I. In matches or handicaps, where extra or lesser weights are to be carried, the Judges shall carefully examine and ascertain before starting whether the riders, 
drivers, or vehicles are of such weights as have been agreed upon or required by the match or handicap, and thereafter the riders and drivers shall be subject to the same penalties and conditions as if they were to carry the weights prescribed by the rules.

Rule 22.-When Riders and Drivers are OverWEIGHT.

SECTION I. If the bodily weight of any rider or driver shall be found to exceed that which is prescribed in the rules, or that which is required by the conditions of the race, and the overweight shall not exceed twenty pounds, it shall be announced from the stand before the heat; and the judges shall have power, if in their belief such extra weight was imposed on the horse for an improper or fraudulent purpose, to substitute another rider or driver of suitable weight; and if they believe the horse has been prejudiced in the race by such overweight, he shall not be allowed to start again or continue in the race, and all bets on such horse may be declared off. [See also Rule 28, Sec. 5.]

SEC. 2. A horse prevented by this rule from continuing in the race shall not be distanced, but ruled out.

\section{Rule 23.-Length of Whips.}

Section r. Riders and drivers will be allowed whips not to exceed the following lengths : for saddle horses, $\mathbf{2} \mathrm{ft}$. ro in.; sulkies, $4 \mathrm{ft} .8 \mathrm{in}$; wagons, $5 \mathrm{ft}$. ro in.; double teams, $8 \mathrm{ft}$. 6 in.; tandem teams and four-in-hand, unlimited; snapheri, not longer than three inches, will be allowed in addition to the foregoing measurement.

Rule 24-Judges' Stand.

Section 1. None but the Judges of the race in progress, the Clerk of the Course, or Secretary and their assistance, shall be allowed in the Judges' stand during the pendency of a heat.

Rule 25--Selection of Judges.

SeCtION I. In every exhibition or race, over any course represented in the National Trotting Association, each 
course for itself, through the proprietor or association controlling the same shall choose or authorize the selection of three (3) cumpetent Judges, for the day or race, who shall understand the rules of the said National Association, and shall rigidly enforce the same; and all their decisions shall be subject to and in conformity with said rules. [See also Art. I3 of By-Laws.]

SEc. 2. Any person who at the time is under penalty of suspension or expulsion, or who has any interest in, or has any interest in either of the horses engaged therein. shall thereby be disqualified and restricted from acting as a Judge in that race. And if any person who is thus disqualified shall intentionally and deceptively violate this restriction, he shall upon conviction thereof by the Board of Appeals, be adjudged guilty of a dishonorable act, for which he shall be expelled from every course represented in said National Association.

\section{Rule 26.-AuthuRity OF Judges. \\ [See also Rule 28 .]}

Section I. The Judges of the day or race shall have authority, while presiding, to appoint Distance and Patrol Judges and Timers; to inflict fines and penalties, as prescribed by these rules, to determine all questions of fact relating to the race over which they preside; to decide respecting any matters of difference between parties to the race, or any contingent matter which shall arise, such as are not otherwise provided for in these rules; and they may declare pools and bets "off" in case of fraud, no appeal to be allowed from their decision in that respect, but all their decisions shall be in strict conformity with the rules, or with the principals thereof. They shall have control over the horses about to start, and the riders or drivers and assistants of the horses, and, in the absence of other provisions in these rules, they shall have authority to punish by a fine not exceeding $\$ 100$, or by suspension or expulsion, any such person who shall fail to obey their orders or the rules. [See Rule 28 ; and Rule $5 \mathbf{2}$, Sec. I and Sec. 2.] 


\section{Rule 27.-Distance and Patrol Judges.}

SeCtion I. In all races of heats there shall be a Distance Judge appointed by the Judges of the race or by those in authority, who shall remain in the distancestand during the heats, and immediately after each heat shall repair to the Judges' stand and report to the Judges the horse or horses that are distanced, and all foul or improper conduct, if any has occurred under his observation. But, in the absence of a Distance Judge, or in his failure to act, the Judges of the race shall determine what horses are distanced.

SEc. 2. Patrol Judges may be similarly appointed, and it shall be their duty to repair in like manner to the Judges' stand, and report all foul or improper conduct, if any has occurred under their observations.

Rule 28.-Power and Duties of Judges.

[See also Rule 26.]

Section I. The Judges shall be in the stand fifteen minutes before the time for starting the race; they shall weigh the riders or drivers, and determine the positions of the horses, and inform each rider and driver of his place, before starting; they may require the riders and drivers to be properly dressed; they shall be prepared to take the time of each heat in the race, and they may appoint some suitable person or persons to assist them in that respect, and the time so taken shall be recorded and announced in conformity with these rules. [See also Rule 26 and Rules 39 to 44 inclusive. and Art. I3 of By-Laws.]

SEC. 2. The Judge shall ring the bell, or give other notice, ten minutes previous to the time announced for the race or heat to come off, which shall be notice to all parties to prepare for the race or heat at the appointed time, when all the horses must appear at the stand, ready for the race or heat, and any rider or driver failing to obey this summons may be punished by a fine not exceeding $\$ 100$, or his horse may be ruled out by the Judges and considered drawn; but in all stakes and matches a failure to appear promptly at the appointed time shall render the delinquent party liable to forfeit. 
SEC. 3. The result of a heat shall not be announced until the Judges are satisfied as to the weights of the riders or drivers, and sufficient time has elapsed to receive the reports of the Distance and Patrol Judges.

SEc. 4. The Judges shall not notice or consider complaints of foul from any person or persons, except the Distance and Patrol Judges appointed by themselves or by those in authority, and from owners, riders, or drivers in the race. [See also Rule 48.]

SEC. 5. If the Judges believe that a horse is being or has been "pulled," or has been ridden or driven in other respects improperly, with a design to prevent his winning a heat or place which he was evidently able to win, and that such act was done on the part of the rider or driver for the purpose of throwing the race, or to perpetrate or aid a fraud, they shall have power to substitute a competent and reliable rider or driver for the remainder of the race, who shall be paid a reasonable compensation for his services, but not to exceed $\$ 50$, which shall be paid by the member, and the member may retain the amount paid from the purse if any, which said substitute driver may win; and any professional rider or driver who. without good and sufficient reason, refuses to be so substituted, may be fined, suspended, or expelled, by order of the Judges and upon approval of the Board of Appeals; and the Judges may declare such heat void, if it be a deciding heat of the race; and, if the result and circumstances of the race shall confirm their belief, the rider or driver so removed shall be expelled by the Judges. And if the owner or person or persons controlling the offending horse shall be a party or parties to such fraud, he or they together with the horse, shall be punished by expulsion. [See also Rules 22 and 48.]

Rule 29.-Starting and Keeping Positions.

SECTION I. No rider or driver shall cause unnecessary delay after the horses are called up, either by neglecting to prepare for the race in time, or by failing to come for the word, or otherwise; and in scoring, if the word is 
not given, all the horses in the race shall immediately turn, at the tap of the bell or other signal given, and jog back for a fresh start. But their shall be no recall after the starting word or signal has been given, and the horses shall be deemed to have started in the race when the word " $g o$ " is given for the first heat; provided, however, that if the Judges shall through any error give signal of recall, after having given the zeord, DISTANCE shall be waived in that heat, except for foul riding or driving. [See also Rule 6o, Sec. 2.]

Sec. 2. The Judges shall, after the first scoring, choose one of the contending horses (the pole horse be. ing selected, if deemed suitable,) to score by. And no driver shall come up in advance of said horse, nor shall he hold back under penalty of a fine of not less than $\$ 5$, nor more than $\$ 50$, which shall be imposed and collected at once. [See also Rule 40, Sec. 3.]

SEC. 3. No driver shall be allowed to sponge out his horse or horses oftener than once in five times scoring.

SEc. 4. If these requirements are not complied with on the part of any rider or driver, the Judges may not only start the race, or give the word without regard to the absence or position of the offending party or parties, but the offender may be punished by a fine not exceeding $\$ 100$, or by suspension not to exceed one year.

SEC. 5. In all cases, the starting word or signal shall be given from the Iudges' stand, and in no instance shall a standing start be given.

SEC. 6. No warning shall be necessary on the part of the Judges before inflicting fines or penalties for a violation of any of the provisions of this rule.

SEC. 7. The horse winning a heat shall take the pole (or inside position) the succeeding heat, and all others shall take their positions in the order assigned them in judging the last heat. When two or more horses shall make a dead heat, the horses shall start for the succeed- 
ing heat in the same positions with reference to the pole that they occupied in the finish of the dead heat.

SEC. 8. In comi g out on the homestretch the foremost horse or horses shall keep the positions first selected, or be liable to be distanced; and the hindmost horse or horses, when there is sufficient room to pass on the inside or anywhere on the homestretch withcut interfering with others, shall be allowed to do so, and any party interfering to prevent him or them shall be distanced.

SEC. 9. If a horse, in attempting to pass another on the home stretch, should at any time cross or swerve, so as to impede the progress of a horse behind him, he shall not be entitled to win that heat.

SEc. Io. Although a leading horse is entitled to any part of the track, except after selecting his position on the homestretch, he shall not change from the right to the left, or from the inner to the outer side of the track, during any part of the race, when another horse is so near him that in altering his position he compels the horse behind him to shorten his stride, or causes the rider or driver of such other horse to pull him out of his stride; neither shall any horse, rider, or driver cross, jostle, or strike another horse, rider, or driver, nor swerve, or "carry him out," "sit down in front of him," or do any other act which constitutes what is popularly known as "helping," or which shall impede the progress of another horse.

SEC. IJ. In any heat wherein there shall be a violation of any of these restrictions, the offending horse shall not be entitled to win the heat, and he shall be placed behind all other horses in that heat. And if the impropriety was intentional on the part of the rider or driver, the offending horse may be distanced, and the rider or driver shall be suspended or expelled. [See Sections 8, 9, and ro; also Rule 48.]

Rule 30.-Horses Breaking.

SECTION I. When any horse or horses break from their gait in trotting or pacing, their riders or drivers shall 
at once pull them to the gait in which they were to go the race, and any party failing to comply with this requirement, if he come out ahead, shall lose the heat, and the next best horse shall win the heat; and whether such breaking horse come out ahead or not, all other horses shall be placed ahead of him in that heat, and the Judges shall have discretionary power to distance the offending horse or horses, and the rider or driver may be punished by a fine not to exceed $\$ 100$, or by suspension not exceeding one year.

SEC. 2. Should the rider or driver comply with this requirement, and the horse should gain by a break, twice the distance so gained shall be taken from him at the coming out; but this provision must not be so construed as to shield any trotting or pacing horse from punishment for running.

SEC. 3. In case of any horse (in trotting race) repeatedly breaking, or running, or pacing, while another horse is trotting, the Judges shall punish the horse so breaking, running, or pacing, by placing him last in the heat.

SEC. 4. To assist in determining the matters contained in Sections I, 2, and 3, it shall be the duty of one of the Judges to call out during the progress of the race every break made, designating by colors or name the horse making it and the character of the break, and a Judge or assistant shall at once note the fact in writing.

SEC. 5. A horse breaking at or near the score shall be subject to no greater penalty than if he broke on any other part of the track.

\section{Rule 3i.-Relative to Heats and Horses Eligible To START.}

Section I. In heats one, two, three, or four miles, a horse not winning one heat in three shall not start for a fourth, unless such horse shall have made a dead heat. In heats best three in five, a horse not winning a heat in the first five shall not start for a sixth, unless said horse shall have made a dead heat, but horses so ruled out shall 
have a right to a share of the purse or premium, according to the rank at the close of their last heat. And where ten or more horses start in a race, every horse not distanced shall have the right to compete until the race is completed-subject, however, 'to all other penalties in these rules.

\section{Rule 32,-Dead Heats.}

Section. I. A dead heat shall be counted in the race, and shall be considered a heat which is undecided only as between the horses making it, and it shall be considered a heat that is lost by all the other horses contending therein; and the time made in a dead heat shall constitute a record or bar for each horse making such dead heat. [See also Rule 40, sec. 2.]

SEC. 2. Whenever each of the horses making a dead heat would have been entitled to terminate the race had he won said dead heat, they only shall start again.

SEC. 3. A horse prevented from starting by this rule shall not be distanced, but ruled out, and shall be entitled to a share of the purse or premium according to his rank at the close of his last heat.

Rule 33 -Time Between Heats; Passing to the Left; Horses Permitted on the Track.

SECTION I. The time between heats shall be twenty minutes for mile heats; and for mile heats best three in five, twenty-five minutes; and for two-mile heats, thirty minutes; and for three-mile heats, thirty-five minutes; and should there be a race of four-mile heats, the time shall be forty minutes.

SEC. 2. Not more than two races shall be "sandwiched" in the performance on one day, but when one race of the two has been finished, another may be called on. And when races are "sandwiched" the first race started shall be trotted out on time as far as practicable.

SEc. 3. After the first heat the horses shall be called five minutes prior to the time of starting. 


\section{Passing to the Left.}

SEC. 4. The rule of the road is reversed on the track; that is, horses meeting shall pass to the left.

Horses Permitted on the Track.

SEC. 5. Horses called for a race shall have the exclusive right of the course, and all other horses shall vacate the track at once.

Rule 34.-Time Allowed in Case of Accidents.

Section x. In case of accidents, ten minutes shall be allowed; but the judges may allow more time when deemed necessary and proper.

Rule 35.-Collision ANd BREAK-Down.

Section I. In case of collision and break-down, the party causing the same, whether willfully or otherwise, may be distanced; and if the Judges find the collision was intentional or to aid fraud, the driver in fault shall be forthwith suspended or expelled, and his horse may be distanced; but if necessary to defeat fraud, the Judges shall direct the offending horse to start again.

SEc. 2. No horse but the offending one shall be distanced in such a heat, except for foul driving.

SEC. 3. The Judges in a concluding heat, finding that a collision involved a fraudulent object, may declare that heat void. [See also Rule 48.]

\section{Rule 36.-Placing HoRses.}

SECTION I. A horse must win a majority of the heats which are required by the conditions of the race to be entitled to the purse or stake; but if a horse shall have distanced all competitors in one heat the race will then be concluded, and such horse shall receive the ertire purse and stakes contended for. [See Rule 37, Sec. 3.]

SEC. 2. When more than one horse remains in the race entitled to be placed at the finish of the last heat, the second best horse shall receive the second premium, if there be any; and if there be any third or fourth premium, etc., for which no horse has won and maintained a specific 
place, the same shall go to the winner; provided, that the number of premiums awarded shall not exceed the number of horses which started in the race.

SEC. 3. The foregoing provisions shall always apply in such cases, unless otherwise stated in the published conditions of the race.

SEC. 4. In deciding the rank of horses other than the winner, as to second, third, and fourth places, etc, to be assigned among such as remain in the race entitled to be placed at the conclusion of the last heat thereof, the several positions which have been assigned to each horse so contending shall be considered as to every heat in the race-that is, horses having won two heats, better than those winning one; a horse that has won a heat, better than a horse only making a dead heat; a horse winning one or two heats and making a dead heat, better than one winning an equal number of heats but not making a dead heat; a horse winning a heat or making a dead heat and not distanced in the race, better than a horse that has not won a heat or made a dead heat; a horse that has been placed "second" one heat, better than a horse that has been placed "third" any number of heats.

SEC. 5. When two or more horses appear equal in rank in the summary of the race, they shall share equally in the award of premiums won by them.

SEC. 6. In case these provisions shall not give a specific decision as to the second and third money, etc., the Judges of the race are to make the awards according to their best judgment, but in conformity with the principles of this rule.

\section{Rule 37.-Distances.}

Section $x$. In races of mile heats, 80 yards shall be a distance. In races of two mile heats, 150 yards shall be a distance. In races of three mile heats, 220 yards shall be a distance. In races of mile heats, best three in five, I o yards shall be a distance. In heats of not over one mile, wherein eight or more horses contend, the distance shall be increased one half; but in any heat wherein the 
number of starters shall be reduced to less than eight, the ordinary distance shall be restored.

SEc. 2. All horses whose heads have not reached the distance-stand as soon as the leading horse arrives at the winning-post shall be declared distanced, except in cases otherwise provided for, or the punishment of the leading horse by setting him back for running, when it shall be left to the discretion of the Judges. [See Rule r6, Sec. 4; Rule 29, Sec. I; Rule 35, Sec. 2; and Rule 40, Sec. 2.]

SEC. 3. A distanced horse is out of the race, and if in any heat one horse shall distance all competitors, the race will then be completed, and the winner shall be entitled to the entire purse and stakes contended for, unless otherwise stipulated in the published conditions of the race. [See Rule 36, Sections $I$ and 3.]

Rule 38.-Rank Between Distanced Horses.

Section I. Horses distanced in the first heat of the race shall be equal, but horses that are distanced in any subsequent heat shall rank as to each other in the order of the positions to which they were entitled at the start of the heat in which they were distanced.

\section{Rule 39.-Time and its ReCoRd.}

SECTION I. In every public race the time of each heat shall be accurately taken and placed in the record, and upon the decision of each heat the time thereof shall be publicly announced by the Judges, except as provided in in these rules concerning those heats which are not awarded to either of the leading horses.

SEC. 2. It shall be the duty of the Judges of the race to take the time as aforesaid, or to appoint some suitable person or persons to assist them in that respect, and no unofficial timing shall be announced or admitted to the record, but in any case involving alleged suppression of time, or false announcement of time, nothing in this rule shall be construed to limit the Board of Review as to the evidence admissible.

SEC. 3. In any case of alleged error in the record, 
announcement, or publication of the time made by a horse in a public race, the time so questioned shall not be changed to favor said horse or owner, except upon the sworn statement of the Judges and Timers who officiated in the race. [See also Article 20, of By-Laws; Rules 40, $4 \mathrm{I}$, and 43.]

Rule 40.-HoRses to Be Timed.

SECTION I. The two leading horses shall be separately timed, and if the heat is awarded to eitner, his time only shall be announced and be a record or bar as the case may be; and if the winning horse shall afterwards be ruled out of the race for fraud or ineligibility, he shall retain the record or bar acquired by the time so announced. [See also Rules 39, 41, and 43.]

SEC. 2. In case of a dead heat, the time shall constitute a record or bar for the horses making the dead heat; and if for any other cause the heat is not awarded to either of the leading horses, it shall be awarded to the next best horse, and no time shall be given out by the Judges or recorded against either horse; and the Judges may waive the application of the rule in regard to distance in that heat, except for foul riding or driving. [See also Rule 32, Sec. I.]

Skc. 3. The time shall be taken from the pole horse, or from the horse that is selected to score by.

$$
\text { Rule 4I.-Suppression of Time. }
$$

SECTION $\mathrm{r}$. In any public race, if there shall be any intentional suppression or misrepresentation in either the record or the announcement of the time of any heat in the race, it shall be deemed fraudulent. And any horse winning a heat or making a dead heat wherein there was such a fraudulent suppression of time, together with the parties implicated in the fraud, shall by operation of the rules be henceforth disqualified from the right to compete on the grounds of members; which disqualification may be removed only by order of the Board of Review, when upon investigation the board shall believe that the con- 
structive fraud was not premeditated, but only then upon a restitution or return to the custody of the Treasurer of this Association of any premiums that under any circum. stances have been awarded such horse on the grounds of members during the time of disqualification, and upon the payment of a fine of $\$ \mathrm{roo}$, to go to this Association. [See Rules 39, 40, 43, and 44.]

SEC. 2. A fine of $\$ 100$ shall be imposed upon any member of this Association on whose grounds the first section of this rule shall be violated; one-half of said fine to be paid to the informer upon recovery.

\section{Rule 42 -Public Race.}

SeCtion I. Any contest for purse, premium, stake or wager, or involving admission fees, on any course and in the presence of a Judge or Judges, shall constitute a public race.

\section{Rule 43.-Time Records, ANd Bars.}

[When Time Becomes a Bar.]

Section 1. A record can be made only in a public race, the horse to trot or pace a full mile according to rule; and the time must be taken by at least two timers selected for the purpose, and the record of their names as well as the time must be kept.

SEC. 2. Time otherwise taken, at fairs and on any track, whether short or not, shall be known as a bar, and shall constitute a bar the same as if regularly made over 2 track that was full measurement.

SEc. 3. Any public race at a less distance than one mile, and exceeding a half mile, shall be regarded as irregular, and time made in any such race shall create a bar.

SEC. 4. Time heretofore made on non-association tracks shall be records or bars, as the case may be, the same as if made over association tracks.

SEC. 5. If it should appear to the Board of Appeals, upon investigation, that any record was fraudulently obtained, it shall be declared not a record but a bar. 
Rule 44.-When Time Shall Not Be a Bar.

Shiction r. Time made under the saddle, or on snow or ice, as well as time made when two or more horses are harnessed together, shall constitute a bar for races of the same character, but shall not be a bar for races of a different character.

Rule 45.-Complaints by Riders or Drivers.

Section I. All complaints by riders or drivers, of any foul riding or driving, or other misconduct, must be made at the termination of the heat, and before the rider or driver dismounts or leaves his vehicle.

RULe 46.-DeCorum.

Section I. If any owner, trainer, rider, driver, or attendant of a horse, or any other person, use improper language to the cfficers of the course or the Judges in a race, or be guilty of any improper conduct, the person or persons so offending shall be punished by a fine not exceeding $\$ 100$, or by suspension or expulsion. [See also Rule 48.]

\section{Rule 47--Loud Shouting.}

Section r. Any rider or driver guilty of loud shouting, or making other improper noise, or of making improper use of the whip during the rendency of a heat, shall be punished by a fine not to exceed $\$ 25$, or by suspension during the meeting. [See also Rule 48.]

\section{RUle 48.- "Fouls."}

Section I. - If any act or thing shall be done by any owner, rider, driver, or their horse or horses, during any race or in connection therewith, which these rules define or warrant the Judges in deciding to be fraudulent or foul, and if no special provision is made in these rules to meet the case, the Judges shall have power to punish the offender by a fine not to exceed $\$ 100$, or by suspension or expulsion. And in any case of foul riding or driving they shall distance the offending horse, unless they believe such a decision will favor a fraud.

SEC. 2. The penalty imposed herein for "Fouls" shall 
apply to any act of a fraudulent nature, and to any unprincipaled conduct such as tends to debase the character of the trotting turf in the estimation of the public. [See Rule 28, Sections 4 and 5; Rule 29, Sec. II; See also Rule 35,46 , and 47 .]

\section{Rule 49.-Fines.}

Section r. All persons who shall have been fined under these rules, unless they pay the fines in full on the day when imposed, shall be suspended until they are so paid or deposited with the Treasurer of The National Trotting Association. [See By-Laws, Article I 7; See also Rule 52, Sec. r.]

SEC. 2. All fines which shall be paid to the association or proprietor on whose grounds they were imposed, shall by them be reported and paid to the Treasurer of said National Association. See By-Laws, Art. I2, Sec. 4.]

Rule 50.-No Compromise of Penalties by Judges. OR Memiers.

SeCtion I. In no case shall there be any compromise or change on the part of the Judges or member in the manner of punishment prescribed in the rules, but the same shall be strictly enforced; but members may accept compromise settlements of suspended dues, and the penalties in such cases shall be reduced in proportion. [See Rule 52.]

Rule 5 I.-Suspension and Expulsions.

Section I. Whenever a penalty of suspension is prescribed in these rules, if applied to a horse, it shall be construed to mean a disqualification during the time of suspension to compete in any race to be performed on the course of the association or proprietor; and if applied to a person, it shall be construed to mean a conditional witholding of all right or privilege to make an entry, or to ride, drive, train, or assist on the course and grounds of the association or proprietor; provided that an entry made by any person or of any horse so disqualified shall be held liable for the entrance fee thus contracted, with- 
out any right to compete during suspension, and further provided that any suspended person who shall ride or drive in a race on the grounds of a member while so suspended shall be fined not less than $\$ 50$, or more than $\$ 100$, for each offence; one-half of such fine to go to the informant upon conviction and recovery.

SEC. 2. If no limit is fixed in an order of suspension and none is defined in the rule applicable to the case, the punishment shall be considered as limited to the season in which the order was issued. [See Section 7.]

SEC. 3. Whenever the penalty of expulsion is prescribed in these rules, it shall be construed to mean unconditional exclusion and disqualification from any participation in the privileges and uses of the course and grounds of the association or proprietor.

SEC. 4. No penalty of expulsion for fraud shall be removed or modified after confirmation by the Board of Review, and on an appeal to the Board of Review the burden of proof shall be on the applicant, but expulsions for offenses not fraudulent may be so modified or removed.

SEC. 5. Any associate member allowing the use of their track by any expelled man or horse, after notice from the Secretary of The National Trotting Association, shall be subject to a fine not exceeding $\$ 100$.

SEc. 6. Whenever either of these penalties has been imposed on any horse or person, on the grounds of any association or proprietor holding membership in said National Association, written or printed notice thereof shall immediately be forwarded to the Secretary of said National Association, giving the name and residence of the person, and the color, sex, and name of the horse, and stating the offense and the character of punishment, who shall at once transmit the information to each associated course or member; and thereupon the offender thus punished shall suffer the same penalty and disqualification with each and every association and proprietor holding membership in said National Association.

SEC. 7. All suspensions imposed on horses for non- 
payment of entrance dues, shall cease and become void by limitation, at the expiration of six years from the date of their imposition, as per the records of this Association; but such release of the horse shall not operate to release the owner.

Rule 52.-Right of Appeal.

Section I. Appeals may be taken to the associate member in cases of suspension imposed by order of the Judges of a race or of an officer acting for the member, but members shall not remove or modify any fine imposed by the Judges of a race, nor review any order of expulsion. [See Sections 2 and 3 as to Appeals, and Rule 49 as to fines.]

SEC. 2. All decision and rulings of the Judges of any race, and of the several associations and proprietors belonging to The National Trotting Association, may be appealed to the Board of Review or to a District Board in the proper district, and shall be subject to review by such Board, upon facts and questions involving the proper interpretation and application of these rules: provided, that parties to be affected thereby shall be notified as the board shall direct, of a time and place when such appeal will be acted on; and provided further, if the appeal relate to the decision of a race, immediate notice shall have been given to the Judges of the race of the intention so to appeal. [See By-Laws, Art. 7, Sec. 8, and Sec. 9. See also Rule 26, Sec. I and Rule 5I, Sec. 4.]

SEC. 3. Any person who shall appeal from any order suspending him or his horse for non-payment of entrance money or a fine, may deposit the amount claimed with the Treasurer of said National Association, who may thereupon issue a certificate or notice, through the Secretary, temporarily reinstating or relieving the party and his horse from such penalty, subject to the final action of the Board of Appeals; and any perssn who shall make deposit under this rule, or under protest, shall file with the Secretary of this Association, within sixty days thereafter, a sworn statement of the grounds of appeal or pro- 
test, in the absence of which the protest or appeal shall be regarded as and become void, and the deposit may be administered as a payment applicable to the claim involved.

SEC. 4. In any case of deposit with any member of this Association for account of any claim of another member, or on account of any claim of which notice has been furnished from the office of this Association, the deposit shall be forwarded, within one week of the close of the meeting, to the office of this Association, for custody of its Treasurer, pending appropriate action thereon; and it shall be the duty of the member receiving any such deposit to notify the Secretary of this Association of the same, by telegraph when possible, otherwise by mail, within forty-eight hours from the receipt of the deposit.

Rule 53.-AGe of a Horse-How Reckoned.

SeCtion I. The age of a horse shall be reckoned from the first day of January of the year of foaling.

Rule 54-Colts and Fillies-Equally Eligible TO ENTER.

Section i. All colts and fillies shall be eligible alike to all premiums and stakes for animals of their age, unless specially excluded by the conditions imposed.

Rule 55-Green Horse.

Section I. A green horse is one that has never trotted or paced for premiums or money either double or single.

Rule 56.-Races Made and "No Hour Named."

Section 1. All races shall be started at 2 o'clock P. $M$, from the Ist day of April to the $\mathbf{I}^{\text {th }}$ day of September, and after that date at. I o'clock P. M., until the season closes, unless otherwise provided.

Rule 57-Race Made and no Distance Specified.

Section I. When a race is made and no distance specified, it shail be restricted to the following distances, viz: One mile and repeat; mile heats, best 3 in 5 ; two miles and repeat, or three miles and repeat, and may be performed in harness, to wagon, or under the saddle; the 
distance and mode of going to be named by the party accepting the race.

Rule 58.-Race Made to "Go as They Please."

Section I. When a race is made to "go as they please," it shall be construed that the performance shall be in harness, to wagon, or under the saddle; but after the race is commenced no change shall be made in the mode of going, and the race shall be deemed to have commenced when the horses appear on the track.

Rule 59-Race Made to Go "in Harness."

SECTION I. When a race is made to go "in harness," it shall be construed to mean that the performance shall be to a sulky.

Rule 60.-Matches Made Against Time.

SECTION I. When a horse is matched against time, it shall be proper to allow any other horse to accompany him in the performance, but not to be harnessed with or in any way attached to him.

SEC. 2. In matches made against time, the parties making the matches shall be entitled and limited to three trials, unless expressly stipulated to the contrary, which trials shall be had on the same day-the time between trials to be the same as the time between heats in similar distances. In such races there shall be no recall after the word is given.

Rule 61.-Horses Sold With Engagements.

SECTION I. The seller of a horse sold with his engagements has not the power of striking him out.

SEC. 2. In case of private sale, the written acknowledgment of the parties that the horse was sold with engagements, is necessary to entitle the buyer to the benefit of this rule.

A true copy from record, February I3, I884. Attest-

THO'S. J. VAIL. 


\section{PREF ACE TO BETTING RULES.}

In framing the general Rules and Regulations, the first Congress (in 1870) made no reference therein to betting. But, acting upon the belief that a published code of betting rules, emanating from a suitable committee, would assist in the correction of abuses, and thus promote the reformatory objects of the National Association, it was moved that the presiding officer appoint such a committee, which being agreed to, the chair appointed three prominent gentlemen to discharge that duty, with authority to select and add two more to their number. Through that committee, there was established the Code of 32 Betting Rules published in 1870 , and these were revised and amended by another committee of five gentlemen appointed from the Congress of $187 \mathrm{I}$, who reported the Code of $3^{\mathrm{I}}$ Betting Rules published that year; since which time (no change having been made therein), the same Code has continued in use among turfmen, and is now re-published as remaining in force.

These Betting Rules form no part of the laws of the Association, but they are published in this place for the convenience of those who desire to consult them.

HARTFord, CONn., February I3, is84. 


\section{BETTING RULES.}

\section{IN FORCE FROM AND AFTER FEBRUARY 1, 1871.}

Number I. All pools and bets must follow the main stakes, purse or other prize, as awarded by the decision of the judges, except in cases where the horse that comes in first is found to be disqualified, or the bets are declared off for fraud or collusion.

No. 2. If the race is postponed, it shall not affect the pools or bets that may have been made on it. They shall stand until the race comes off, unless the contrary shall be agreed on between the parties betting; provided the race takes place within five days of the time first named; after which time all bets and pools are drawn, unless made play or pay.

No. 3. When any change is made in the conditions of a race, all pools and bets made previous to the announcement of the change shall be null and void.

No. 4. When a bet is made on one horse against the field, he must start or the bet is off, and the field is what starts against him; but there is no field unless one start against him.

No. 5. In pools and betting, the pool stands good for all the horses that start in the race; but for those horses that do not start the money must be returned to the purchaser.

No. 6. In races made play or pay, outside bets are not play or pay unless so made by the parties.

No. 7. All bets are void on the decease of either party, but in case a horse should die, play or pay bets made on him stand.

No. 8. If a bet is made on any number of straight heats, and there is a dead heat made, the heats are not straight, and the party betting on straight heats loses. 
No. 9. If in any case the Judges declare a heat null and void, it does not affect the bets as in case of a dead heat as to winning in straight heats.

No. 10 . When a race is coming off, and a party bets that a heat will be made in two minutes and thirty seconds $(2.30)$, and they make two thirty. $(2.30)$ or less, he would win. If he bets they will beat two minutes and thirty seconds (2.30), and they make exactly two thirty (2.30), he loses; but if he takes two minutes and thirty seconds (2.30), against the field, and they make exactly two thirty $(2.30)$, it is a tie or draw bet. All time bets to be decided accordingly.

No. II. In a double event-where there is no action on the first race in order, in consequence of forfeit or other cause, the bet is off; but where there is an action on the bet, and the party betting on the double event shall have won the first, the bet shall then stand as a play or pay bet for the second event.

No. I2. If a bet should be made during the contest of a heat that a named horse will win that heat, and he makes a dead heat, the bet is drawn, but if, after the horses have passed the score, a party bets that a certain named horse has won the heat, and the Judges declare it a dead heat, the backer of the named horse loses.

No. 13. In races between two or more horses, of a single dash at any distance, which result in a dead heat, it is a draw between the horses making the dead heat, and bets between them are off; and if it is sweepstakes, the money of the beaten horses is to be divided between the horses making the dead heat.

No. I4. When a bettor undertakes to placeithe horses in a race, he must give a specified place, as first, second, third, and so on. The word "last" shall not be construed to mean "fourth and distanced," if four start, but "fourth" only, and so on. A distanced horse must be placed "distanced."

No. 15. Horses shall be placed in a race and bets decided as they are placed in the official record of the 
day; provided, that when a horse comes in first and it is afterward found that he was disqualified for fraud, the bets on him shall be null and void, but pool-sellers and stake holders shall not be held responsible for moneys paid by them under the decision of the Judges of the race. [See article 13 of By-Laws.]

No. 16. Bets made during a heat are not determined until the conclusion of the race, if the heat is not mentioned at the time.

No. I 7. Either of the bettors may demand stakes to be made, and, on refusal, declare the bet to be void.

No. I8. Outside bets cannot be declared off on the course unless that place was named for staking the money and then it must be done by filing such declaration in writing with the Judges, who shall read it from the stand before the race commences.

No. 19. Bets agreed to be paid or received, or bets agreed to be made or put up elsewhere than at the place of the race, or any other specified place, cannot be declared off on the course.

No. 20. Bets on horses disqualified and not allowed to start are void, unless the bets are play or pay.

No. 2r. A bet cannot be transferred without the consent of parties to it, except in pools.

No. 22. When a bet is made on a horse's time, it shall be decided by the time made in a public race, he going single and carrying his proper weight.

No. 23. When a horse makes time on a short track it shall not constitute a record for the decision of bets.

No. 24. Horses that are distanced or drawn at the conclusion of a heat, are beaten in the race by those that start afterward. A horse that is distanced in a heat is beaten by one draw at the termination of the same heat.

No. 25. When a man lays odds and intends to take the field against a single horse, he must say so, and the other party will choose his horse. When a man under- 
takes to name the winner, whether he bets odds or takes odds, he must name some one horse.

No. 26. All bets are relative to the purse, stake, or match, if nothing to the contrary is specified at the time of making the bet.

No. 27. Parties wishing all the horses to start for a bet, must so name it at the time the bet is made.

No. 28. When the Judges declare a heat null and void, all bets on that heat shall stand for decision on the next heat.

No. 29. All pools and bets shall be governed and decided by these rules, unless a stipulation to the contrary shall be agreed upon by the parties betting.

No. 30. Should any contingencies occur not provided for by these rules, the Judges of the day shall decide them.

No. 3r. When a horse which has not been sold in the pools wins the race, the best horse sold in the pools wins the money.

A true copy from record.

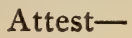

THO'S. J. VAIL,

Secretary.

\section{Different Styles of Betting by Turf Speculators of the Present Day.}

Perhaps a brief explanation of the manner in which wagers are laid upon turf events will not be out of place in this volume. Every prominent race meeting of the present day offers its patrons the opportunity of investing their wealth upon the "favorite," or the "field," in any race that may come off. The favorite method of betting money on races is the auction pool system, which was introduced here by a man named Doctor Under- 
wood, about thirty years ago, who became not only an attraction, but a necessity at every large race meeting of his day and time, as no meeting was complete without Doc. Underwood, as he was familiarly called by all the patrons of the turf. Many "silver tongued orators" have appeared in Underwood's role as pool-sellers, but a gentleman named Herdic, hailing from Williamsport, Pennsylvania, I think can transfer more money from speculators pockets into the pool box in a given time, than any man that has appeared since Underwood's day. Pool-sellers are merely the stakeholders of speculators who desire to deposit the amount of their bet where they know they can get it when the event is decided upon which the wager is laid, as poolsellers are compelled by all large racing associations to give bonds, or secure their patrons against any default of payment as soon as the bet is decided. To illustrate: Suppose ten horses start in a race, or are expected to start, the pool-seller commences by selling at auction the first choice which may bring $\$ 100$; he then sells in the same way the second choice, which may bring $\$ 50$; now there is $\$ 150 \cdot$ in the pool, and he will probably sell the "field," or all the other horses in a bunch, for $\$ 20$, and the total pool amounts to $\$ I 70$. If you have bought the favorite, or any other part of the pool, you step up to the cashier and pay him the amount you bid and receive a card, or pool ticket as it is called, which states the name of the horse you have selected, the amount you have paid, and the total amount of the pool. If the horse you have selected wins the race, you, upon presentation of your ticket, are paid the total amount of the pool, less three per cent. which pays the pool-seller for his time and trouble. Money deposited with the poolseller at any large meeting is just as safe as though it was in a bank, as far as he is concerned, as pool-buyers would be a little too desperate a class of creditors for any man to fool with. In some cases the horses are all sold separately, which is called "selling them down." In such a case, of course, there is no "field." 
Paris Mutuals, or "French pools," as they are called, are conducted differently. The horses are all sold at the same price, from $\$ 5$ to $\$ 25$; each and every heat is a race. The sales are kept track of by means of a register called a Paris Mutual machine, which registers in plain sight of all the buyers the number of tickets sold on each horse, as well as the total number of tickets, and a speculator can see at a glance exactly the value of each ticket sold on the winner at that moment. At the conclusion of each heat the total amount of the receipts for tickets is divided between the holders of tickets on the winner, less the commission of the pool-selier, which is five per cent. usually.

Book-making is another system of betting, which is a style of betting in vogue in England for a long time, but has been introduced in this country quite recently, and within the last ten years has made rapid strides into popular favor, particularly at all "running meetings." Book makers bet against every horse in the race winning, and generally give "odds," such as five to one, ten to one, and as high as seventy to one. If you desire to back any particular horse and the book-maker is giving the odds of five to one on him, he will not let you bet less than five dollars, so you lay five against twenty-five that the horse you have backed will win the race over all others, and the book-maker has the "field " against you in every transaction. No commission is collected by book-makers. In trotting and pacing races every heat is a race, same as in the French pool system. 


\section{List of 2:30 Trotters in Harness to the Close of 1883 .}

(New horses of 1883 are designated thus: *)

*Abbottsford, b s, by Woodford's Mambrino, dam by Young Columbus

Abdallah, b s, by Volunteer

Abdallah Boy, b s, by Abdallah Messenger.......... 2.24

Abe Downing, ch s, by Joe Downing ................ 2.20

Abe Edgington, gr $\mathrm{g}$, by Stockbridge Chief, $\mathrm{Jr}_{\ldots} \ldots \ldots \ldots \ldots 2.23 \frac{3}{4}$

Adair, b g, 4 yrs, by Electioneer ................... 2.30

Ada Paul, ch m, by Red Buck .................... 2.26

*Addie E. C., b m, by Burger....................... 2.30

Addison Lambert, $\mathrm{b}$ s, by Daniel Lambert.............. 2.27

Adelaide, b m, by Phil Sheridan .................... 2.193

*Adelaide, b m, 5 yrs, by Milwaukee................ 2.26

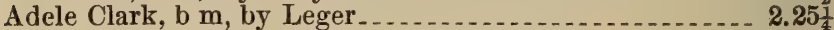

Adele Gould, ch m, by Jay Gould .................. 2.19

Administrator, b s, by Rysdyk's Hambletonian ......... 2.291

Emulus, br s, by Mambrino Pilot ................... 2.25

Ajax, b s, by Whipple's Hambletonian.

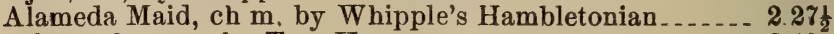

Albemarle, gr g, by Tom Hunter.................... 2.19

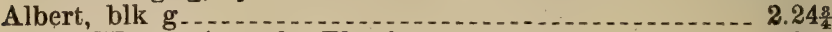

Albert W, b c, 4 yrs, by Electioneer ...................... 2.

Alcantara, b c, 4 yrs, by George Wilkes .............. 2.23

*Alcyone, br s, by George Wilkes... . . . . . . . . . . 2.27

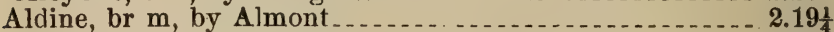

Alexander, b s, by Goldsmith's Abdallah............ 2.28

Alexander, blk s, by Ben Patchen ....................

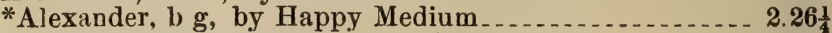

Alexander Button, b c, 4 y rs, by Alexander............ 2.26

Alexander S., rn g, by a Morgan horse ............... 2.281

Alfred (Little Alfred), b g, by Cloud Mambrino ....... 2.26

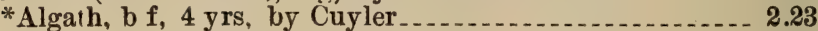

Alice, $\mathrm{b} \mathrm{m}$, (Canadian)

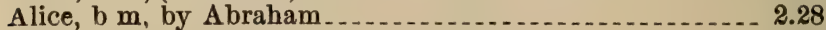

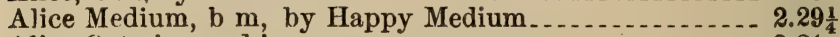

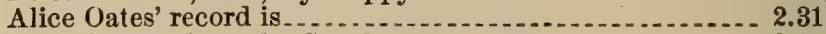

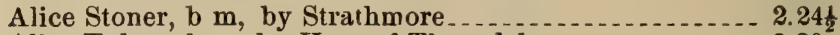

Alice Tyler, ch m, by Hero of Thorndale . . . . . . . . . 2.30

Alice West, blk m, 5் yrs, by Almont $\ldots \ldots$ 
*Alleghany Boy, rn s, by Wood's Hambletonian Allen, b g, by Woodward's Ethan Allen .............. *Allen Roy, gr g by Patchen Vernon Allen W. H., b s, by Volunteer

*Almonarch b s, by Älmont

*Almont Gift, b s, by Aimont Chief.

Almont $\mathrm{Jr}$ b $\mathrm{s}$, by Almont

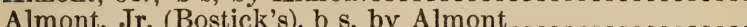

*Almont M., b s, by Almont

$2.24 \frac{3}{4}$

$2.29 \frac{1}{4}$

2.26

$2.29 \frac{1}{4}$

230

Alonzo Hayward, gr $\mathrm{g}$, by Billy Hayward . . . . . . . . . . 2.30

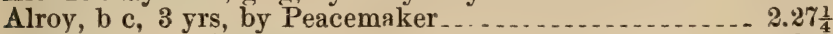

*Alta, b m, by Almont ................

Alton Boy, rn s, by Honest Allen, Jr . . . . . . . . . . . 2. 2.29

Ambassador, blk s, by George Wilkes................ 2.251

Amber, b s, by Clear Grit

Ámbler, b g, by Wood's Hambletovian ............... 2. 2.30

Amboy, ch s, by Green's Bashaw $\ldots \ldots \ldots \ldots$

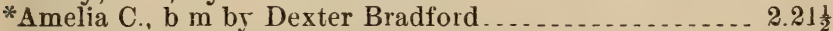

American Girl, b m, by Amos' C. M. Clay . . . . . . . . . . 2 2.16

Amy, b m, by Volunteer....................... $220 \frac{1}{4}$

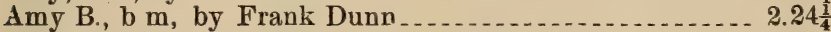

Ancient Order Boy, ch g, by Gen Morgan (Kurtz Horse) _. 2.27

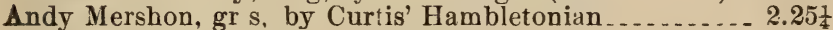

Angeline (Western Girl), b m, by Richard's Bellfounder _. 2.27

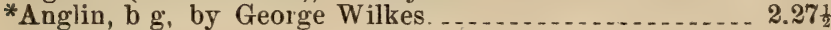

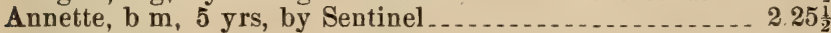

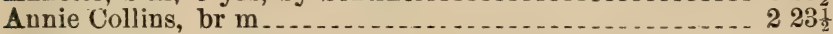

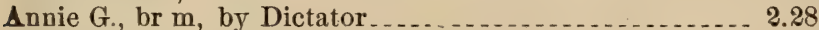

Annie Laurie, b f, 3 years, by Echo ..................... 2.30

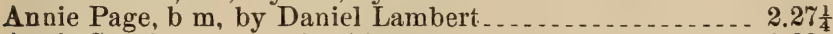

Annie S., ch m, 5 yrs, by Almont ....................... 28

Annie W., ch m, 5 yrs, by Almont, Jr... . . . . . . 2.20

Auodyne, ch g, by Ross Colt .................... 2.25

*Arab, b g, 5 yrs, by Electioneer $\ldots . . . . . . .24$

Archie, b s, by Rutter's Garibaldi .................. 2.281

Argonaut, br g, by Wond's Hambletonian .............. 2.231

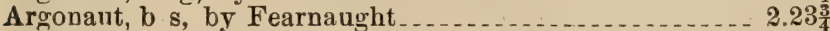

Aristos, b s, by Daniel Lambert ..................... 2.278

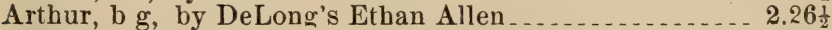

Arthur, blk g, by Lexington, son of Brandywine . . . . . . 2.281

Arthur, ch g. by Golddust _.................... 2.283

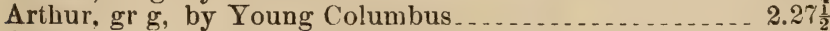

Arthur T. br g, by Col Ellsworth .................... 2.30

Ashland Kate, ch m, by Ashland Chief. . . . . . . . . . . . . 2.293 
Ashley, ch g, by Plumas ............ 2.25

*Astoria, b m, by Rysdyk's Hambletonian ............. 2.291 Aulinda, b m, by Woodward's Ethan Allen ........... 2.25

Aurora, ch m, by John Nelson .................... 2.27

Baby Boy, wh g, by Winthrop Morrill ................ 2.30

*Baby Mine, rn m, by Stonewall Jackson ............. 2.271

*Backman Maid, b m, by Charles Backman . . . . . . . . . . 2.25

Badger Boy, b g, by Leon ......................... 2.29

Badger Girl, gr m, by Black Flying Cloud............ 2.22t

*Banker, ch s, by Mambrino Patchen ................ 2.29

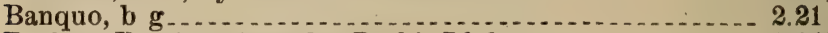

Barbara Patchen, b m, by Peck's Idol ................. 2.24t

Barkis, b g, by Whirlwind........................ 2.25

Barney, b g, by Mike .............. 2.25

*Barney B., b g, by Forrester Patchen......... .2 .27$

Barney H. ch g... ............................. 2.30

Barney Kelly, b g, by Holland's Ethan Allen......... 2.25

Baron Luff, b g, by Happy Me ium ............... 2.27

Barrett, b s, 5 yrs, by Chester Chief................ 2.25

Bashaw, Jr, ch s, by Green's Bashaw ............... 2.248

Bashaw Maid, ch m, by Plow Boy ................. 2.30

Basil Duke, rn g, by Ḧippy ...................... 2...28t

Bateman. b g, by Doty's Black Harry Clay ........... 2.22

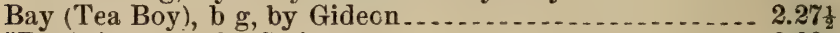

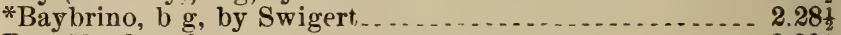

Bay Charley, b g ................................... 2.28

Bay Chieftain, b g, by Jokn F Payne............... 2.28

Bay Dick, b g, by Howser's Hiatoga ................ 2.29

Bay Fannie, b m . ............................... 2.28

*Bay Frank, b g, by Tornado ................... 2.20

Bay Henry, b g, by Mambrino Chief................ 2.281

Bay Jack, b g, by Victor ............................ 2.30

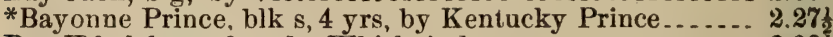

Bay W halebone, $\mathrm{b} g$, by Whirlwind ................ 2.26 .

*Bay William, b g, by Clear Grit ................... 2.27

Beautiful Bells, blk m, by The Moor ............... 2.29

Beecher, H. W.. blk s, by Phil. Sheridan .............. 2.28

Bella, b m, by Rysdyk's Hambletonian ............... 2.22

Belle, b m, by Ericsson ............................. 2.284

Belle Brassfield, b m, by Viley's Cripple .............. 2.20

Belle Dean, blk m, by Gen. Lyon.................. 2.30

Belle Echo, b f, 4 yrs, by Echo ..................... 2.23t

*Belle F., b m, 5 y rs, by Masterlode................. 2.29 .

Belle of Fitchburg, b m, by Paragon .................. 2.30

Bellflower, b m, by Milliman's Bellfounder........... 2.284

Belle H., ch m, by Fisk's Belmont .................. 2.23t

Belle Lawrence, b m, by Denmark .................. 2.28

Belle of Lexington, ch m, by Magna Charta............ 2.263 
Belle Oakley, ch m, by Garibaldi......... .......... 2.24t

Belle of Portland, b m, by Witherell Messenger......... 2.26

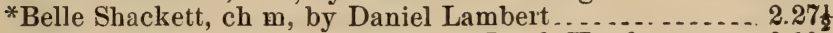

Belle of Saratoga, br m, by Vermont Black Hawk ....... 2.29

Belle Smith. ch m, by the Berce Horse ............... 2.29

Belle Stricklaud, $\mathrm{ch} \mathrm{m}$, by the Merrow Horse.......... 2.26

Belle of Toronto, br m, by Toronto Chief.............. 2.30

Belle Wilson, ch m, by Blue Bull................... 2.231

*Belle Wilson, b m, by Mambrino Bruce.... . . . . . . . . 2.24

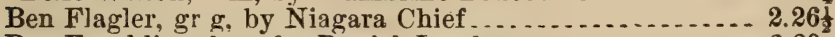

Ben Franklin, ch s, by Daniel Lambert ............... 2.29

Ben McClellan, ch g, by the Drew Horse............ 230

Ben Morrill, br s, by Winthorp Morrill............... 2.27

Ben Smith, gr g, by Young Columbus ............... 2.27

*Ben Star, b g

Bertie, gr m, by Blue Bull .......................... 2.27

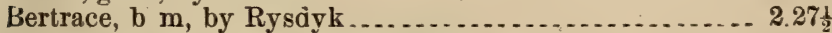

Betsy Ann, ch m, by Marshall Chief ............... 2.28

Betty Bump, blk m, by Stockholm .................. 2.30

Bickford, dn g, by Black Chief.................... 2.29t

Big Fellow, b g, by Edward Everett............... 2.26

Big Ike, gr g, by Yankee Bonner . . . . . . . . . . . . . . . . . . 2.291

Big John, b g, by Pilot Duroc ... ........ ......... 2.241

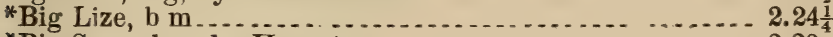

*Big Soap, b g, by Honesty .... . . . . . . . . . . . . . . . . 2.23

Bill Ed, b g, by Gen. Washington ................... 2.28

Bill Thunder, b g, by Robin Clay ................... 2.25

Billy, br g, by Victor Denmark ................... 2.29

Billy, ch g............................................ 2.30

Billy Bad Eye, b g, by Marshal Ney .................. 2. 29.

Billy Barefoot, blk g, by King Herod............... 2.28

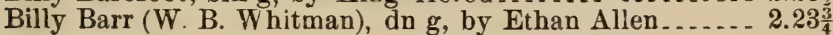

Billy Bolden, b g................................. 2.30

Billy Boy, b g, by Mambrino Temple . ............ 2.26

Billy Burr, b g, by Walkill Chief ...................... 2.29

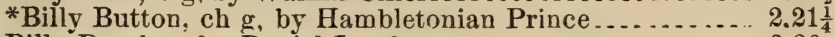

Billy D., ch g, by Daniel Lambert ... . . . . . . . . . . . . . . 2.26

Billy Dow, b g .... . . . . . . . . . . . . .

*Billy Ford, ch g, by son of Clark's Mohawk, Jr....... 2.30

Billy Hoskins, gr g, hy Edwin Forrest................ 2.26

Billy L, b g ... ............................... 2.281

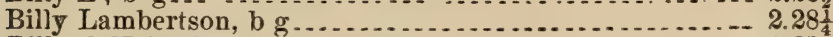

Billy O'Neil, (Harry Robertson), br g ................. 2.27

Billy Platter, gr $\mathrm{g}$

*Billy R., blk g, by Clay Pilot........................ 2.29

Billy Ray, rn g, by Wood's Hambletonian............ 2.23ㄴ...

*Billy Sheridan, br g, by Phil Sheridan ............... 2.291

Birdie C., b m, by Rutter's Garibaldi............... 2.281 
Blackbird, (Cal), blk s, by Simpson's Blackbird ......... 2.22

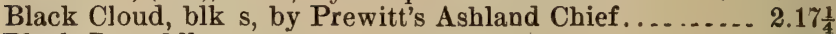

Black Dan, blk s . ................................. 2.30

*Black Diamond, blk s, by Mambrino Diamond......... 2.30

Black Douglas, blk g, by Henry Clay ................ 2. 230

Black Frank, blk g, by Frank ....................... 2. 2. 284

Black Frank (Chaney's), blk g, by Pony Frank......... 2.30

Black Frank, blk g, by Wild Wagoner................ 2.24

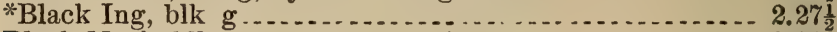

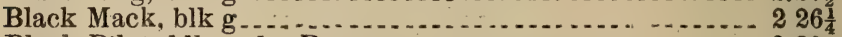

Black Pilot, blk s, by Roscoe ........................ 2.30

Blackstone Belle, blk m, by Clark's Whalebone ........ 2.2.28

Black Swan, blk m, by McCracken's David Hill .......... 2.28

Blackwood Jr, blk s, by Blackwood ................. 2.22 $\frac{1}{2}$

Blackwood Prince, blk s, by Blackwood .............. 2.231

Blaine, blk g, by Messinger Hunter .................... $2288^{\frac{3}{4}}$

*Blanchard, b g, by Daniel Lambert................. 2.25

Blanche, blk m, by The Railsplitter................. 2.23

*Blanche, b f, 4 yrs, by Little Eastern .................. 2.30

Blanch Amory, b m. by Clark Chief ................. 2.26

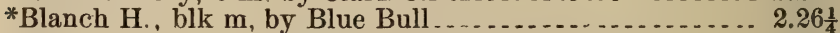

Bliss, b m, 5 yrs, by Bayard, dam by Sam Hazard ..... . 2.21

Blonde, gr m, by Hoagland's Grey Messenger........... 2.29

Blondine, ch $\mathrm{m}, 5$ yrs, by George Wilkes.............. 2.248

*Blue Jay, rn g, by Ben Lomand ....................... 2.291

Blue Mare, rn m, by Wood's Hambletonian ............ 2.23

Bob Acres, ch g, 4 yrs, by Honest Allen ............... 2.28

Bodine, b g, by Volunteer. . ..................... 2.191

Bolly Lewis, b g, by Seely's American Star............ 2.29

Bonesetter, b s, by Brooks ........ ................. 2.19

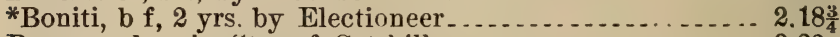

Bonner, ch g, by Star of Catskill .................. 2.23

Bonner Boy, b g, by Gill's Vermont ................. 2.23

*Bonnie, b f, 4 yrs, by Gen. Binton ................ 2.25

*Bonnie L., ch g, by Charley B ..................... 2.28

*Bonnie Wilkes, b m, by George Wilkes............... 2.291

Boston, b g, by Daniel Lambert...................... 2.271

Bradley, J J (Lookout \& John Nesbitt), b g . . . . . . . . . . . 2.25

Brandy Boy, b g, by Admiral Patchen ................ 2.20

Breeze, b g, by Rysdyk's Hambletonian ................. 2.24

*Breeze Medium, b m, by Happy Medium ............. 2.293

* Brigadier, b s, by Happy Medium ................... 2.21

Brignoli (Mambrino Prince), b s, by Mambrino Chief ..... 2.29

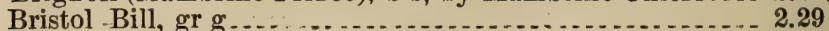

Bristol Girl, b m, by Jim Irving ..................... 2.28

*Bronze, b f, 4 yrs, by Morgan Messenger............. 2.211

Brookside Flora, br m, by Hamlet................. 2.29

Brother Jonathan, b g, by the Potter Horse ............. 2.24 
Brown Dick, br g, by son of American Star ........... $225_{\frac{1}{4}}$

Brown Dick, br g................................ 2.241

Brown Dick, br g, by Anthony Wayne............... 2.29

*Brown Wilkes, br s, by George Wilkes .............. 2.26. 264

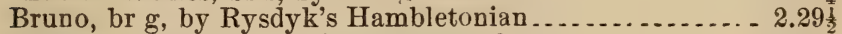

Brushy John, blk g, by Rappahannock .............. 2.27

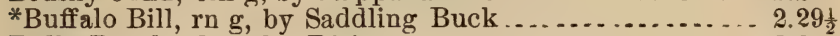

Bully Brooks, b g. by Dirigo........................ 2.28

*Burns, b s, by Kirkwood...

Bushwhacker, b s, by Joe Hooker................... 2.29

Business, b g, by Gossip Jones .... . . . . . . . . . . . . . . . 2.29

Buzz. br c, 4 yrs, by Toronto ..................... 2.28

Buzz Medium, b m, by Happy Medium ............. 2.20 201

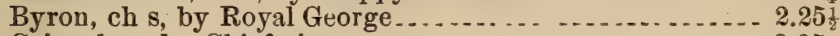

Cairo, b g, by Chieftain ........................... 2.25

Calamus, b m, by Swigert ....................... 2.241

Caledonia Chief, ch s, by Howe's Royal George ........ 2.29 29.

California Damsel, ch m, by Andrew Jack on Jr . . . . . . 2.24 24

Callahan's Maid (Chicago Maid), ch m, by Revenge..... 2.25

Calmar, b g, by Bourbon Chief .................... 2.22

Camors, b g, by Dirigo .............................. 2.25 . . . .

Camors, blk g, by Gen Knox ... . . . . . . . . . . . . . . . 2.19

Capitola, b m................................. 229

Capitola. br m, by Gilbreth Knox ................. 2.22

Capoul, b s, 5 yrs, by Sentinel ..................... 2.28

Captain, b s, by Billy Denton

Captain Emmons, ch g, by Continental... ........... 2.20

Capt. Gill, br g .................................. 2.30

*Capt. Herod, ch s, by Son of King Herod ........... 2.25

Capt. Jack, b g, by Fisher's Patchen .................. 2.26

Capt. Jenks, ch g................

Capt. Lewis, ch g, by Spink..................... 2. 20.2

Capt. Smith, gr g, by Fenian Chief . . . . . . . . . . . . $2.28 \frac{1}{2}$

Capt. Smith, br g, 4 yrs, by Locomotive .... . . . . . . . . 2 2.29

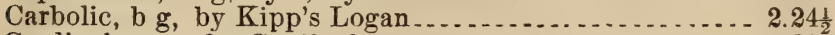

Cardinal, gr g, by Cardinal.......................... 2.30

C'areless Boy, b g, by Young Brandywine............ 2.28

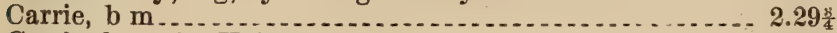

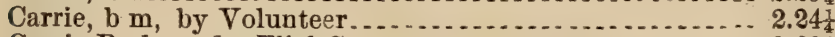

Carrie B , b m, by Elial G......................... 2.28

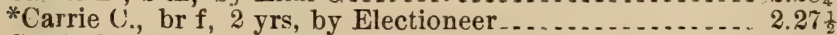

Carrie K., wh m, by Blind Eagle .................... 2.3C

Carrie Medium, b m, by Happy Medium, Jr.......... 2.2.27

Carrie N., b m, by Young Woeful .................. 2.27

Cassius Prince, ch s, by Ballard's C. M. Clay ........... 2. 2.29

Castle Boy, b g, by Gooding's Champion.............. 2.21

Castleton, b g, by Chesbrough ..................... 221

${ }^{*}$ Catchfly, b m, by Administrator .................. 2.19 
Catskill Girl, blk m, by Kossuth ................. 2.281

Cattaraugus Chief, b g, by Rough and Ready .......... 2.298

*Center, gr g, 3 yrs, by Sultan ..................... 2.291

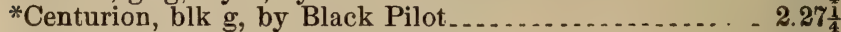

Champaign, g.t g, by Edwin Forrest.................... 2.30

*Champion Girl, b m, by Gooding's Champion ......... 2.291

Champion, Jr., br s, by Mambrino Champion.......... 2.24

Champion Morrill, br s, by Vermont Ranger.......... 2.27

Chance, ch g, by Blue Bull ........................ 2.201

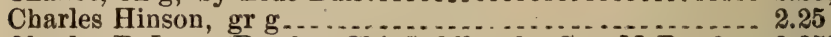

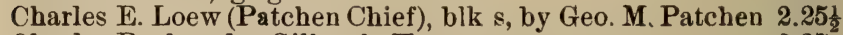

Charles R., b g, by Gilbreth Knox .................. 2.27

Charley B. (Gifford), ch g, by Chicamauga ............ 2.30

Charley B. (Lark), ch s, by King's Champion..... . . . . 2.25

Charley C, b g, by Woodward's Ethan Allen ............. 2.281

Charley Champlin, b g, by Messenger Duroc ............. 2.218

Charley Douglas, b g, by Tom, son of Scott's Hiatoga .... 2.30

Charley Ford (Billy Basteder), gr g, by Ferguson's Gray

Eagle $\ldots \ldots \ldots$
Charley Green, b g, by Careless $\ldots \ldots \ldots \ldots$

Charley Hood, b g, by Pearsall ..................... 2.29 .

Charley Mac, ch g, by Holabird's Ethan Allen .......... 2.25

Charley T., ch g . ................................. 2.291

Chauncey H., br s, by Robert Bonner.............. $227 \frac{1}{4}$

Chauncey M. Bedle, b g, by Gooding's Champion . ... . . . 2.30

Chester, ch g, by Patrick Henry .................... 2.28

Chester, b g, by Rysdyk's Hambletonian .............. 2.27

Chestnut Hill, b s, by Strathmore .................... 2.221

Chicago (Hardbread and Jim Rockuey), b g, by Ole Bull .. $224 \frac{3}{4}$

Chicago Jack, b g, by Sherman Black Hawk.......... 2.30

Chieftain, b g, by William Miner.................. 2.25t

Clara (Crazy Jane), b m, by Sager Horse ............ 2.27

Clara Cleveland, $\mathrm{ch} \mathrm{m}$, by Amboy ................... 2.23

Clara G., b $m$, by son of Miles Horse ................. 2.26

Clara J., ch m, by Black Diamord ................. 2.28

*Clara M., b m, by Jack Sheppard .................. 2.29

Claremont, b s, by St. Clair ...................... 229

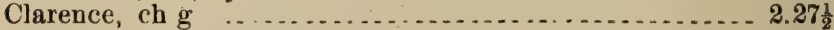

Clark S, gr g, by Edward Everett................. 2.274

Clay, blk g, by Fred Low .... . . . . . . . . . . . . . . 2.25

Clementine, b m, by Addison, $\mathrm{Jr} \ldots \ldots \ldots \ldots \ldots \ldots \ldots 21$

*Clemmie G., ch m, 5 yrs, by Magic .................. . 2.17

Cleora, blk m, by Menelaus ........................ 2. 2.18

Clermont, ch g, by Almont....................... 230

Cleveland, b g, by Hughes' Ned Forrest.............. 2. 2.281

Clifton Boy, blk g, by Joe .......................... 2.23

Clifton Boy, br g, hy Major Winfield............... 2.30

Clingstone, b g, by Rysdyk ......................... 2.14 
Clover (Brightwood), b g, by Young Hindoo .......... 2.251

Coaster, b s, by Calliban............................ 2.26

* Cobden, ch s, by Daniel Lambert . . . . . . . . . . . . . . 2.28

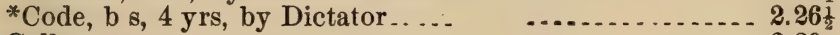

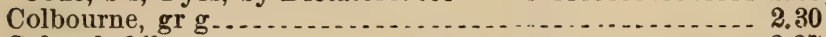

Colonel, blk g $\mathrm{n}$

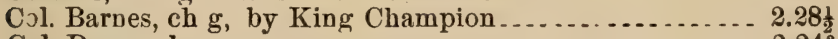

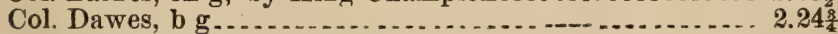

Col. Lewis, gr g, by Rifleman ..................... 2.18

Col. Moulton, ch s, by Daniel Lambert .................. 2.28

Col. Pike, b g, by Ballard's C M. Clay ................ 2.29

Col. Russell (Hop), b g, by Lewis Napoleon............ 2.25

Columbia Chief (Stump Puller), blk s, by Mambrino Black

Hawk.

Columbus Hambletonian, b s, by Ajax..............

Comee, b g, by Daniel Lambert ........................

Commander, blk s, 5 yrs, by Blue Bull

$2.29 \frac{1}{2}$

2.26

$2.19 \frac{1}{2}$

Commodore, b g, by Young Post Boy ................ 2.23

Commodore Nutt, b g, by Grantham Chief . . . . . . . . . 2.29

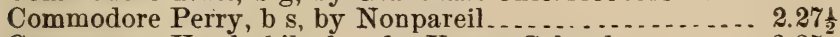

Commodore Vanderbilt, b s, by Young Columbus....... 2.25

Commonwealth (Dred), br s, by Phil Sheridan........ 2.22

Confidence, $\mathrm{ch}$ g, by Gillis' Gorse $\ldots . . . . . . . . . . . .2 .2 .26$

Confidence, gr h, by old Columbus ................ - 2.28

Convoy, gr g, by Woodford Mambrino .............. 2.22

Cooley, blk g, by Daniel Boone..................... 2.26

Coolo, b g

Coquette, ch m, by Jack Hawkins, Jr ............... . $2.28 \frac{1}{4}$

Cora, b m, by Charles Douglas ....... . . . . . . . . . . . . 2.291

Cora Belmont, gr m, by Belmont.................. 2.24

Cora $\mathrm{F}$., gr m, by Brown Harry ................... 2.28

Corbin's Bashaw, ch s, by Amboy................. - 2.263

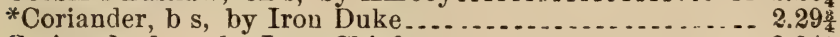

Corisande, b m, by Iowa Chief..................... 2.24t

Cornelia, blk m, by Col. Bonner.................... 2.21

Cottage Girl, ch m, by Mambrino Star................ 2.291

Cozette, blk m, by Blumberg's Black Bashaw .......... 2. 2.19

Crown Point, ch s, by Speculation .................... 2,24

Crown Prince, wh g, by Logan's Messenger............. 2.25

Croxie, b m, by Clark Chief ......................... $2.19 \frac{1}{4}$

*Cunard, b g, by Von Moltke....................... 2.30

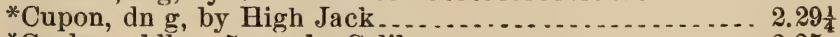

*Cyclone, blk s, 5 yrs, by Caliban..................... 2.25

* Cyclop. b s, by Caliban .............................. 2.27

Dacia, blk $\mathrm{m}$, by Woodford Mambrino.............. 2.291

Daciana, blk m, by Harold.................. . . . . . . . 2.27 $27 \frac{1}{2}$

Daisy Burns, b m, by Shenandoah

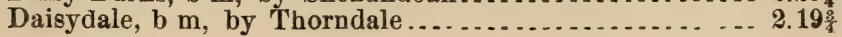


Daisy Hamiltan, b m, 5 yrs, by Blackstone........... 2.28

Dacota Maid, ch m ................................ $226 \frac{1}{4}$

Dame Trot, $\mathrm{b} \mathrm{m}$, by Messenger Duroc ............... 2.22

Damon, b s, by Palmer Bogus ..................... 2.238

Dan, ch g........................................ 2.281

Dan Bryant, ch g, by Plow Boy ................... 2.24

Dan Donaldson, ch $\mathrm{g}$...... . . . . . . . . . . . . . . . . . . 2. 2.243

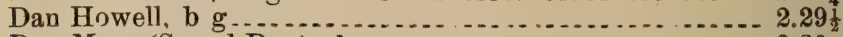

Dan Mace (Sorrel Dan), ch g ........................ 2.30

Dan Smith, b g, by Reporter ........................ 2.21

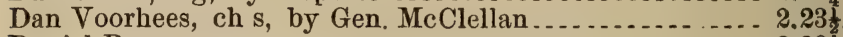

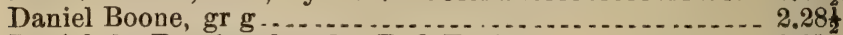

Daniel the Prophet, b g, by Red Eagle ............. 2.27

Darby, b g, by Delmonico.......................... 2.16

David C., b g . . . . . . . . . . .

David Wallace, ch s, by Mambrino Pilot.............. 2.28

*Day Dream, ch f, 4 yrs, by Cuyler ................. 2.213

Deceit, br g, by Jean Baptiste . . .................... 2. 2.30

Deceiver, br $\mathrm{g}$. . . . . . . . . . . . . .

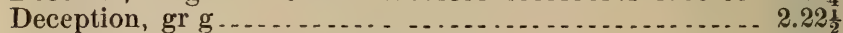

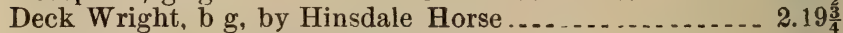

*Defender, blk s, by George Wilkes .... . . . . . . . . . . . . . 2.26

Defiance, br g, by Chieftain ........................ 2.24

Delaware, ch g, by Morgan Black Hawk............ 2.28

Delhi, b g .......................................... 2.291

Del Sur, b s, 5 yrs, by The Moor $\ldots . \ldots \ldots \ldots \ldots \ldots . . .24 \frac{1}{2}$

Denmark, br g. by County Boy ..................... 2.30

Derby (Dutchman). b g, by Rough and Ready ... ....... 2.251

Despatch (Windsor), rn g, by Lewiston Boy ....... . ... 2.24

*Deucalion, b s, by Rysdyk's Hambletonian........... 2. 2.22

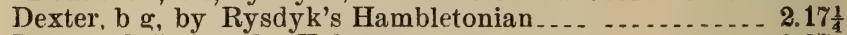

Dexter (Cal), b g, by Volunteer.................... . . 2.27

Diamond, blk s, by Wild Bashaw .................... 2.28

Dickard, ch g, by Daniel Lambert.................... 2.27

Dick Jamison, b g, by Miller's Joe Downing ............ 2.26

Dick Moore, ch g, by Belmont .... . . . . . . . . . . . . . . . . 2.221

Dick Organ, b g, by Commodore ..................... 2.258

Dick Swiveller, $\mathrm{b} g$, by Walkill Chief ................ 2.18

Dick Taylor, gr g, by Bob Didlake ................... 2.241

Dictator, b g, by Goldsmith's Abdallab................ 2.27

Dictator (Huckleberry, Brown Jack, and John T.) by

Comet, son of Vt. Black Hawk

Dinah, rn $\mathrm{m}$, by Young Flying Cloud ............... 2.30

Dio, b g, by Gen. Sherman......................... 2.30

*Director, blk s, 5 yrs, by Dictator ................... 2.17

Dirigo, br g, by Fox Hunter ...................... 2.27

Dixie, gr m, by Pilot, Jr........................... 2.30

*Dixie Sprague, b m, by Gov. Sprague.............. 2.25t 


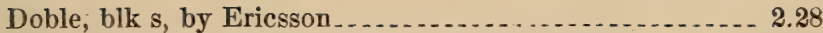

Doctor Lewis (Leander), ch g, by Marshall Chief ........ . 2.24

Doctor Norman, b g, by Col. Moore................. 2. $2.19 \frac{3}{4}$

Dolly, b m, ky Frauk .......................... 2.30

Do:ly D vis (Easter Maid), b m, by Almont........... . 2.29

Dom Pedro, b g by Blue Bull ..................... 2.27

*Don, gr g. by Peck's Idol . . . . . . . . . . . . . . . . . . . . . . 2.221

Donald, $\mathrm{b} \mathrm{g}$, by Dictator................................ 2. 28

Don Cossack, b s, 5 yrs, by August Belmont ........... 2.28

Don E'ipha......

*Dora (Gracie D), b m, by Corbeau ................. 2. 2.20

Dot, b g, by American Emperor.................... 2.293

Doty, b g, by Challenge............................. 2.21

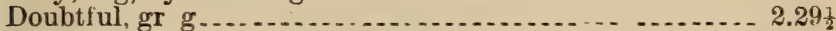

Douglass, gr g, by Thomas Scott................... 2.25

Draco, blk s, ly Young Morrill.................... 2.28

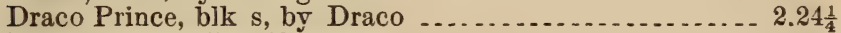

Dread, b g, by Jim Monroe.......................... 2.27

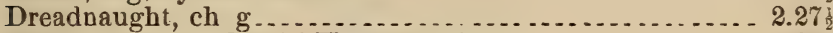

Dream, b m, by Curtis' Hambletonian................. 2.25

Drift (Norwood),br g, by Rysdyk's Hambletonian ........ 2.298

Driver, b g, by Volunteer............................ 2. 2.191

Drummer Boy, b g, by Joun W Conley ................ 2.29 .

Duck, blk m, by Seotı's Hiatoga ..................... 2.

Duke, b g, by Warner's Duke of York................. 2.26

*Duquesne, ch s, by Tippoo Bashaw .................. 2.17\%

Duroc, b s, by Banker's Messenger..................... 2.26

Duster, b g ........................................... 2.30

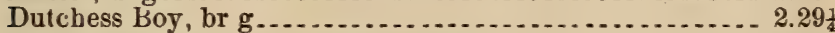

Dutch Girl, gr m, by Dusty Miller ................... 2.291

*Dutch Girl, rn m, by Abdallah Boy .................. 2.273

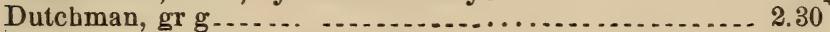

Eagle Plume, gr g, by Bayard.................... 2.29

*Earl, ch g. . . . . . . . .

Early Rose, ch m. by Almont...................... 2.201

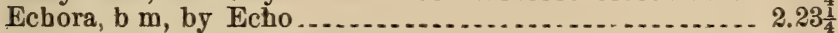

Ed Eaton, gr g, by White Ghost...................... 2.28

Edgar, ch g, by Col Winfield........................... 2.30

Ed Getchell, br g, by Winthrop Morrill .................. 2.27

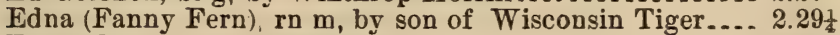

Edward, ch g, by Masterlode............................ 2.19

Ed White, b g, by Jim Scott........................... 2.27

Ed Wilder, ch g. by Blue Bull........................ 2.30

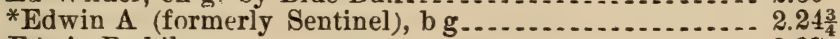

Edwin B., blk g ........................................ 2.27

Edwin Forrest, b g, by Brannock's Ned Forrest......... 2. 2.18

Edwin Thorne, ch $\mathrm{g}$, by Thornedale ................... 2.16

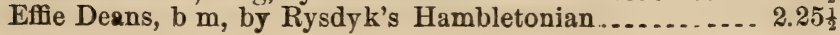


Elaine, b m, by Messenger Duroc .................. 2.20

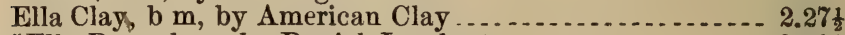

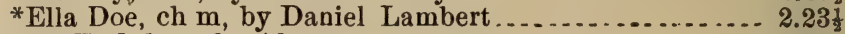

Ella Earl, b m, by Almont......................... 2.25

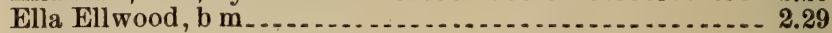

Ella Lewis, b m, by Vermont ...................... 2.27

Ella Madden, b m, by Rysd vk's Hambletonian .......... 2. 2.25

Ella Wilson, b m, by Blue Bull ..................... 2.30

Ella Wright, b m, by Trojan ...................... 2.248

Ellsworth, S. S. ch g, by Andy Johnson..... . . . . . 2.29

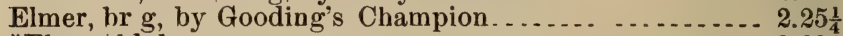

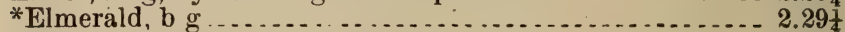

Elmo (St. Elmo), ch s, by Mohawk ................. 2.27

Elmore Everett, b g, by Andrew Jacksou . . . . . . . . . . . . 2.30

*Elmwood Chief, br g, by Black Ranger ............. 2.28

Elsie Good, ch m, by Blue Bull .................... 2.22t

Elsie Groff, b m .................................. 2.25

*Elvira, blk f, 3 yrs, by Cuyler................... 2.27

Elwood Medium, b s, by Happy Medium ............ 2. 2.243

Emma B, gr m, by Bayard..................... 2.22

Emma C., blk m, by Superb....................... 2.30

Emma E, br m (Lizzie Keller) .................... 2.29

Emperor, b g, b r Rollin's Horse ..................... 2.30

Emperor, bik s, by Newman Horse .................. 2.291

Emperor William, b s, by Gen. Knox................ $2.27 \frac{1}{2}$

Empress, b m ......................................... 2.30

Empress, ch m, by Whipple's Hambletonian............ 2.24

Enchantress, b m, by Happy Medium ................... 2.263

Enfield, b s, by Rysdyk's Hambletonian ............... 2.29

Enigma, b m, by Alcalde ........................... 2.26

*Ensign, b s, by Enchanter... . ................... 2.28

Envoy, br s, by Gen. Hatch ......................... 2.28

*Erehus, blk g, by Scott's Hiatoga ................. 2.28

Eric, b g, 4 yrs, by Ericsson ......................... 2.281

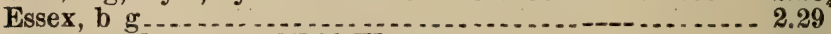

Essex Maid, b m, by Wild Wagoner................ 2.30

Ethan Allen, b s, by Vt Black Hawk .................. 2.25

Ethel, b m, by Blue Bull ............................ 2.23

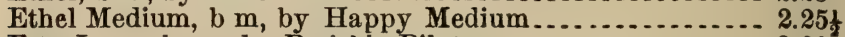

Etta Jones, br m, by Parish's Pilot..................... 2.20

Eureka, blk g, by Gen. Grant ....................... 2.23

Eva (Swallow), b m, by Gooding's Champion........... 2.251

*Eva, b f, 2 yrs, by Sultan ......................... 2.25

Eva, blk m, by Black Dutchman ................... 2.27

*Eva, gr m, by Princess............................. 2.291

Everett Ray, b g, by Edward Everett............ .2 .25$

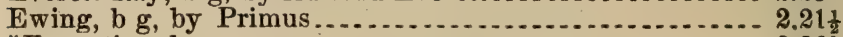

*Exception, b g..................................... 2.26 
Executor, b s, by Administrator . . . . . . . . . . . . . . 2.26

*Ezra L., b g, by Gideon ............................ 2.21

Factory Girl, b m, by Rysdyk's Hambletonian ......... . 2.291

Fairmount, ch g, by " ild Billy .................... 2.291

Falmouth Boy, ch g, b. Potter Horse .............. 2.291

Fancy, b m ....

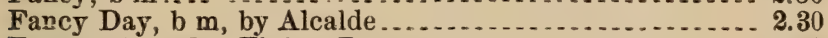

Fanny, ch m, by Flying Banner................... 2.29

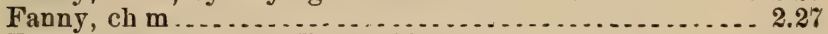

Fanny Allen, b m, by Ethan Allen ................. 2.28t

Fanny Jefferson, blk m, by Thomas Jefferson .......... 2.281

Fanny Lee, b m, by Ethan Allen .................... 2.291

Fanny Otis (Louise), b m, by Post Boy ................ 2.28

Fanny Raymond (Princess), b m, by American Ethan .... 2.30

Funny Robinson, b m, by Blood Chief .... ........... 2.20

Fanny Wilkes, br m, 5 yrs, by George Wilkes .......... 2.261

*Fanny IVitherspoon, ch m, by Almunt. ........... 2.17

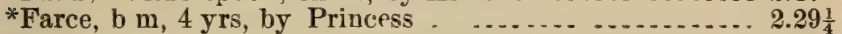

Farmer Boy, gr $g$, by Young Columbus ............. 2.28

Farmer Maid, b m ................................ 2.28

Fashion, b m, by Clark's Mohawk Jr................. 2.23

Faugh-a-Ballagh, b g .......................... 2.25

${ }^{*}$ Faustina, b $\mathrm{m}$, by Phil Sheridan ................... 2.28

Favorite, ch $\mathrm{m}$, by Senator ..................... 2.30

Fearless, b m, by Meeker Horse.................... 2.28

Fearnaught, br s, by Canada Black Hawk ... . . . . . . 2. 2.29

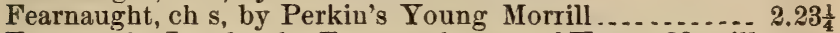

Fearnaught Jr., ch s, by Fearnaught, son of Young Morrill 2.26

*Felix, b g, by Nutwood ............................ 2. 2.251

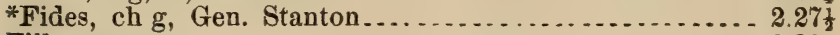

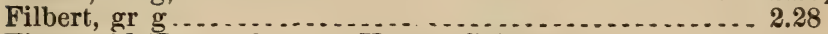

Fitzgerald (Dunn), b g, by Young Columbus ........... 2.30

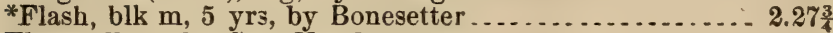

Fleta, blk m, by Gen. Hatch ....................... 2.28

Fleetwood, b s, by Happy Medium ................. 2.29

Fleetwood, ch $\mathrm{g}$, by Winthrop Morrill ............... 2.29

Fleety Golddust, gr m, by Golddust.............. 2.20

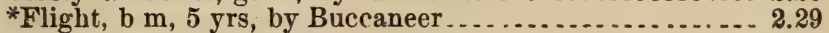

Flirt, $\mathrm{ch}$ m, by Gen. Knox......................... 2.281

*Flora B., b m ..... . ............................. 2.28

*Flora Belle, ch m, by Prince, son of Wm. Tell ........ 2.298

Flora Belle, b m, by Stevens' Uwharie.............. 2.22

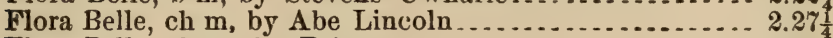

Flora Belle, ch $\mathrm{m}$, by Prince....................... 2.30

Flora F., b m, by Clear Grit ....................... 2.24t

${ }^{*}$ Flora Jefferson, b m, by Thos. Jefferson ............... 2.28

Flora Shepherd, ch m, by Gen. McClellan............. 2.30

Flora Temple, b m, by Bogus Hunter ................ 2.193 
Flora Windsor, b m, by Windsor................. 2.30

Florence, ch m, by Highland Gray ................... 2.231

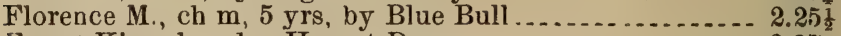

Forest King, b g. by Honest Dan ........................... 27

*Forest Patchen, br g, by King Patchen .............. 2.19

Fox, ch g, by Peacock ............................ 2.30

*Foxie V, ch m, by King Herod.................... 2.23르.

Frances, wh m, by H. W. Genet................. 2.27

Frank, b g, (Bemis) . . . . . . . . . . . . . .

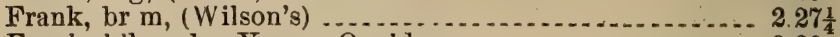

Frank, blk g, by Young Oneida................... 2.20

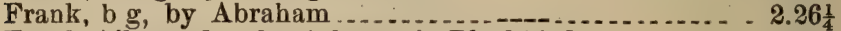

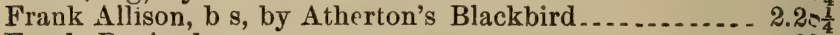

Frank Davis, b g................................... 2.29

Frauk F, by Emperor William ...................... 2.264

Frank Ferguson, b g, by Billy Glenn ............... 2.26

Frank Fisk, rn g, by Black Hawk Bertrand............ 2.29

Frank Forester, b $r$, by Abdallah .................... 2.30

Frank J., (Milton Day), dn g ....................... 2.233

Frank Kernan, b g ..................................... $226 \frac{1}{2}$

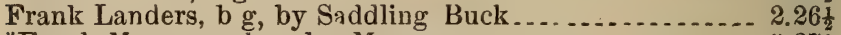

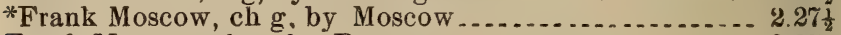

Frank Munson, ch g, by Paragon ................... 2.25

Frank Palmer, b g ................................... 2.26t

*Frank Patchin, ch g, by Seneca Patchin .............. 2.30

Frank Reeves, b g, by Skedaddle .................... 2.231

Frank Wood, b g, by Volunteer..................... 2.24

Fred, b g, (Roden's) ..................................... 2.30

Fred, b g, by Democrat............................. 2.30

Fred (Texa-), b g . . . . . . . . .

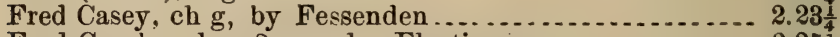

Fred Crocker, b c, 2 yrs, by Electioneer............ 2.251

Fred Douglas, ch s. by Green's Bashaw ................ 2.201

Fred Douglas, blk g, by Black Frank ................. 2.25

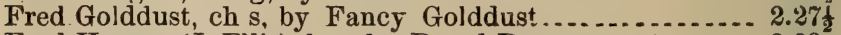

Fred Hooper (J. Ellis), b g, by Royal Revenge.......... . . 2.23

*Fred Neil, b g, by Bay Tom ......... . . . . . . . . . . . . 2. 2.29.

Freeman, blk s, by Macedonian..................... 2.29

Freestone, b g, by Capt. Webster................... 2.29

Fritz, b g, by Bay Richmond....................... 2.27\%

*Frustone, b g, by Republic ...................... 2.28

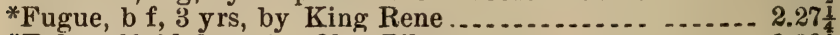

*Fulton Maid, b m, by Clay Pilot .................... 2.291

Galatea, b m, by Fearnaught ........................ 2.24

Gazalle, b m, by Rysdyk's Hambletonian................ 2.21

Gen. Beamish, gr g, by Royal George................. 2.261

Gen. Butler, blk g, by Smith Burr................... 2.21

Gen. Garfield, b g, by Ky. Black Hawk............. 2.21 
Gen. Grant, ch s, by Wapsie....................... 2.21

*Gen. Hancock, b g, by Lightning ................... 2.25

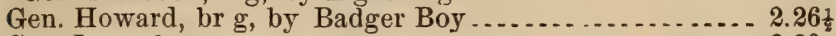

Gen. Lee, ch g....................................... 2.29

Gen. Love, ch s, by Field's Royal George............. 2.30

Gen. McClellan, b s, by Drew Horse................. 2. 2.29

Gen. McClellan, dn $\mathrm{g}$, by Montauk.................. 2.29

Gen. Picton, gr g, by Rattler...................... 2.30

Gen. Sherman, gr g, by Pilot, Jr................. 2.28

Gen. Tweed, ch g, by Myron Perry ................. 2.26.

George, $b$ g.................................... 2.24

George, blk g, by Mambrino Patchen................. 2.24

*George, br s, by George Wilkes..................... 2.30

*George A., b g, by Daniel Lambert................... . 2.25

George A. Ayer, gr $\mathrm{g}$. by Woodford Mambrino ......... 2.30

George B. Daniels, ch g, by King's Champion .......... . 2.24

George Gooley, b g, by Neave's C. M. Clay .............. . 2.27

*George D. Sherman, blk g, by Black Ralph.......... 2.29

George F. Smith, b g, by Niagara Chief . . . ............ 2.28

George $\mathrm{H}$, br g, by Gen. Benton ................. 2.263

George H.. b g, by Godfrey's Patchen ................ 2.25

George Henry, b g ............................... 2.27

George H. Mitchell, b g, by American Ethan......... 2.26

George Judd, rn g.............................. 2.26

George K., gr g, by Swigert...................... 2.25

George M., b g, by Westfield Boy .... .............. 2.24

George Miller, b g, by Boston Boy .................... 2. 30

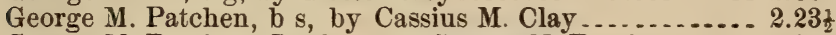

George M. Patchen, Jr, br s, by George M. Patchen..... 2.27

George Palmer, b g, by Palmer Bogus .................. 2.191

George Treat, br g, by McCracken's David Hill .......... 2.25

* George V., ch g, by Masterlode...................... 2.20

George Wilkes, br s, by Rysdyk's Hambletonian........ 2.22

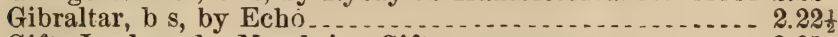

Gift, Jr., br s, by Mambrino Gift .................... 227

*Gilbird's Sprague, blk s, by Gov. Sprague........... 2.29t

Gilbreth Knox, blk s, by Gen. Knox .............. 2.263

* Gladiator, b g, by Blue Bull $\ldots \ldots \ldots \ldots \ldots \ldots .2 .22 \frac{1}{4}$

*Glamis, gr g, by Godfrey's Patchen................ 2.25

Glendale, b g, by Mambrino Wagner $\ldots . . . . . . . . .2 .20 \frac{1}{2}$

Glengarry (Uncle Abe), br g, by Winthrop Morrill ...... . 2.27

*Glen Miller, gr s, by White Line . . . . . . . . . . . . . . . . . 2.28 2.

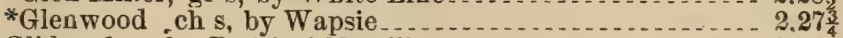

Glide, ch s, by Perkins' Morrill ..................... 2.24

Gloster, b g, by Volunteer........................ 2.17

Gloucester, b g, by Highland Boy $\ldots . . . . . . . . . . .2 .23 \frac{1}{4}$

*Golden Bow, ch s, by Satelite ..................... 2.27

Golden Girl, gr m, by King's Champion ............... 2.25 
*Golden Girl, b m, by Golden Bow ................ 2.28 28

Goldfinder, ch s, by John Lambert . . . . . . . . . . . . . . 2.23 2.

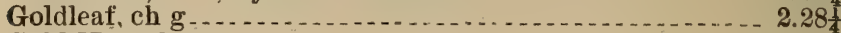

Gold Note, b g . . . . . .

Goldsmith Maid, b m, by Alexander's Abdallah.. . . . . 2.14

Good Morning, b m, by Harold . . . . . . . . . . . . 2. $28 \frac{1}{2}$

Governor, gr s........

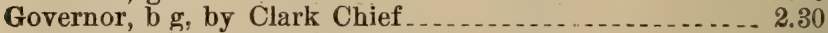

Gov. Plaisted, b g, by Gray Dan ................... 2... 291

Gov. Sprague, blk s, 5 yrs, by Rhode Island (?) ... . . . . $2.20 \frac{1}{2}$

Gov. Stanford, ch g, by John Nelson .............. 2.27

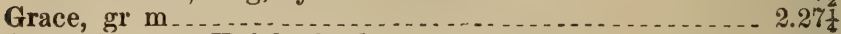

Grace, b m, by Knickerbocker

Grace Bertram, ch m, by New Jersey .............. 2.29

Grafton, ch g, by Van Meter's Waxy .................. 2. 2221

Grand Duchess (Mary Ann), b m, by Hanley's Hiatoga... 2.26

*Grand Sentinel, b s, by Sentinel .................. 2.27t

Granville, ch g, by American Clay ................ 2.26

Grateful, ch g, by the Brown Horse

Graves, ch g, by Whipple's Hambletonian . ........... 2.20

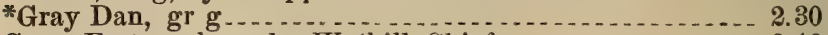

Great Eastern, br g, by Walkill Chief.............. 2.18

Great Western, blk g, by Superb .................... 2.29

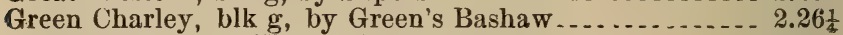

Grey Bill, gr g, by Young Brandywine............. 2.30

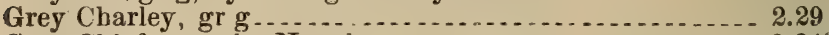

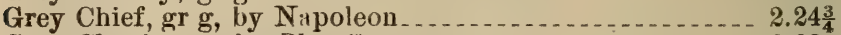

Grey Cloud, gr s, by Blue Grass . . . . . . . . . . . . . . . 2. 2.23

Grey Eddy, gr g, by Morse Horse $\ldots \ldots \ldots \ldots . . .2 .30$

Grey Eddy, gr g, by Blue Colt $\ldots \ldots \ldots \ldots \ldots \ldots \ldots \ldots . . .27$

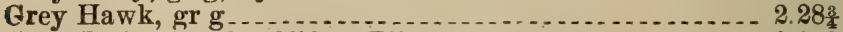

Grey Jack, gr g, by Clifton Pilot,

Grey Mack (Mack), gr g, by Black Hawk Hero _........ 2.25

Grey Salem, gr g ............................. 2.24

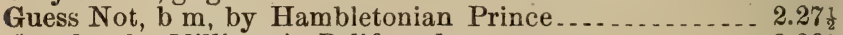

Gus, b s, by Milliman's Bellfounder................ 2.26星

Gypsy, b m, by Winthrop Morrill .................. 2.24

Gypsy Boy, blk s, by Stonewall Jackson ................ 2.28

Hall Terrill (S. V. Switz), b g …................. 2.28

Hambletonian Bashaw, b s, by Green's Bashaw ......... 2.21

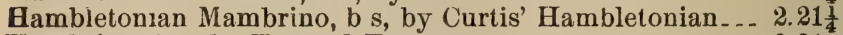

Hambrino, b s, by Edward Everett.................... 2.21

Hambrino Belle, b m, 5 yrs, by Hambrino .............. 2.2 $2 \tilde{j}_{\frac{1}{2}}$

Hamperion, b s, by Rysdyk's Hambletonian ........... 2.29

Hancock, b g, by Whipple's Hambletonian............. 2.29

*Handi zap, rn g, by Stephen A Douglas .............. 2... 22

Hannah D, br m, by Magna Charter................ 2.22 $\frac{1}{4}$

Hannis, ch $\mathrm{s}$, by Mambrino Pilot.................... 2.17혼... 


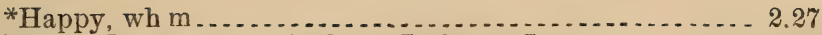

Happy Jack, b g, by Andrew Jackson, Jr............. 2.30

*Happy Thought. b s, by Happy Medium ................ 2. 22. $21 \frac{1}{2}$

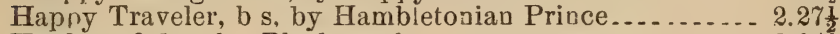

Hardwo d, b s, by Blackwood...................... 2.24

Harry, b g, by Happy Medium ...................... 2.20

Harry Clay, blk s, by Neaves' Cassius M Clay .......... 2. 2.29

Harry Clay, blk g, by Strader's Cassius M. Clay ......... 2238

Harry Conklin, b g, by Superb ................... 2.2. 26

Harry Gilbert, ch $\mathrm{g}$, by Jupiter ..................... 2.24

Harry Harl'y, b g, by Young Columbus............... 2.258

*H irry Mills, br g, by Sweepstakes... ................ 2.271

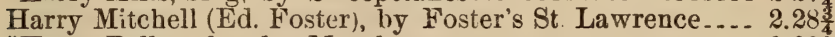

*Harry Pallon, b s, by Menelaus..................... 2.291

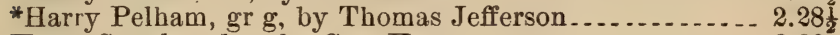

Harry Spanker, b g, by Gen. Knox.................. 2.30

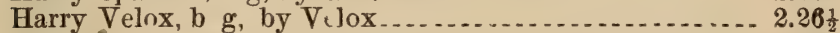

Harry W. Genet (Danvers Boy), b s. by Godfrey's Patchen 2.26

Harvest Queen, b m, by Rysdyk's Hambletonian . . . . . . . 2.29 2.

Hattie, ch $\mathrm{m}$..................................... 2. 2.30

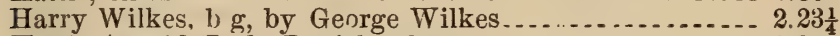

Hattie Arnold (Lady Daniels), b m .................... 2.2 $\mathrm{i}$

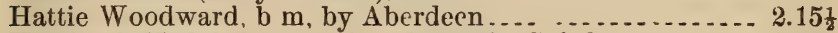

Haviland (Ned Cole), b g, by Mountain Chief .......... 2.291

Hazor (Atwood) gr g, by Young America.............. 2.26 .

H. B. Winship, bik g, by Áristos .................... 2.20 .

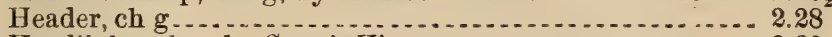

Headlight, ch g, by Scott's Hiatoga................. 230

Hector, $\mathrm{b} g$, by Otego Chief ......................... 223

Heleve, ch m, by Hambletonian Prince................ 222

*Henderson, ch g, by Strathmore..................... 2.271

Henry (Whitcomb) b $\mathrm{g}$............................. 2.2!1

Henry, b $g$, by Harry Lathrop ........................ 2. 20

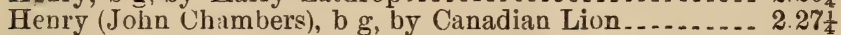

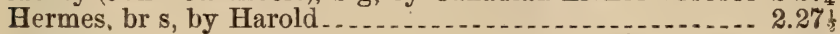

Herod, blk s, by King Herod..............

*Hersey, br s, by Macedonia

*Hetty Pearl, br m, by Princeps.................... 227

Hickok, O. A., b y

Hickory, b s, by Goldsmith's Abdallah ............... 2.278

Highlaud Grey, gr s, by Darkey ..................... 2.28

Highland Maid, b m, bo Saltram $\ldots \ldots \ldots \ldots \ldots \ldots$

Highland Mary, br m, by Pocahontas B y............. 2.26

Highland Stranger, b s, by Mambrino Patchen......... 2.251

Hili, H. C, b g

*Hinda Rose, b f, 3 yrs, by Electioneer

Hiram Woodruff, br g, by Phi] Sheridan.............. 2.25

Hogarth, blk s, 5 yrs, by Messenger Duroc............ 2.26 
Honest Billy, b g, by Green Mountain Morgan ... . . . . . . 2.291 Honest Dutchman, ch s, by Hoagland's Grey Messenger _ 2.26 Honest Harry, rn g, by Winthrop Morrili............ 2.22i Honesty, ch s, 4 yrs, by Priam ..................... 2.25 Hope, ch g, by T'elegraph......... . . . . . . . . . 2.28

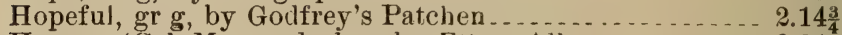
Hot:pur (Col. Maynard), b g, by Ethan Allen ........ . 2.24

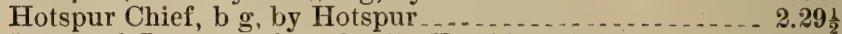

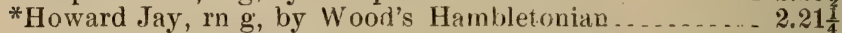
Hudson, b g. by Tippo ........... Hugh MicLaughlin, b s, by Aberdeen................ 2.23 Humboldt, $\mathrm{b} g$, by Stocking Chief .................. 2.20 Hunter (Wild Irishman), ch g, by Black Dutchman ..... 2.29

Huntress, b m, by Volunteer....................... 2.203 *Huntress, ch m, 5 yrs, by Admiral ................ 2.28

Hylas, ch s, by Alcalde ......................... 2.24

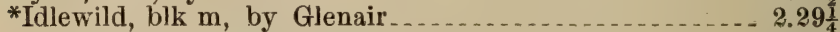

Idol, ch $\mathrm{m}$, by Black Warrior .................... 2.27

Idol (Myrtle 'T'hompson), b m, by stephen A Douglass... 2.23

Ina $\mathrm{G}, \mathrm{b} \mathrm{m}$, Blue Bull ........................ 2.24

Inca, br s. by Woodford Mambrino .............. 2.27

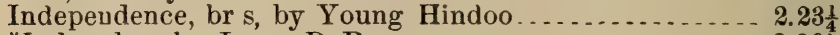

*Index, b g, by James R Reese .................. 2.26 .

Indianapolis, br s, by Tattler $\ldots \ldots \ldots \ldots \ldots \ldots \ldots \ldots . .2 .21$

India Rubber, blk g, by Rocket . . . . . . . . . . . . . . . 2.29⿺

Indicator, ch s, by Golddust $\ldots \ldots \ldots \ldots . .27$

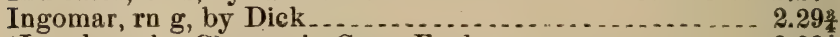

*Ino, b m, by Chenery's Gray Eıgle .............. . 2.221

Irene, gr m, by Dusty Miller................... 2.20 .

Iron Age, rn g, by Jules Jurgensen . . . . . . . . . . . . . . 2.23 2.

Iron King, b g, by Key's Abdallah ...............................

*Isuac, b g, by George Wilkes..................... 2.29

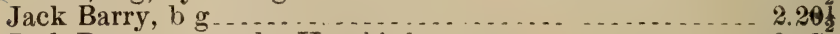

Jack Draper, gr g, by Humbird ................... 2.27

Jack Lewis, b g, by Clifton tilot ................. 2.28

Jack Sailor, b g, by Sweepstakes ...................... 2.251

Jackson (Corrigan Jackson), b s, by Fine Cut . . . . . . . . 2.278 28.8

Jacksonville Boy, b $\mathrm{g} \ldots . . . . . . . . . . .26$

*James Halfpenny, b $\mathrm{g}$, by Blue Bull ............. 2.30

James H. Burke (Gov. Morgan), blk g, by Tippoo Horse . - $227 \frac{1}{2}$ James Howell, Jr., br g, by Rysdyk's Hambletonian .... . 2.24 James D. McMann (Shoo-Fly), b g. by Geo M. Patchen Jr 2.28 Janesville, b g, by Robert Fulton ................... 2.291 *Jaybird, b m, by Kent, son of Skepton ............. 2.30

* Jay Eye See, blk g, 4 yrs, by Dictator ............. 2.10 . Jay Gould, b s, by Rysdyk's Hambletonian ............ 2.2. $21 \frac{1}{2}$ Jenny, b m, by Red Eagle............................ 2.22 *Jenny, b m, by Dandy, son of L. I. Black Hawk ....... 2.291 
Jenny Hoiton, b m, by Billy Bacchus ............... 2.221

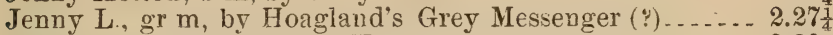

Jenny W. b m, by Brown Harry ..................... 230

Jericho (Everett), b g . . . . . . . . . . . . . . . . . . . 2.30

Jerome, ch g, by Keokuk ........................ 2.27

Jerome (Legal), b g, by Rysdyk's Hambletonian . . . . . . . . 2.27

Jerome, b g, by Hamil' on ....................... 2...... $25 \frac{3}{4}$

Jerome Eddy, b s, by Louis Napolean .... . . . . . . . . . . . . 2.16

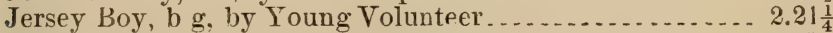

Jessie Dixon, b m, by Mambrino Patchen .......... . . . 2.27

Jessie Hayes, b m, by Ned Forrest .................. 2. 2.24

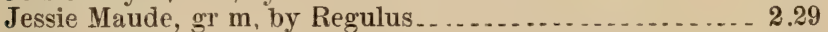

Jessie Wales, blk m, by Smith's Ajax .............. 2.30

Jewell, b g, by Buckingham ..................... 2...28

Jewess, The, b m, by Mambrino Patchen.............. 2.26

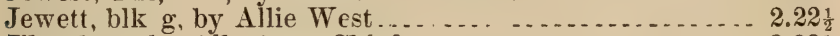

Jilt, ch $\mathrm{m}$, by Allegheny Chief ..................... 2.28

Jim, rn $\mathrm{g}$, by I Janiel Lambert ..................... $2.23 \frac{1}{2}$

Jim Bowman, $b \mathrm{~g}, 4$ yrs, by Mambrino Patchen .... ..... 2.29 $2.2 \frac{1}{2}$

Jim Crandall, ch g ............................... 2.30

Jim Irving, b g, by Wilson's Snowstorm.............. 2.23

Jim Raven, blk g, by Star of the West.............. 2.30

Jimmy Stewart, b g. by Daniel Lambert..... . . . . . . . . . . 2.241

Jim Ward, b g, by Young Columbus................ 2.28

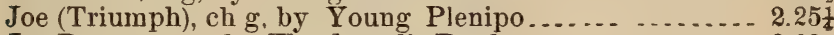

Joe Brown, gr s, by Woodward's Rattler.............. 2.22

*Joe Bunker, gr g, by Gen. Wilkes ... . . . . . . . . . . . . . . . 2.1914

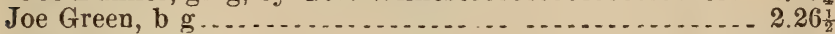

Joe Hooker, ch g, by Andy Johnson ................ 2.30

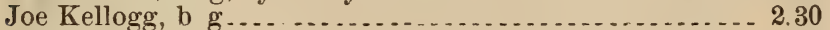

Joe Pettit, b g, by Ashland...................... 2.30

Joe Rhea, b g.... . . . . . . . . . . . . . . . . . . . . . . 2.23

Joe Ripley, b g, by Sawin's Hambletonian............ 2.25

Joe S., b g. by Daniel Lambert................ . . . . . . 2. 2.30

Joe Udell, b g . . ......... . . . ....................... 2.30

*Joe Young, blk s, by Star of the West.............. 2.291

John B., b g ...................................... 2.27

John S Clark, by Thomas Jefferson ................... 2. 2.198

John W Conley (Beppo), b g, by Tom Wonder......... 224

John J Cook, gr g, by Star of the West.............. 2.291

John E., rn g, by Clark's Chief....................... 2.28

John Fero (Western Boy), b g ...................... 2.27 $27 \frac{1}{2}$

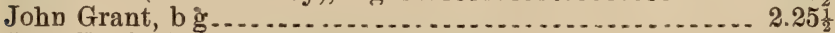

John H., by Blumburg's Black Bashaw . . . . . . . . . . . . . 2.20

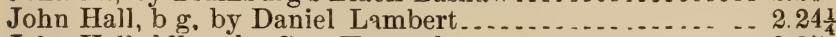

John Hall, blk g, by Gen Howard ....................... . . 2.25

John W. Hall, ch $g$, by Independence............... 2.25

John S. Heald, br g, by Whalebone Knox .............. 2.271 
*John Love, b g, by Billy Denton ..................... 2.2.28

John McDougall, b g, by Bay Billy ................... 2.29

John Morgan (Medoc), ch g, by Pilot Jr................. 2.24

John R., br g, by Peck's Idol ......................... 2.23

John Stewart, b g, by Tom Wonder . . . . . . . . . . . 2.30

John Taylor, b g ................................... 2.25

John Virgin, ch g. by Dirigo ........................ 2. 2.29

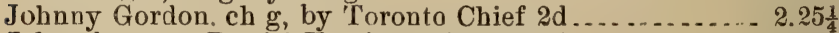

Joker br g, by Parris' Hambletonian .................... 2.221

Joseph, b g . . . . . . . . . . . . . . . . . . . . . . . . . . . . . . 2.291

Joseph A., b g, by Sackett's Hambletonian .............. 2.24

Josephine, b m, by Green's Bash $\bullet$ w . . . . . . . . . . . . . . . . 2.30

Josephine S., blk m. by Guy Miller Jr ... . . . . . . . . . . . 2.291

Josephus, ch g, by Green's Bashaw .................. 2.198

Josh Billings, ch g, by Mott's Independence........... 2.293

Jubilee Lambert, b s, by Daniel Lambert............... 2. 2.25

*Judge Davis, b g, by Joe Brown ..................... 2.22

Judge Fullerton, ch g, by Edward Everett ............ 2. 2.18

Judge Hawes, b $\mathrm{g}$, by Jim Monroe .... . . . . . . . . . . . . . . 2.24

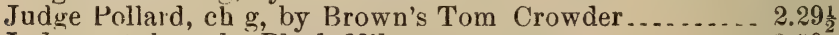

Judgment, br $\mathrm{g}$ by Black Milo ...................... 2.2.29

Kansas Chief, b g, by Young Josephus............... 2.211

Kate Bennett, rn m, by Blue Bull .... ................ 2.29

Kate Campbeil, br m, by Scott's Hiatoga............. - $225 \frac{1}{2}$

Kate Hall, b m, by Blue Bull ...................... 2. 2.24

Katie Jackson, b m, 4 yrs, by Almont............... 2.25

Kate McCall, gr m, by Blue Bull ..................... 2.2. 23

Katie Mi d dleton. ch m, by Mambrino Patchen ........... 2.23

Kate Sprague. b m, by Gov. Sprague .... . . ........ 2.18

Kate Taylor, b m, by Aberdeen . . . . . . . . . . . . . . . . 2. 2.238

Keene, Jim, rn g, by Lookout...... ................ 2.19

Keney, ch $\mathrm{g}$.................................. 2.291

Keno, b g, by Magic ................

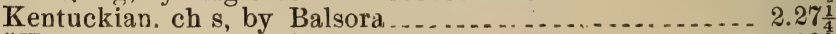

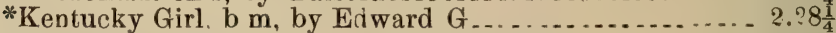

*Kentucky Wilkes, blk s, by George Wilkes .... ....... 2.20

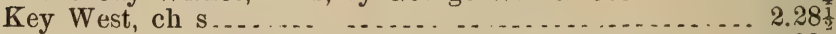

Ki Ki (G. W. Patterson), b g by Henry B Patchen..... 2.28

Kilburn Jim, b s, by Wood's Hambletonian............. 2.23

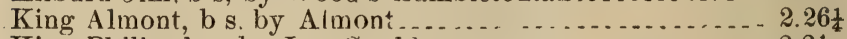

King Philip, b s, by Jay Gould .................... 2.21

*King Wilises, br s, by George Wilkes ............... 2..23

King William, blk g $5 \mathrm{yrs}$, by Washington Denmark ... 2.208

Kinsman Boy, blk s. by Case's Dave Hill ........ .... 2.28 $28 \frac{1}{2}$

Kirkwood, br s, by Green's Bashaw ................ 2.24

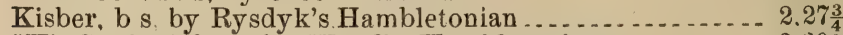

*Kit Sanford, b m, by Wood's Hambletonian ........... 2.291

Kitty, b m, by Andrew Jackson . ................. 2.30 
Kitty Bates, gr m, by Jim Monroe.................. 2.19

*Kitty Burch, ch m, by Geo. B. McClellau ............ 2.28

Kitty Cook, b m, by Abraham ....................... 2.26

Kitty Clyde, br m, by Kirkwond..................... 2.291

Kitty D., br m, by Tuckahoe Horse .................... 2.264

Kitty Ives, gr m, by Bacon's Ethan Allen .............. 2.281

Kitty Fisher, b m, by Glenn's Hambletonian ........... . 2.291

Kitty Morris, b m, by Lon Morris .................... 2. 2.30

*Kitty Patchen, ch m, by Jeb Stewart............... 2.221

Kitty Silver, ch m, by Mambrino Patchen............. 2.278

*Kitty Van, b m, by Walker's Morrell ................. . 2.24

Knox Boy, br s, by Gen. Knox ....................... 2.231

Lady Alice, b m . . . . . . . . . . . . . . . .

Lady Augusta, b m, by Rysdyk's Hambletonian ......... 2.30

Lady Banker, b m, by Rysdyk's Hambletonian.... .... 2.23

Lady Blanchard, gr m, by Whipple's Hambletonian ..... 2.261

Lady Blanche, b m ........ . . . . . . . . . . . . . . . 2.28

Lady Blessington, $\mathrm{b} \mathrm{m}$, by Middletown ................ 2.27

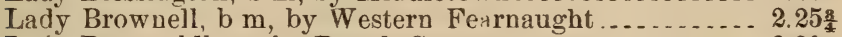

La 1 y Byron, blk m, by Royal George............... 2.28

Lady Clark, rn m, by Clark's Mohawk Jr .............. 2.27

Lady Crossin, b m, by Sussex Chief_... . . . . . . . . . 2. 2.28

Lady Daggett, gr m. by Logue Horse... . . . . . . . . . . . . 2.26

Lady Dahlman, b m, by Robert Bonner ............. 2.28

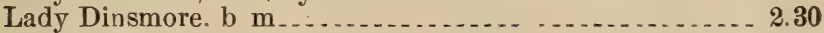

*Lady Elgin, b m, by Legal Tender Jr... . . . . . . . . . . . 2.268

Lady Ellen, b m, by Carr's Mambrino . . . . . . . . . . . . . 2.28

Lady Emma, ch m, by Jupiter...................... 2.261

Lady Emma, b m, by Champion (Poscora) ............. . . 2.28

Lady Faustina, b m. by Vermont..................... 2.291

Lady Fox, ch m, by Drury's Ethan Allen ............. . 2.30

Lady Foxie, ch m, by Daniel Lambert............... 2.24

Lady Garfield, b m . . . . . . .

Ladiy Griswold, gr m . . . . . . . . .

Lady Groesbeck, gr m, by Star of the West............ 2.25

Lady H., gr m, by Manchester's Tuckahoe.............. 2.27

Lady Hamilton, gr m, by Royal George ............. 230

Lady Hughes, b m, by Jupiter................... 2.30

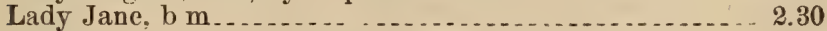

Lady K., b m, by Gen. Geo. H. Thomas.............. 2. $29 \frac{1}{2}$

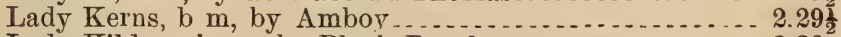

Lady Kildeer, br m, by Black Dutchman . . . . . . . . . . . 2.28

*Lady Leah, gr m . . . . .

Lady Lemmon, b m, by Knickerbocker .................. 2.30

Lady Lockwood, b m, by Neaves' C. M. Clay ........... 2.25

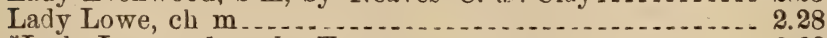

*Lady Lucas, ch m, by Tramp ..................... 2.291

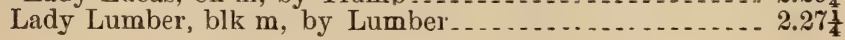


Lady M., gr m, by Vermont Hero .................. 2. 2.30

Lady Mac, b m, by Whirlwind .................... 2..23

Lady MicFatridge, $\mathrm{b}$ m, by Woodford Mambrino . . . . . . . 2.29

Lady Mack, b m . . . . . . . . . . .

*Lady Martin, b m, by Downing's Abdallah... . . . . . . . 2.23

Lady Maud, br m, by Gen. Knox.................. 2.18

Lady Mills, b $\mathrm{m}$, by Chosroes.......................... $2.24 \frac{3}{4}$

Lady Monroe, gr m, by Jim Monroe . . . . . . . . . . . . . . . . 2.26

Lady Moore, $b \mathrm{~m}$, by Peacemaker.................. 2. 2.25

Lady Morrison, b m, by Volunteer.................. 2.27 $27 \frac{1}{2}$

Lady Moscow, b m .

Lady Prewitt, b m, by Clark Chief .................. 2.30

Lady Pritchard, ch m, by Green Mountain Banner ....... 2.21

Lady Rolfe, b m; 5 yrs, by Tom Rolfe .............. 2. 2.22⿺

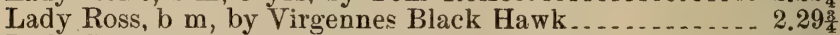

Lady Sampson, b $\mathrm{m}$, by Dolphus .................. . 2.28

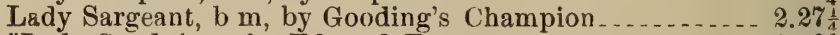

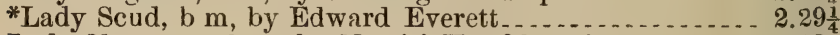

Lady Shannon, ch $\mathrm{m}$, by Harris' Hambletonian ......... . 2.28

Lady Steridan, b m . . . . . . . . . . . . . . . . . . . . . . . . . . 2.28

Lady Sherman, br m, by Gen. Sherman ............ 2.251

Lady Snell, b m, by Godfrey's Patchen ................ 2.231

Lady Star (Capitola), b m, by Sir Henry ................ . 2.24

Lady Stout, ch m, 3 yrs, by Mambrino Patchen $\ldots . . . . . .22 .29$

Lady Suffolk, gr m, by Engineer 2d ................ 2.26 2.

Lady Sutton, b m, by Morgan Eagle ................... 2.30

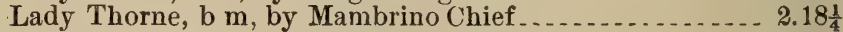

Lady Thornton, b m, by Mapes' Hamiltonian ........... . . 2.26

Lady Thorne, b $\mathrm{m}$, by Darlbay .................... 2.25

Lady Tighe, blk m, by Felter's Hamiltonian.......... 229

Lady Turpin, blk $\mathrm{m}$, by Bell Morgan .................. 2.23

Lady Vernon, gr m.............................. 2.291

Lady Voorhees, $b \mathrm{~m}$................................... $2.23 \frac{1}{2}$

Lady Williams, ch m, by Parson's Horse .............. 2.28

Lady Woodruff, b m, by Burr's Washington ............ 2.29

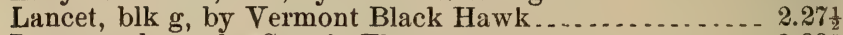

Largesse, br m, by Seott's Thomas.................. 228

*Laura M., b m, by Washington, son of G. M. Patchen... 2.27

Lacra Williams, gr m, by Holabird's Ethan Allen ....... 2.241

Leda, $\mathrm{b} \mathrm{m}$, by Aberdeen .......................... 2. $255_{\frac{1}{2}}$

*Lee W. (Sorgum), b g ............................

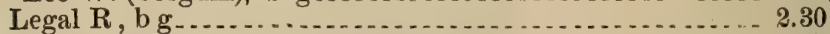

Legal Tender, $\mathrm{b} g$, by Legal Tender ................ 2.271

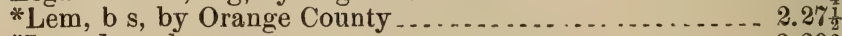

*Leon Boy, b g . . . . . . . . . . . . . . . . . . . . . . . . . . 298

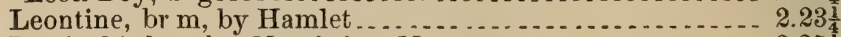

Lewinski, b g, by Mambrino Messenger............... 2.251

Lew Ives, b g, by Bacon's Ethan Allen ................ 2.28 
Lew Pettee, b g, by Benson Horse .... . . . . . . . . . . . . . 2.29

Lew Sayres, rn $\mathrm{g}$, by Neaves' Cassius M. Clay Jr . . . . . . 2.28 $2.2 \frac{3}{4}$

Lew Scott, b g, by Scott's Hiatoga.................. 2. 2.23

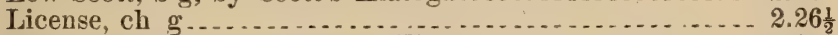

Lida Bassett, b m, by Forrest King ... . . . . . . . . . . 2.201

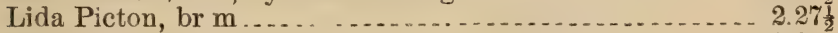

Lillian, ch $\mathrm{m}$, by Almont. . . . . . 2.23

Lilly, ch m

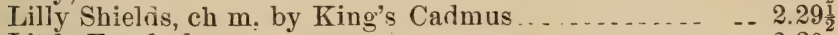

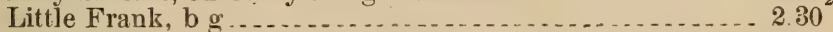

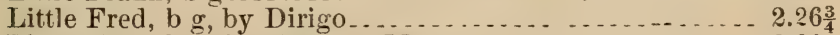

Little Fred, b g, by Eastman Morgan .... . . . . . . . . . . . 2. 2.20

Little $\mathrm{Gem}$, ch $\mathrm{g}$, by Henry B. Patchen ................ 2. 291

Little Gypsy, b m, by Shawan's Tom Hal .......... 2.22

Litile Jake (Erastus), rn $\mathrm{g}$. . . . . . . . . . . . . . . . . . . . 2.30

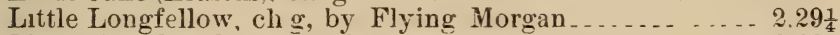

Little Mac, b s, by columbus .................... $2.28 \frac{1}{8}$

Litte Mary, ch m, by Billy Mustapha ............... 2. 2.24

*Little Miss, b m, by Goldsmith's Abdallah ............. 2.26 2.

Little Sam, ch g, by Marshall Chief . . . . . . . . . . . . . . . 2.29

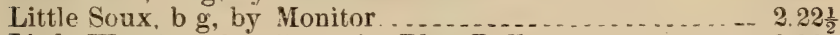

Little Wonder, ch s 5 yrs, by Blue Bull ................. 2.30

Litlle Wonder, b s, by Tom Wonder................ 2. 2.30

*Lizzie. rn m .........

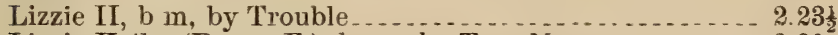

Lizzie Keller (Emma E.), br m, by Tom Moore ..... . . . . 2.30

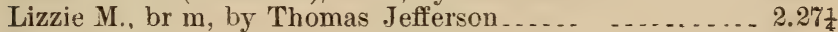

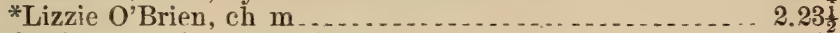

Loafer, rn g, by Copperbottom ................... 2.241

Logan, ch s, by Wadleigh's Logan $\ldots \ldots \ldots \ldots . . .28$

Lola, rn m . . . . . . . . . . . .

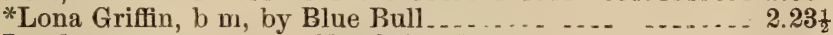

London, cb g, 5 yrs, by Mambrino Patchen ............ 2.28

*Longfellow W hip, blk s .... . . . . . . . . . . . . . . . . 2.231

Lothair, blk s, by Gilbert Knox .................... 2.291

Loitery, gr g, by Rysdyk's Hambletonian ........... 2. 2.27

Lot1ie, b m, by Rysdyk's Hambletonian ............... 2.28

Lottie K, b m, by American Emperor Jr . . . . . . . . . . 2.27

Louis D, b g, by King William .................... 2.248

Louise, b m, by Volunteer . . . . . . . . . . . . . . . . . . . 2. 29.

*Louise N., b m, by Alpine.......................... 2.201

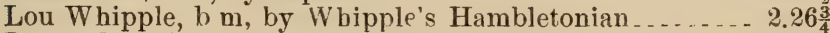

Lucca, $\mathrm{b} \mathrm{m}$, by DeLong's Ethan Allen ................ 2.30

*Lucilla, b f, 3 yrs, by Nephew . . . . . . . . . . . . . . . . . . . 2. 2.281

Lucille, b m, by Exchequer......................... 2.

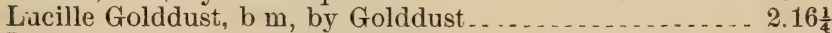

Lucrece, b m, by Robert Whaley . . . . . . . . . . . . . . 2.23i

Lucy, b m, by George M. Patchen ................ 2.18 


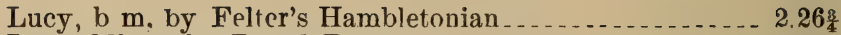

Lucy, blik m, by Royal Revenge .................. 2.201

Lucy C., ch $\mathrm{m}$, by Hotspur....................... 2.30

Lucy Fleming, ch $\mathrm{m}$, by Peavine.................... 2.24

Lula, b m, by Alexander's Norman . . . . . . . .

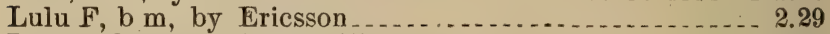

Lumps, br s, by George Wilkes.................... 2.21

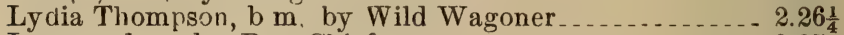

Lyman, dn g, by Bay Chief....................... $225 \frac{1}{2}$

Lysander Boy, ch g, by Lysander ......

Mack, br g, by Morgan Cæsar...................... 2.28

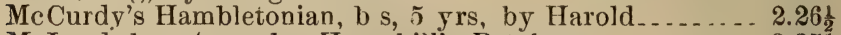

McLeod, b g. 4 yrs, by Hemphill's Patchen ........ ... 2.25

Madawaska Maid, ch m .......................... 2.29.

*Madeline, b m, by Rysdyk's Hambletonian ............ 2.23i

Magdallah, ch m, by Primus ....... . . . . . . . . . . . . . 2.24

Magenta. b $\mathrm{m}$, by Woodiord Mambrino .............. 2.241

Maggie Briggs, b m, by American Clay ............. 2.27

Maggie C, b m, by Whipple's Hambletonian ...... . . . 2.25

Maggie F., b m, 5 yrs, by Menelaus ................ 2. 2.27

*Maggie $\mathrm{H}$, gr m

Maggie M. blk m. by Patrick Henry

* Maggie Morrell, ch m, by Charley B............. 2.291

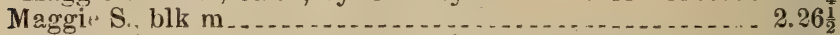

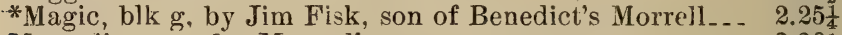

Magoolia, gr $\mathrm{g}$, by Magzolia ....................... 2.26

Maid of llonte, $\mathrm{b}$ m, by Benedict's Comet .............. 2.28

* Majolica, b g, by Startler .......................... 2.17

Major Allen (Locust), ch g, by Frank Allen ........... 2.214

$M$ ajor Edsall, b s, by Alexander's Abdallah . . . . . . . . . 2.2.29

Major King, ch g, by Careless ...................... 2.30

Major Lord, dn g, by Edward Everett................. $223 \frac{8}{4}$

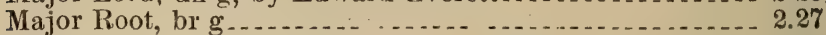

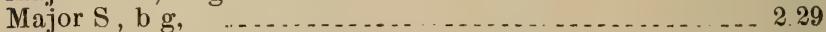

Mallory, W. M., gr g, by Orange County ........... 230

*Malvina, b m, by Fearnaught Spy .. .............. 2.24t

Mambrino Boy, blk s, by Mambrino Patchen .......... 2.261

Mambrino Diamond, blk s, by Mambrino Palcheu ....... 2.30

Mambrino Dudley, b s, by Woodford Mambrino ........ 2,22

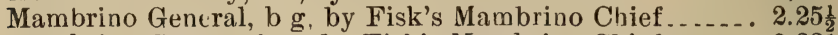

Mambrino George, br s, by Fisk's Mambrino Chief ........ $223 \frac{1}{2}$

* Mambrino George, b s, by Fisk's Mambriuo Chief ..... 2.30

Mambrino Gift, ch s, by Manıbrino Pilot ............. 2.20

Mambrino Kate, gr m, by Mambrino Patchen ............ 224

* Mambrino Southam, blk s, by Mambrino Gift.......... 2.26

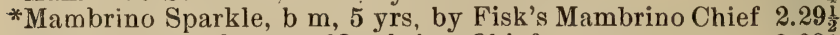

Mambrino Star, b s, by Mambrino Chief . . . . . . . . . . . . 2.28

Mamie, b m, 5 yrs, by Blue Bull .................... 2.21 . . . 
*Mamie M., b m, 5 yrs, by Crittenden . . . . . . . . . . . 2. 2.25

*Manon, b m, 5 yrs, by Nutwood .................... 2.221

Marguerite, b m, by Rysdyk's Hambletonian .......... 2.29

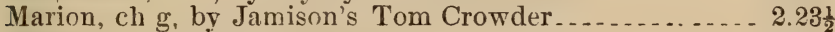

*Marion, ch g, by Harold (?) . . . . . . . . . . . . . . . . 2.29

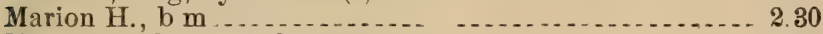

Mars, ch s, by Gen. Sherman .................... 2.21

Martha. b m, by Prospect.................... . . 2.30

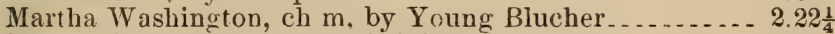

Marvel, b g, by Messenger Chief .................. 2.28

Mary, b m, by Geo. M. Patchen .. ................. 2. 2.28

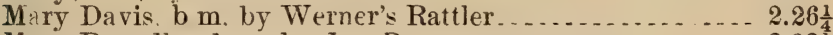

Mary Russell, wh m, by Joe Brown ................. 2.231

Mary A. Whitney, b m, by Volunteer.............. 2.28

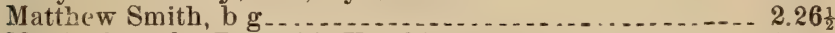

Mattie, b m, by Rysdyk's Hambletonian.............. 2.22

Mattie Graham, b m, by Harold.................... 2.21

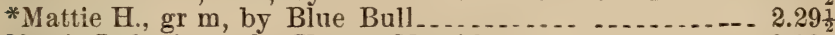

Mattie Lyle, br m, by Young Morrill ................. 2.28

Matt Kirkwood, b g, by Sam Kirkwood .............. 2. 2.30

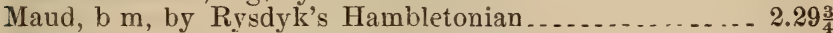

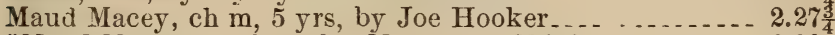

*Maud Messenger, b m, by Messenger Chief ...... . . . . 2.20

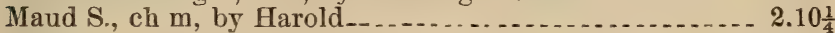

Maud T., b m, by Allie Gaines.................... 2.26

*Maxey Cobb, b s, by Happy Medium................ 2.201

May, ch $\mathrm{m}$, by Young Moscow .................... 2.27

May Bird, blk m, by George Wilkes............... 2.21

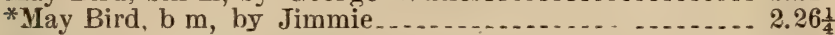

May Day, b m, by Ballard's C. M Clay ............... 2.30

*May H., b m, by Chicago Volunteer............... $226 \frac{1}{4}$

May Howard, gr m, by Capt Hanford .............. 2. 2.24

May Morning, b m, by Dıniel Lambert. . . . . . . . . . . . . 230

May Queen, b m, by May Day .................... 2.2. 26

May Queen (Nashville Girl), b m. by Alexander's Norman 2.20

May lhorne, $\mathrm{b} \mathrm{m}$, by Thornedale .... . . . . . . . . . . . 2.248

Mazomanie, ch g, by General Morgan . . . . . . . . . . . . . 2.20 2

* Ic Clure, blk g, by Messenger Duroc . . . . . . . . . . . . . . 2.30

* Mc.Mahon, br s, by Administrator................... 2.27

*Meander, b s, 4 yrs, by Belmont ................... 2.30

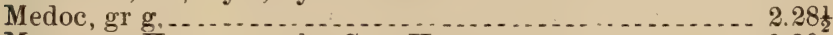

Messenger Knox, gr s, by Gen. Knox ............ . . 2.30

Metropolis, br g ......................... 2.30

Middlesex, ch g, by Seneca Chief................. 2.24

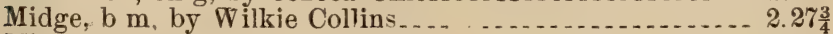

Midnight, blk g, by Peacemaker.................. 2.18

Mignon, b m, by Sentinel ....................... $227 \frac{1}{4}$

Mike, br s, by Beecher............. $28 \frac{1}{4}$ 
*Mike, br g, by Beecher.............................. 2.

Mike Jefferson, cb g, by Thomas Jefferson ............. 2.29

Mila C. (Mila Caldwell), ch m, by Blue Buil ........... 2.261

Mill Boy. br g, by Jay Gould ...................... 2.26

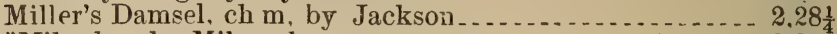

*Milo, b s, by Milwaukee ................................ 2.26

Milton Medium, b s, by Happy Medium .............. 2. 251

*Minnie D, b m, by Alexander................... 2.30

Minnie Maxfield, b m, by Charley .................. 2...28

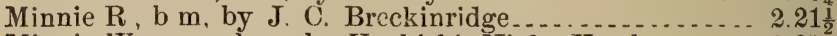

Minnie Warren, ch m, by Vankirk's Night Hawk ....... 2.27

Mistietoe, blk m, by Mambrino Patchen _.............. 2.30

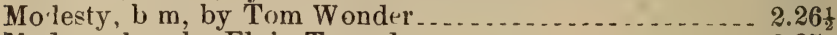

Modoc, $\mathrm{ch} g$, by Ely's Tornado $\ldots . . . . . . . . . . .25$

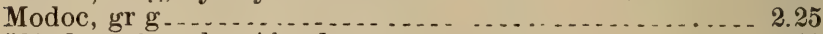

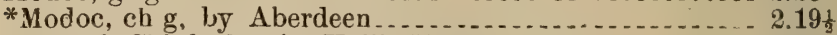

Mohawk Chief, ch s, by Hall's Mohawk Jr.......... 2. 2.30

*Mohawk Gift, ch s, by Hall's Mchawk ............. 2. 2.291

Mohawk Jr. (Clark's), b s, by Mohawk............... 2.25

Mohawk Jr. (Hall's), b s, by Mohawk ................. 2.26

Mohawk Prince, $\mathrm{b} y$, by The Commodore ............ 2.28

*Mollie B., br m, by Duke of Saratoga ............... 2.30

*Mollie Middleton, b m, by Bay Middleton ............ 2.291

Molly, b m, by Dolphus ............................. 2.27

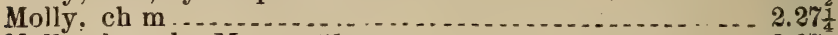

Molly, b m, by Magna Charta..................... 2.27

Molly Bell, br m, by Consternation................ 2.30

Molly Drew, ch $\mathrm{m}$, by Winthrop................... 2.27

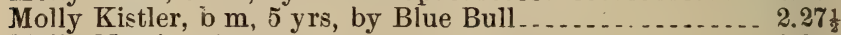

Molly Morris, ch m .................................. 2.

Molsey, b m, by Whiteside's Black Hawk............ 2.218

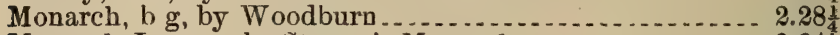

Monarch Jr, rn s, by Strawn's Monarch ................. 2.24

Monarch Rule, b m, by Strawn's Monarch . . . . . . . . . . . 2.24

Monitor, gr g, 5 yrs, by Strathmore ................. 2.29

Monroe, ch s, by Miller's Iron Duke .................. 2.27

Monroe Chief, b s, by Jim Monroe................... 2.18

Monroe D, b s, by Jim Monroe . ...................... 2.28

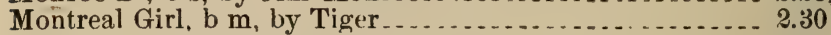

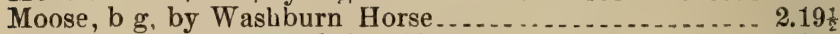

Morning, gr m, by Mambrino Pilot................ 2.30

*Morocco, b g, by James R. Reese ......... 2.30

Morrill, J. G., ch g, by Winthrop Morrill ........ . . . . . 2.29

Morris, br g, by Sherman Horse .................. 2.29

Morris, J. P, br g. by Robert R. Morris . . . . . . . . . . . . . . 2.201

Morrissey, ch g, by Black Warrior.................. 2.26 . $26 \frac{1}{2}$

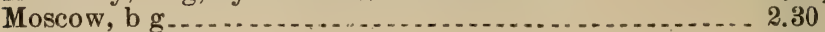

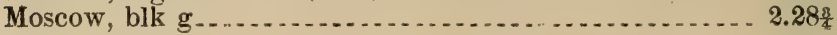


Motion, ch s, by Daniel Lambert ... . . . . . . . . . . . 2. 2.29

Mountain Boy, b g, by Edward Everett............ 22 20 $\frac{3}{4}$

Mountain Girl, b m, by Weige ................. - 2.30

Mountain Maid, b m, by Yorrill .......... . . . . . 2.278

Mountain Quail, b m, by Widgeon ............... 2.28

M. R, b g, by Jupiter........................ 228

Musette, b m, by Álmont ...................... - 2. $29 \frac{1}{4}$

Music, b m ........ . . . . . . . . . . . . . . . . . . 2. 2.29

Music, ch m, by Middletown .................... 2.21

Myron Perry, b g, by Young Columbus................ 2.24

Myrtle, b m, by King's Champion............... 2.25 .

Myrtle, rn m, by Flying Cloud ................... 2.26 . . .

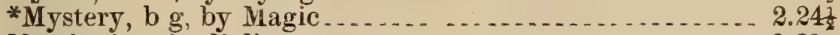

Mystic, b g, by Reliance .................... . . 2.22

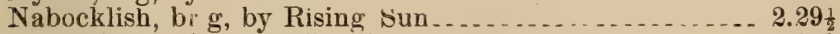

Naiad Queen, b m, by Gooding's Champion............ . 2.201

Nancy, ch $\mathrm{m}$, by Daniel Lambert.................... $3.29 \frac{2}{2}$

Nancy Hackett, rn $\mathrm{m}$, by Wood's Hambletonian...... 2.2.20

Nannie Talbot, ch m, 5 yrs, by Strathmore.......... 2.2. 28

Natchez, b g .... .............................. 2.30

Ned Forrest, blk g, by King's Brandywine .............. 2.28

Ned Wallace, b s, by Taggart's Abdallah.............. 2.25

Neli, b $\mathrm{m}$, by Thomas Jefferson ..................... 2.27

Nelia, b m, by Camden Denmark.................... 2.26

Nell, blk m . . . . . . . . . . . . . . . . . . . . . . . . . 2.29

*Nellie Burns, b m, by Milliman's Bellfounder........ 2.27 $27 \frac{1}{2}$

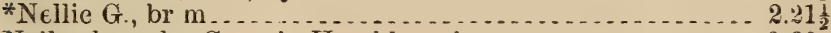

Neliy, b m, by Green's Hambletonian.............. 2. 2.30

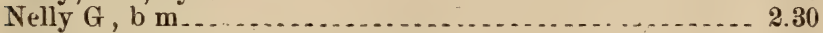

Nelly Holcomb, gr m, by American ... . . . . . . . 2.28

Nelly Irwin, $b \mathrm{~m}$, by Middletown ................. 2.25

Neily K., blk m, by vlambrino Templar......... . . 2.29

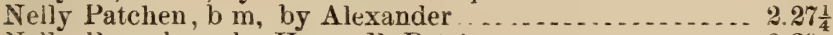

Nelly Ruse, b m, by Henry B. Patchen ............... 2.30

Nelly Walton, b m, by Jules Jurgensen ............... 2.26 . . .

Nelly Webster, br $m$, by American Eth

Nemo, b g, by John Nelson......................... 2.30

Neome, br $\mathrm{g}$, by Post Boy Frank ................... 2.24

Nerea, ch $\mathrm{m}$, by John Nelson...................... 2. $2.23 \frac{1}{2}$

Neta Medium, b $m$, by Happy Medium .............. 2. 2. 22:

Nettie, b m, by Rysdyk's Hambletonian ............... 2.18

Nettie Burlew, b m, by King's Champion.............. 2. 2.24

*Nettie R., ch m, by Gen VicClellan, Jr . . . . . . . . . . 2.19 2.1

Nettie Ward, ch m, by Peavine.................. 2.29 .

*Neva, b m, Straler's Hambletonian .................. 2. 2.231

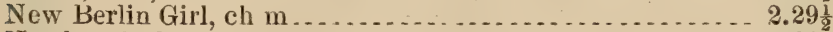

Newbrook, blk g, by Wilson's Henry Clay ............ 2.30

Newburg, b g, by Seely's American Starr............ . 2.30 
Nick, blk g . . . . . . . . . . . *Nickle, b g, by Oak Hill ... ................... 2.21

Nigger Baby, blk g, by Yankee Bill ............... 2.27 . 27

Mightingale, b m, by Ericsson....................... 2.298

Nil Desperandum, b s, by Bélmont ................ 2.24

Nino, b g .......

Nira Belle, b $m$, by son of Ethan Alien ............... 2.29

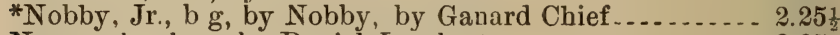

Nonesuch, ch m, by Danie] Lambert .. . ............. 2.25

Noontide, gr m, by Harold ........................ 2.201

*Nora Temple, $\mathrm{b} \mathrm{m}$, by Belmont................... 2.291

North Stur Mambrino, b s, by Mambrino Chief........ 2.26 2.

Novelty, ch m, by Gooding's Champion............... 2.231

Nutwood, ch s, by Belmont....................... 2.18

Gakland Maid, gr m, by Speculation................. 2.22

O'Blenuis, b g, by Abdallah......................... 2.27

Observer, ch g, by Revenge....................... 2.241

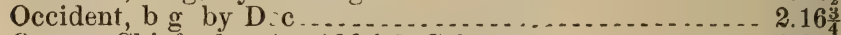

Oceana Chief, ch s, by Aldrich Colt................. 2.23

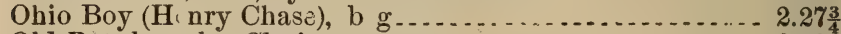

Old Put, br s, by Clarion.......................... 2.30

Onawa, blk s, by Goodwin's Hambletonian............ 2.221

Onward, blk s, by George Wilkes................... 2.25

Orange Blossom, b s, by Middletown $\ldots . . . . . . . . . .2 .26 \frac{1}{2}$

Orange Girl, b m, by Rysdyk's Hambletonian.......... 2.20

Orient, b g, by Smith's Mambrino Patchen ............. 2.24

Orient, ch m. 4 yrs, by Cuyler.................... 2.30

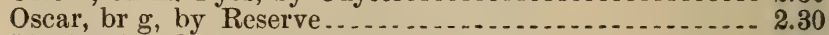

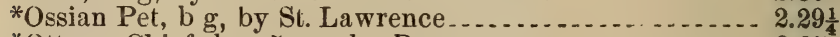

*Ottawa Chief, b s, 5 yrs, by Byron................... 2.25

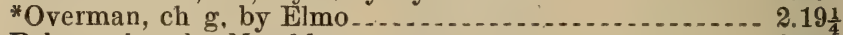

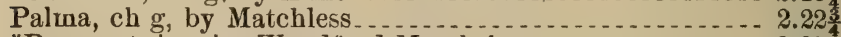

*Pancoast, b s, by Woodford Mambrino ............... 2.25:

Panic (Frank Vernon), b g, by Sherman Black Hawk ... . 2.28

Parana, b m, by Mambrino Hambletonian.............. . 2.191

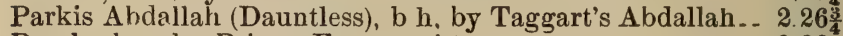

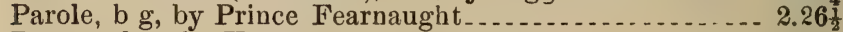

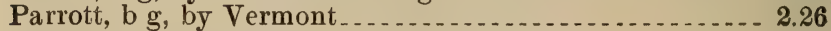

Patch, b g. by Detective Patchen ... . . . . . . . . . . . . . 2.291

Patchen (Orwell Bny), c g ......................... 2.18

*Pathfinder, Jr, br s, by Pathfinder ................. 2.30

Pat Hunt, ch g, by Tecumseh................... 2.25

Pat McCann, blk g, by Sir George . . . . . . . . . . . . . 2.288

Pat Ring, b g .

Peaceful, blk m, by Gen. Knox

Pearl, b m, by Gentle Breeze........................

Pedro, gr g, by Rooney's Hambletonian .............. 2.25⿺

Pelham, b g . . . . . 
Pemberton, b g, by Fearnaught, Jr

Penelope, blue m, by Yuung Kemble Jackson

Peralto, ch g, by Hambletonian Prince............... 2.26 $2 \frac{1}{2}$

Fete, b g .................

*Phallas, b s, by Dictator.......................... 2. $2.15 \frac{1}{2}$

Pbil, b g . . . . . . . .

Phil Duugherty, ch g, by Frank Pierce Jr ........... 2.26

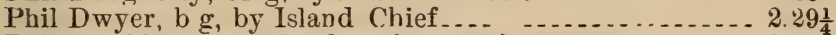

Phil Sheridan, wh g, by Swanborough's Creeper....... 2.26

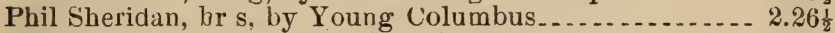

*Phil Sheridan Jr, blk s, by Phil Sheridan............. 2.291

Phil Thompson, gr g, 3 yes, by Red Wilkes............. 2.21

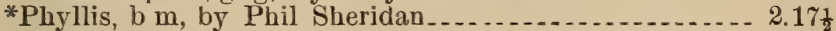

Pickard, b g, by Abdallah Pilot ...................... 2.181

Pickwick, br g, by Backman's Idol................. 2.29

Piedmont, ch s, by Almont...................... 2.17

Pilot, blk g, by Pilot Jr...................... 2.28

Pilot Boy, b g, by Kilmore..................... 2. $27 \frac{3}{4}$

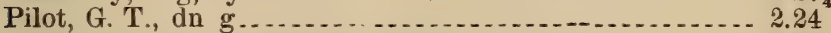

*Pilot Knox, br s, by Black Pilot................... 2244

Pilot R, b g, by Black Knight .................... 2.21

Pilot Temple, b s, by Pilot Jr ..................... 2.24

Planter, ch g, by Red Bird ......................... 2.24

Pluck, blk g ...

Pocahontas, b m, by Ethan Allen ..................... $226 \frac{3}{4}$

Pochuck iiaid, b m . . . . . . . . .

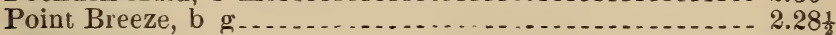

*Polka Dot, ch m, 5 yrs, by Pocahontas B.y......... 2.28

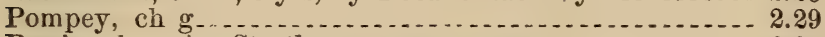

Portia, ch m, by Startle.......................... 2.291

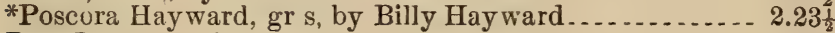

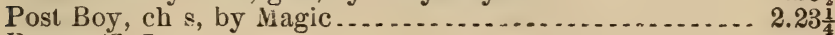

Potter, 'T. J., gr g ................................ 2.291

Powers, br g, by Volunteer........................ 2.

Pratt, br g, by Strideaway............................. 2.28

Preston, dn g, by George Washington ................. 2.28

Prince (Hartf , rd), by L. I. Black Hawk . . . . . . . . . . . . . . 2. 2.24

Prince, ch g, by Jupiter Abdallah................... 227

Prince, rn or $\mathrm{sp} g$............................... $2.27 \frac{3}{4}$

*Prince, b g . . . . . . . . . . . . . . . . . .

*Priuce, blk g, by Royal Reverge.................... 2.23

Prince Allen, ch s, by Honest Allen

Prince Allen, b g, by Woodward's Ethan Allen......... 2.27

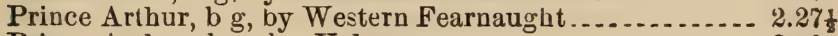

Prince Arthur, b g, by Volunteer..................... 2..29

Prince Charles, ch g .................................

Princess, b m, by Andrus' Hambletonian.............. 2.30

Princess, blk $\mathrm{m}$, by Dictator............................ 2.29 
Princton Boy, ch g. by Vermont Boy ................ 2. 2.28

Proctor, blk $\mathrm{g}$, by Harris' Mambrino Chief Jr . . . . . . . . 2.23

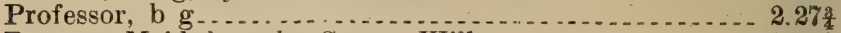

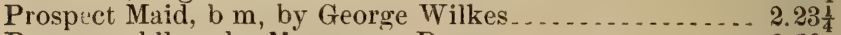

Prospero, blk g, by Messenger Duroc................ . 230

Proteine, br $\mathrm{m}$. by Blackwood....................... 2.18

Purity, ch m, by Blue Bull .........................

Quaker Boy, b g ............................... 2.28

Queechee Maid, br m, by Ballard's C. M. Clay Jr...... 2.25

Queen of the West, gr m, by Pilot Jr............... 2. 26 .

Rachel, b m, by Woodford Mambrino .............. $2.26^{\frac{3}{4}}$

Rachel $\mathrm{B}$, blk m, by Allie West ................. 2.28

Randall, ch g, by Chauncey Goodrich............. 2 241

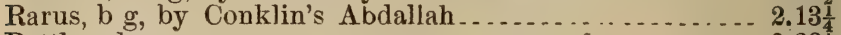

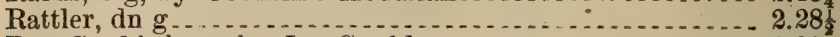

Ray Gould, b m, by Jay Gould ................... 2.29

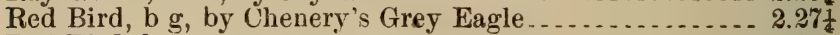

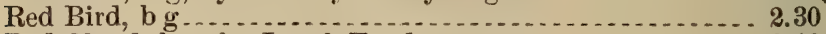

Red Cloud, b g, by Legal Tender

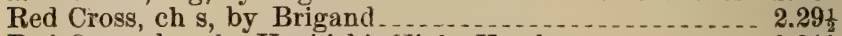

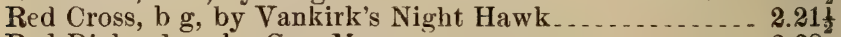

Red Dick, ch g, by Gen. Morgan ..................... 28

Red Jim, b g, 3̈ yrs, by Abdallah Pilot ............. 2.30

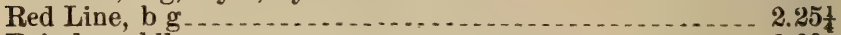

Reindeer, blk g $\mathrm{g} \ldots \ldots \ldots \ldots$

Reliance, blk s, by Alexander ....................... 2.22

Resolute, b g, by Swigert .................

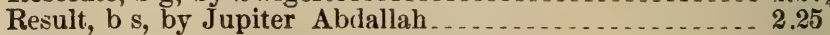

Reveille, br s, by New York ..................... 2.27t

Rex Patchen, br s, by Godfrey's Patche $\ldots . . . . . . . .2 .30$

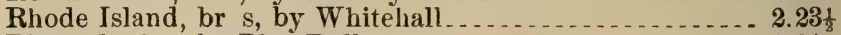

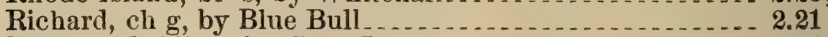

Richmond, blk g, by Gen. Lyon

Richwood, b g

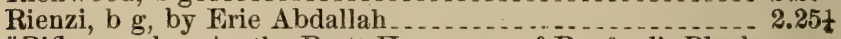

*Rifleman, b g, by the Pratt Horse, son of Rexford's Black

\section{Hawk}

Rigolette, b m, by Exchequer.

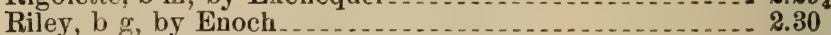

Ripon (Tete Matthews), br s, by Ira Allen

Rip Rap, br g, by Mambrino Brave $\ldots \ldots \ldots . .28 \frac{1}{2}$

Ripton, b g, by American Boy

Rival, gr s, by Whiteside's Black Hawk............ 2.30

Roanoke Maid, b m . . . . . .

Robert H., b g . . . . .

Robert Lee, blk g, by Ridley Horse ... . . . . . . . . . . . 2.23

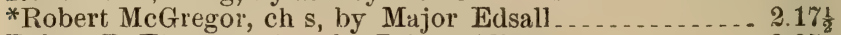

Robert B. Thomas, ch g, by Prince Allen .............. 2.25 
*Robin, gr g, by Enfield

Rockingham, gr g $\ldots \ldots \ldots \ldots \ldots$

Rockton, b g, by Highlånd Beauty

Roger Hanson, gr s, by Alta . . . . . . . . . . . . . . . . . 2.28

Roland, b s, by Crown Chief.... . . .

*Rolla, ch $\mathrm{g}$, by Shelby Chief

Rolla Golddust, br g, by Golddust................. 2.25

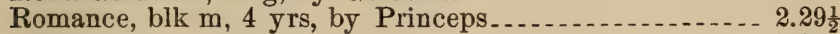

Romeo, b s, by Menelaus

Romero, gr s, 5 yrs, by A. W. Richmond . . . . . . . . . . 2.19

Rosalind, b m, by Alexander's Abdallah............. 2.21

Rosalind, gr m

Rosa Wilkes, b m, by George Wilkes............... 2.18

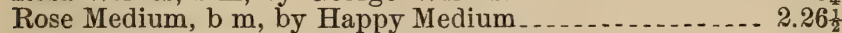

Rose Standish (Maud O.), b m, by Corbeau ............. 2. 2.29

Rose of Washington, gr m, by Green's Bashaw ......... 2.213

Rosewood, br m, by Blackwood .................... 2.27

*Rosewood, b s, by Creole ... . . . . . . . . . . . . . . . . . . 2.28 28

Ross, sptd g - .

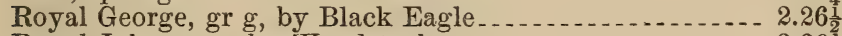

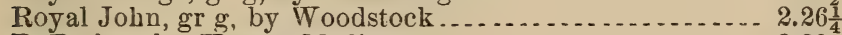

R. P., b g, by Happy Medium ..................... 2.22

Rufus, br g, by Bacon's Ethan Allen ................. 2.29

Russell, gr $\mathrm{g}$, by Blue Bull ........................ 2.26

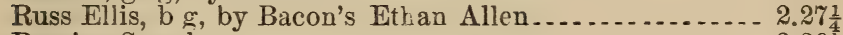

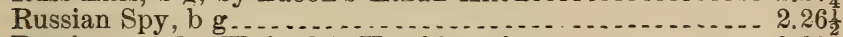

Rustic, gr s, by Whipple's Hambletonian .............. 2.30

Rutledge, b g, by Conqueror ....... 2.30

Sadie Belle, ch m, by Odin Bell ..................... 24

Sadie H., b m, by Williams' St. Lawrence ............ 2.30

Sadie Howe, b m, by Mambrunello ... . . . . . . . . . . . 2.26

St. Charles, sp g, by Grey Eagle

St. Cloud, b s, by Conklin's American Star........... 2.28

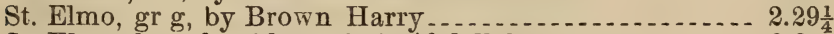

St. Elmo, br $s$, by Alexander's Abdallah................ 2.30

St. Gothard, b s, by George Wiikes.................. 2.2. 29

St. Helena, b m, by Gen. McClellan................... 2.27 $27 \frac{1}{2}$

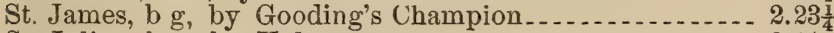

St. Julien, b g, by Volunteer........................ 2.11

St. Louis, b g, by Colossus Mambrino ................ 2.25

St. Remo, br g, by Volunteer.................... $228 \frac{1}{2}$

*Sally Benton, gr f, 3 yrs, by Gen. Benton ............ 2.30

Sally Scott, b m, by Magna Charta .................. 2.281

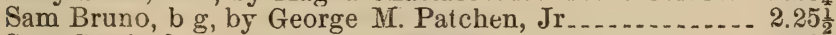

Sam Curtis, b g, by Winthrop Morrill ................ 2.28

Sam Purdy, b s, by George M. Patchen, Jr . . . . . . . . . . 2.20 20

Sam West, b g, by Davy Crocket................... 2.29

Sannie G., gr m, by Almont.................................... 
Santa Claus, b s, by Strathmore $\ldots \ldots \ldots \ldots \ldots \ldots . . . . .2 .17 \frac{1}{2}$ *Saturn, b s, by Satellite ............................. 2.22 *Scandinavian, b g, by Vermont Black Hawk, Jr....... 2.27

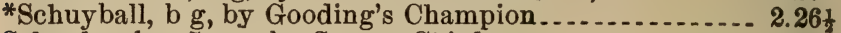
Schuyler, b s, 5 yrs, by Seneca Chief.................. 2.26

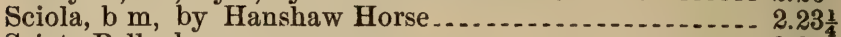
Sciota Belle, br m ..................................... 2.28

Scotland, blk g, by Bonnie Scotland ................... 2.221 Scotland Maid (George M.), b m, by Hambletonian ....... 2.28 Scott's Chief, b g, by son of Edwin Forrest............. 2.23 Scott's Thomas, b s, by Gen. George H. Thomas......... 2.21 Sea Foam, gr m, by Young Columbus................ 2.241 Selkirk, br s.... Sensation, b g, by Dixon's Ethan Allen .............. 2.22 Sentinel, b s, by Rysdyk's Hambletonian .............. 2.29 Shadow (Ayer), b g, by Gen. Lightfoot................ 2.28 Shakespeare, b s, by Honest Allen .................. 2.30 Shamrock, gr g, by Sampson ....................... 2.28

Shepherd Boy, gr g, by Woodward's Ethan Allen ....... 2.231 Shepherd Knapp, Jr., by Shepherd F. Knapp ........... 2.2 $27_{\frac{3}{4}}$ Sheridan, b g, by Edward Everett.................. 2.20 *Sherman, br s, by George Wilkes.................... 2.231 Sherman Morgan, Jr., b s, by Sherman Morgan........... 2.29 Silas Rich, ch g, by Young Priam ..... .............. 2.243 *Silas Wright, b s, by DeGraff's Alexander............. 2.28 Silky B., ch g, by Ely's Tornado, Jr.................. 2.30 Silver ........ . . .

Silver Duke, gr $\mathrm{s}$, by Iron Duke..................... $2.28 \frac{3}{4}$

Silversides, gr g, by Scott's Hiatoga .................. 2.22

Silverton, b g, by Blue Bull .......................... 2.201 Simon, ch $g$, by son of Ethan Allen................. 2.80 Sinbad, b g Sir Guy, b g, 4 yrs, by The Moor ..................... 2,28 Sir Walter, b g, by Abdallah........................ 2.27

Sir Walter, ch s, by Aberdeen ........................ 2.25 Sir William Wallace, b s, by Robinson Horse........... 2.27

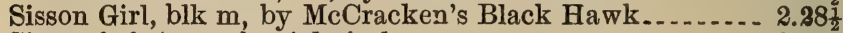
Sister, b f, 4 yrs, by Admiral ......................... 2.291 Skinkle's Hambletonian, b s, by Gage's Logan ............ 2.288 Sleepy Bill, br g.................................. 2.26 Sleepy George, ch g ................................ 2.29 *Sleepy Joe, br g, by Joe Thompson................... 2.191 Sleepy John, b g..................................... 2.241 Sleepy Tom, b g, by Blazing Star.................... 2.28

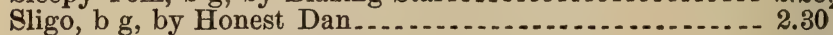

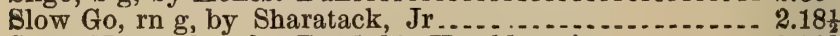

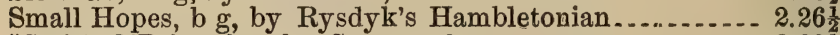
* Smith O'Brien, b s, by Sweepstakes.................... 2.291 
Smuggler, br s, by Blanco

* Smuggler's Daughter, b m, 5 yrs, by Smuggler

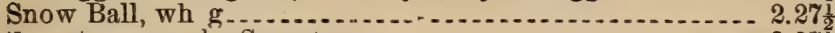

Socrates, rn g, by Socrates .......................... 2.27t

Solo, b m, 5 yrs, by Strathmore..................... 2.28

Sooner, b g, by Hambletonian Rattler................ 2.24

Sophia Temple, br m, by Rattler................... 2.27

Sorrel Dapper (Auburn Horse), ch g, by King's Champion 2.281

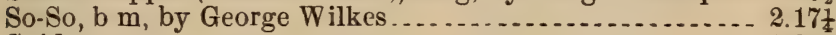

Spider, rn g ................................... 2.30

Spinella, br $\mathrm{m}$, by Louis Napoleon................. 2.30

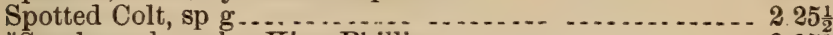

*Spudress, b m, by King Phillip ..................... 2.25

Star, b g, by Aberdeen .......................... 2.251

Star, ch $\mathrm{g}$, by Conkling's American Star ................ 2.30

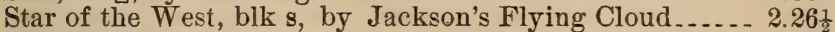

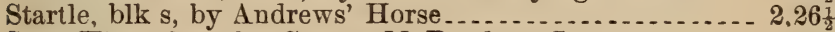

Starr King, dn s, by George M. Patchen, Jr.......... 2.22

Steinway, b c, 3 yrs, by Strathmore .................. 2.258

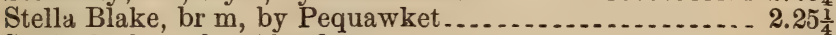

Stella C., b m, by Aberdeen........................ 2.27

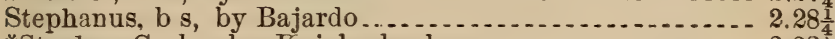

*Stephen G., b g by Knickerbocker................. 2.23

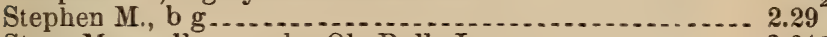

Steve Maxwell, gr g, by Ole Bull, Jr ................. 2.21

Stewart Maloney, b g, by Charles E. Loew ............ 2.27

Stonewall, ch g, by Frank Pierce III ... . . . . . . . . . . . 2. 24.24

*Stormer, b s, by Surprise ............................ 2.291

Stranger, gr g, by Eaton Horse..................... 2.30

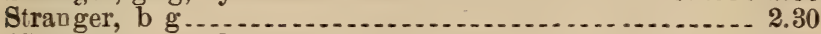

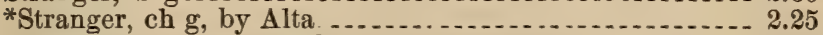

*Stranger, b g, by Mambrino Hambletonian ............ 2. 22.8

Stranger, gr g, by Selim.............................. 2.

*Strathlan, br s, by Strathmore ..................... 2.291

Strathmore, b g ........ . . . . . . . .

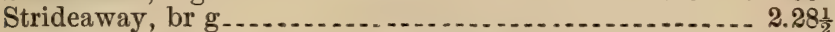

Strong, H. M., ch g, by Bay Middleton ................ 2.25

Sucker Maid, wh m, by Robinson's Rockaway ........... 2.297

Sue Grundy, br m, by Getaway ....................... 2.25

Sunbeam, b m..................................... 2.30

Sunnyside, blk m ...................................... 2.30

Sunshine, ch s, by Curtis' Hambletonian................ 2.30

Surprise, gr g, by Sayre's Harry Clay .................. 2.26

Susie, ch m, by Hampshire Boy ...................... 2.21

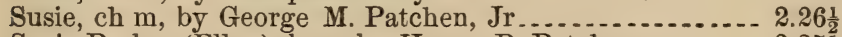

Susie Parker (Ellen), b m, by Henry B. Patchen .......... 2.25

Sussex, blk g, by Dunn's Star ........................ 2.30

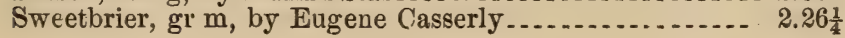


Sweetheart, br m, 3 yrs, by Sultan .................. 2.231 Sweet Home, ch m, 5 yrs, by Milliman's Bellfounder..... 2.36

Sweetness, b m, by Volunteer ... . . . . . . . . . . . . . . . 2.21 T. A, b g, by Sentinel ............................. 2.26

Tackey (Polly) gr m, by Pilot, Jr ................. 2.26

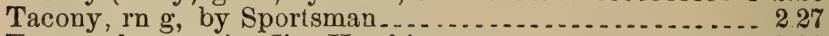

Tamarack, gr g, by Jim H wkins ................... 2.2. 2. $28 \frac{1}{2}$

Tanner Boy, gr g, by Edward Everett............... 2.22

Tariff, b s, by Clarion Chief ......................... 2.20

Tartar, b g, by Royal George....................... 2.28

Tattler, b s, by Pilot Jr.......................... 2.26

Taylor, rn $\mathrm{g}$, by Johnny B ......................... $2.26 \frac{3}{4}$

Taylor, W. H., ch g, by Crawford Horse............ 2.29

*Tecumseh, ch s, by Mambrino Gift .................. 2.291

Tennessee (Dora Thayer) br $\mathrm{m}$, by Commodore......... 2.27

*The King, blk s, by George Wilkes . . . . . . . . . . . . . ... 2.291

Thomas, J. B., b s, by Sterling ........................... $2.18 \frac{3}{8}$

Thomas, J. W, ch g, by Scott's Thomas.............. 2.27\%

Thomas, W. K., gr g, by Osceola ..................... 2.26

Thomas Jefferson, blk s, by Toronto Chief ............. 2.23

Thomas L. Young, ch g, by Well's Yellow Jacket....... 2.191

Thornerale, b s, by Alexander's Abdallah .............. 2.22

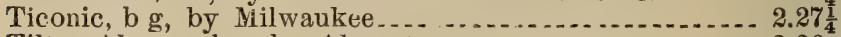

Tilton Almont, b s, by Almont..................... 2.26

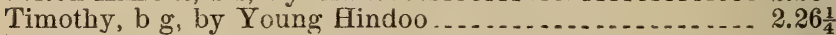

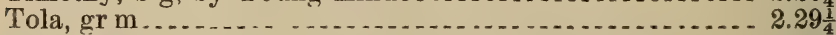

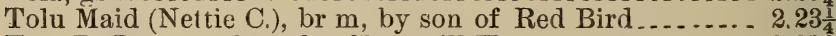

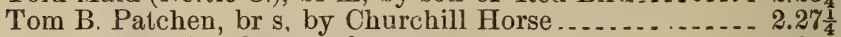

Tom Britton, b g, by Mambrunello .................. 2.26

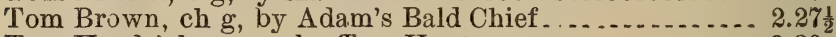

Tom Hendricks, gr g, by Tom Hunter ................... 2.30

Tom Hendricks, b g, by Tom Rolf .................... 2.25

Tom Keeler, b g, by Jersey Star.................... 2.25

Tom Malloy, blk g, by Phil Sheridan................ 2.27

Tom Medley, b g

Tom Moore, b s, by Jupiter Abdallah ................. 2.28

Tommy Dodd, rn g, by Alexander........................ 24

Tommy Gates, br g, by The Moor ................... 2.24

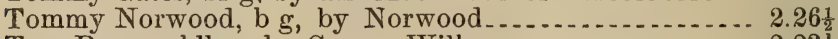

Tom Rogers, blk s, by George Wilkes ................ 2.231

Tom Walter, ch g, by Grey Messenger................ 2.29

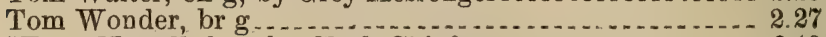

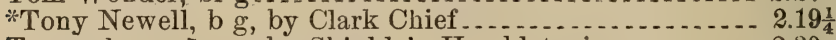

Topsy, br m, 5 yrs, by Skinkle's Hambletonian......... 2.30

Topsy, br m, by Walkill Chief . ...................... 2.21

Toronto Chief Jr, lir s, by Toronto Chief............... 2261

*Toronto Maid, blk m, by Captain .................. 2.30

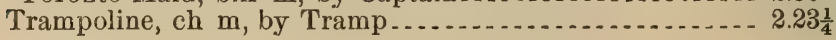


Traveler (Grit), ch g, by Flying Morgan ............... $227 \frac{1}{2}$

Tremont, b s, by Belmont.......................... 2.28

Trinket, b m, by Princeps.... ...................... 2.14

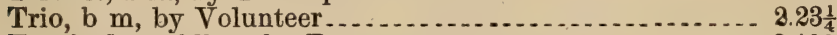

Troubadour, blk g, by Revenge ..................... 2.19 .

*Troublesome, br m, by Messenger Duroc .... . . . . . . . . . 2.291

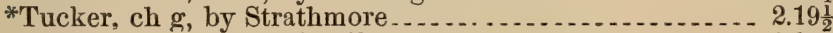

Tump Winston, ch g, by Primus.................... 2.25

Twang (John A. Logan), b g, by Hanley's Hiatoga. .... . . . 2.28 2.2

Twilight, gr m, by Washington Jackson ................ 2.2\%

Una, b m, by Almont......... ..................... 2.291

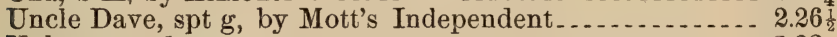

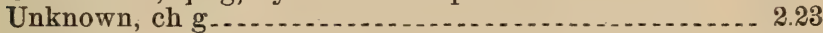

Unolala, b m, by Volunteer............

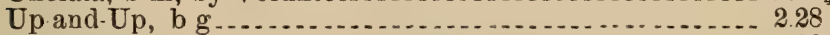

*Urbana Belle, br m, by J. H. Welch............... 2.291

Valliant, b s, by Enchanter....................... 2.281

Valley Boy, b g, by Aberdeen ...................... 2 241

Valley Chief, gr s, by Phil Sheridan ................ 2.25

Vanderlynn, b s, by George M. Patchen, Jr ............ 2.22

Vanity Fair, br g, by Albion ........................ 2.241

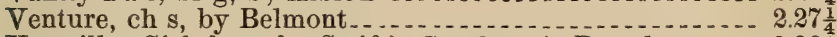

Versailles Girl, b m, by Swift's Stephen A. Douglass .... 2.28 2.

Victor, blk s, by Gen. Knox ........................ 2.23

Victor, br s...

Village Girl, ch $\mathrm{m}$, by son of L. I. Black Hawk. . . . . . 2.28

Viola (Hattie), br m, by Morgan Prince............... 2. 2.28

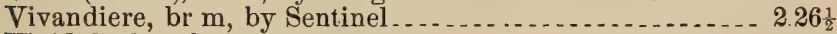

Vivid C., b g, by Schuyler Colfax $\ldots \ldots \ldots . .28 \frac{1}{4}$

*Vision, b m, by Edsall's Clay ...................... 2.26

*Vladimer, ch g, by Woodburn Pilot................ 2.2. $28 \frac{3}{4}$

Volnєy, b g, by Volunteer.......... 223

Voltaire, br s, by Tattler........................... 2.21

Volunteer, br s, by Gen. Dana....................... 2.27

Volunteer Maid, b rn, by Volunteer ................. - 2 27

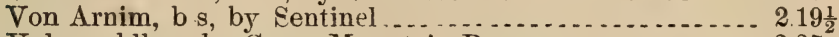

Vulcan, blk g, by Green Mountain Banner.............. 2.25

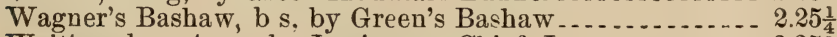

Waiting, b g, 4 yrs, by Lexington Chief $\mathrm{Jr}_{\ldots} . . . . . . . . .2 .25_{4}^{8}$

*Wallace, b g, by Whalebone Knox................. 2.291

Walnut, b s, by Florida.......................... 2.22

Walter, ch g . . .

Warrior, br g, by Indian Chief....................... 2.26

Warwick, b s, by Ethan Allen..................... $229 \frac{1}{2}$

Webber, br g, by Como Chief....................... 228

Wedgewood, br s, by Belmont

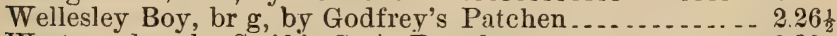

Western, b g, by Swift's S. A. Douglass ............... 2.30

*Western, ch g, by Tramp Dexter................. $225 \frac{1}{4}$ 
Western Boy (John Fero), b g ........................ 2.27

Western New York, b g, by Nonpareil ................. 2.29

Westfield, ch g, by Whipple's Hambletonian.......... 2.261

West Liberty, ch g, by Wapsie....................... 2.28

*Westmont, b s, 5 yrs, by Colonel West.............. $2.27 \frac{1}{4}$

Whalebone, b g................................... 2.29

*Whirlwind, b g, by Whirlwind.................... 2.271

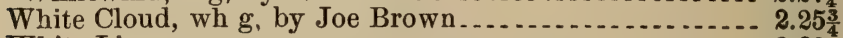

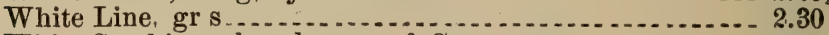

White Stockings, b g, by son of Commerce............ 2.21

Wick, b g, by Justin Morgan ........................ 2.30

Widow Machree, ch m. by Seely's American Star ....... 2.29

Wilbur F., blk g, by Hinsdale Horse ................. 2.241

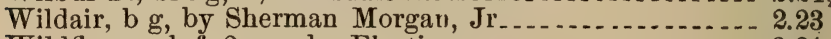

Wildflower, $b$ f, 2 yrs, by Electioneer ................ 2.21

Wild Lily, b m, by Daniel Lambert.................. 2.24

Wild Oats, br g, by Green's Bashaw ................. 2.291

Wildwood, br s, by Blackwood ...................... 2.30

*Will Benham, b g, by Whip Clay

Will Cody, b g, by Blue Bull .......................

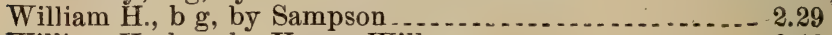

William H, b g, by Young Wilkes .................... 2.18

*Willis Woods, b g, by Rescue..................... 2.25

*Wilson, b g, by George Wilkes .................... 2.161

*Winnie Wick, blk $\mathrm{m}$, by Swigert .................... 2.268

Winthrop Morrill, Jr., blk s, by Metacomet ............. 2.27

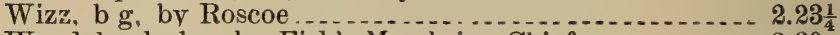

Woodchuck, b s, by Fisk's Mambrino Chief............ 2.30

Woodford Chief, b s, 5 yrs, by Clark Chief .............. 2.221

Woodford Z., b g, by Capt. Beaumont................. 2.22

*Woodlake, b g, by Darlbay .......................... 2.271

Wolford Mambrieo, br s, by Mambrino Chief........... 2.21

Wooley, C W., b g, by Crazy Nick................. 2.22

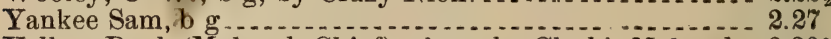

Yellow Dock (Mohawk Chief), ch m, by Clark's Mohawk - 2.208

York State, b g, by Gooding's Champion............... 2.231

Young, J. S., b g, ................................. 2.29.

Young Bruno, br g, by Rysdyk's Hambletonian .......... 2.228

Young Buchanan, b s, by Buchanan II ............... 2.29 .

Young Columbus, b g, by Young Columbus............ 2.30

*Young Fullerton, ch s, by Edward Everett... ........ 2.208

Young Magna, b g, by Magna Charta ................ 2.29

Young Rattler, br g, by Pathfinder................... 230

Young Sentinel, b s, by Sentinel ..................... 2.26

Young Wilkes, blk s, by George Wilkes ............... 2.281

Zelda, b m, by Tattersall'a Hambletonian ............... 2.29

Zephyr, ch s................................... 2.292

Zephyr, b m, by son of Ethan Allen ................ 2.30

*Zoe B., ch m, by Blue Bull ....................... 2.2014 


\section{List of 2:30 Pacers, Complete to the Close of I883.}

(Horses that got their "mark" in 1883 are designated thus: *)

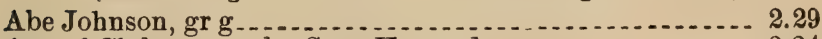

Ace of Clubs, rn $\mathrm{g}$, by Sam Hazzard.............. 2.241

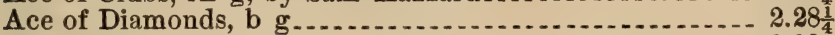

Aggie Downs, b m

Albany Boy, ch g, by Sam Hazzard ................. 2.20

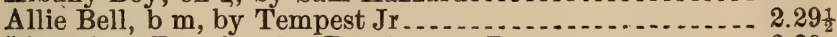

*American Boy, b s, by Pocahontas Boy ............... 2.29

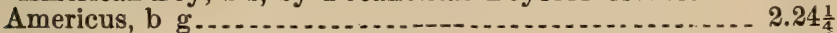

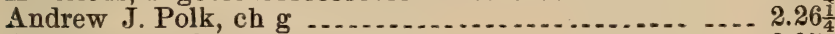

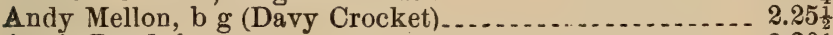

Annie Boyd, b m................................... 2.201

Badger, b s (Badger Boy), by Kerr's Bashaw . . . . . . . . . . 2.29

Bald Hornet, ch s, by Red Buck.................. 2.23

Bay Billy, b g .................................... 2.14

Bay Bob, b g

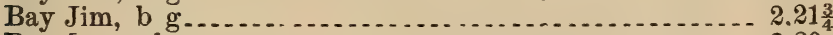

Bay Lucy, b m....................................... 2.

Bay Sally, b m, by Gosnell's Tom Crowder.......... 2.20

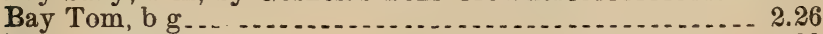

Belle Hamill, b m....................... 2.30

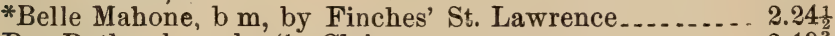

Ben Butler, br g, by St. Clair ...................... 2.193

Ben Hamilton, b g, by DeWitt's Norman.............. 2.16

Ben Higdon, ch g, by Abdallah ..................... 2.27

*Bessie M., blk m, by Pocahontas Boy ................ 2.21委

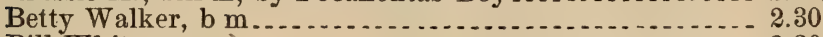

Bill White, rn g .

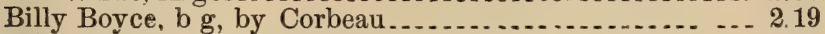

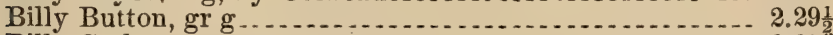

Billy C., b g .

Billy Hopper (Billy Hooper), gr g ................... 2.24

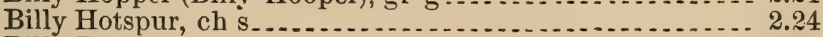

Billy Larkin, b g . ................................. 2.27

*Billy M., ch g, by Clear Grit, dam by Toronto Chief.... 2.24 $\frac{1}{4}$

Billy Mayo, gr g .................................. 2.20

*Billy N., ch g, New Ross, Ind., Aug. 16.............. 230

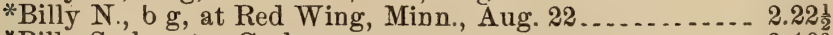

* Billy S., b g, by Corbeau ........................... 2.16

*Billy Scott, ch g, by Billy Green.... 
*Black Bassenger, blk s, by Old Legal Tender

Black Cat, blk m

$2.29 \frac{3}{4}$

Black Jack, blk g .

* Black Rainbow, blk g, by A Rainbow

$2.29 \frac{1}{2}$

Black Shy, blk g

2.30

Black Weasel, blk g, by Longfellow

*Bright Light, br s, by Legal Tender

2.30

*Brown Prince, br g

*Buck Dickerson, ch g, by Red Buck

$2.26 \frac{3}{4}$

2.29

*Buckskin, dn g

$2.27 \frac{1}{2}$

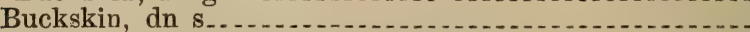

2.27

Buffalo Girl, b m, by Pocahontas Boy ...............

*Burgher, b g

*California Girl, b m

2.27

2.28

Capitola, ch $\mathrm{m}$

$2.12 \frac{1}{2}$

2.30

Capt. Dan, b g

$2.29 \frac{1}{4}$

$2.25 \frac{1}{2}$

Capt Dan, b gy son of Scott's Hiatoga

Capt. Jack, b s

$2.24 \frac{1}{2}$

Capt. Kinney, b g

Capt. Walker, ch s

Carrie T., b m, by Sam Hazzard

Cayuga Maid, $b \mathrm{~m}$

Centreville Maid, $\mathrm{b}$ m

Change, $\mathrm{b}$ g

Charley, blk $\mathrm{g}$

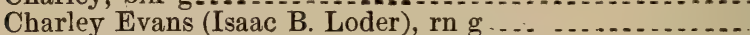

Charley F., b g

Charley H., b g ........................................

* Charley Harvey, b g (to saddle).

* Chestnut Star, ch s

Chief, b

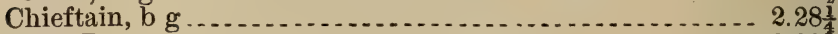

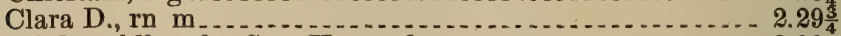

Clinker, blk s, by Sam Hazzard....

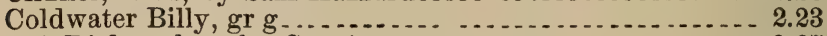

Col. Dickey, b g, by Strathmore..................... 2.27

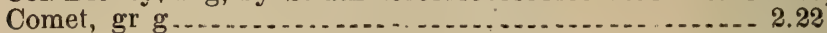

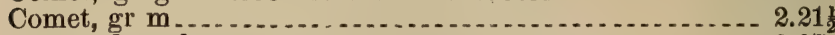

Commodore, b g ............................... 2. 27

Conlisk's (James Conlisk and Jack), rn g............... 227

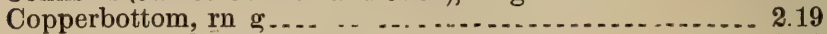

Corette, b m, by Winthrop

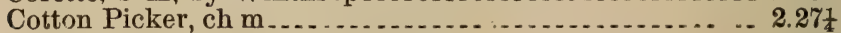

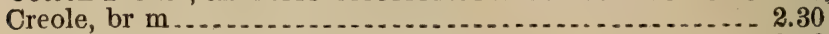

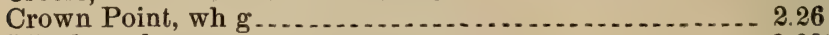

*Cyclone, b g ....

*Daisy D., blk m, by Black Steer ................... 2.221

Dan Mahoney, rn $\mathrm{s} . \ldots \ldots \ldots \ldots \ldots . . .2 .21 \frac{1}{2}$ 
Dan Miller, ch g.................................. 2.23

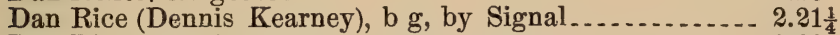

Dan Rice, rn g.......................................... 28

Dan Voorhees, gr g . . . . . . . . .

Dan Webster, b g

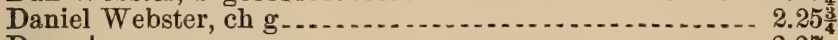

Dave, b g .............

Defiance, br g, by Chieftain........................... 2.24

Dexter, ch g, by Woodward's Ethan Allen ........... 2.29

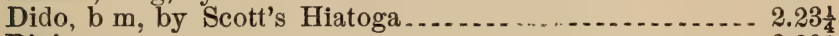

Dixie, gr m . . . . . . .

Doc Snyder, b g, by Wild Tom..................... 2.27\%

*Doctor M., blk g ...........................

Dolly Spanker, b m

*Doñ Cameron, gr g-

Drover, b g

*Eddie C., b g, by Happy Medium...

*Eddie D., gr g, by Accidental . . . . . . . .

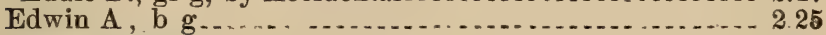

*Edwin Frost, $\mathrm{b}$ g $\ldots \ldots \ldots \ldots \ldots \ldots \ldots$

Ella Davis, b m

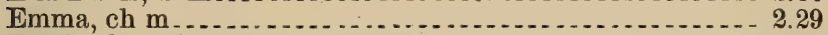

Estelle, b m, by Scott's Hiatoga

*Etta C., h m, by Hampshire Boy ..................... 2. 2.291

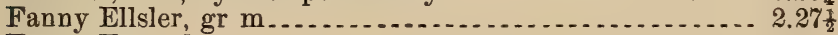

Fanny Fern, b m ................................... 2.28

*Fannie Golddust, $\mathrm{ch} \mathrm{m}$, by son of Golddust, dam by Red Buck.

Felix, rn g, by Dictator.

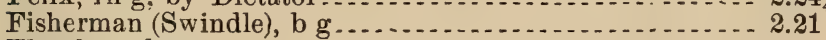

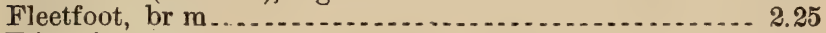

Flitterfoot, ch s $\ldots \ldots \ldots \ldots \ldots \ldots . .24 \frac{1}{2}$

Flora, b m, by Chieftain .......................... 2.30

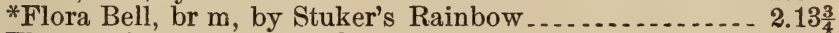

Flying Hiatoga, Jr., br s, by Flying Hiatoga ............ $2.25 \frac{1}{2}$

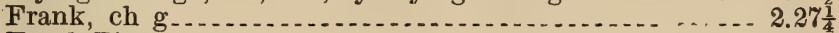

Frank Pierce, ch g . .

*Frank W., dn g

*Fred Akerman, b g

Frederick, gr g

Fred Johnson, gr g

Fred Wormley, b g $\ldots \ldots \ldots$

*Fritz, gr g

* Fuller, b g, by Clear Grit. . . . .

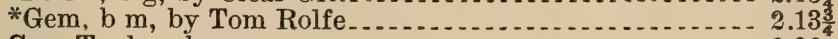

Gen. Taylor, br g

* George G., dn g, by Flying Dutchman.............. 2.231

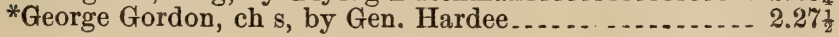




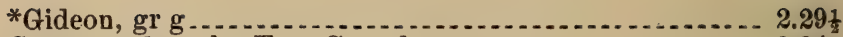

Granger, ch g, by Tom Crowder................... 2.24

Granger Pete, gr g

*Gray Frank, gr g, by Haywood Chief................ 2.26

Grey Dan, gr g......

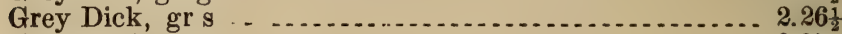

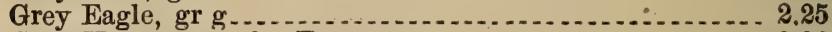

Grey Harry, gr s, by Tempest.................... 2.261

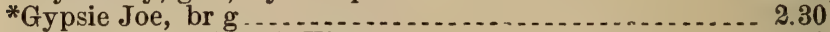

Gypsy, b g, by Scott's Hiatoga..................... 2.281

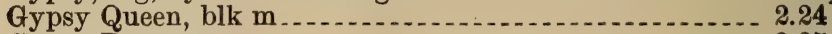

Gypsy Roan, rn m

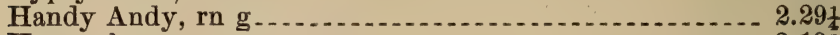

Harry, b g

Harry D., b g

Harry Goodrich (Nigger Boy), b g, by Cadmus.......... 2.253

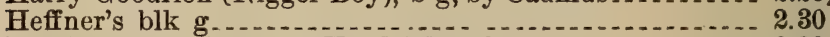

Hendricks, T. A. (Tom Hendricks), b g

Hero, gr g, by Harris' Hambletonian .............. 2.201

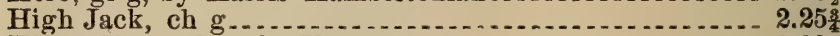

Hiram Tracy, b g, by Tecumseh ................... 2.221

Honest Jim, br g, by Dillon Horse ................... 2.28

Honesty, b g .

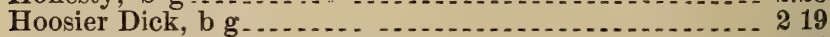

Hoosier Sam, b g

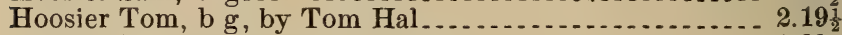

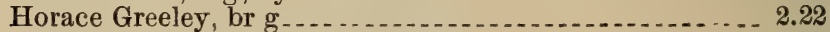

Humming Bird, ch $\mathrm{m}$, by St. Clair

Innocent Sam, b g $\ldots \ldots \ldots \ldots \ldots$

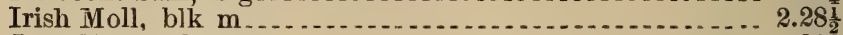

Jack Evans, br g ... .

*Jack Hart, ch g, by American Boy

*Jack Rapid, gr s, by Jack Rapid ...

James K. Polk, ch g .

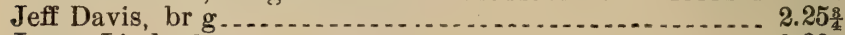

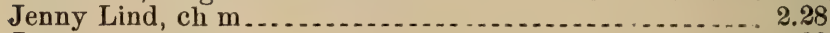

Jerry ... . . . . .

Jim Brown, ch g ..................

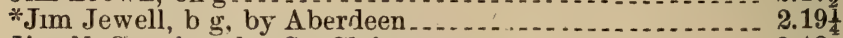

Jim McCue, b s, by St. Clair........................... 2.18

Joe Bowers, Jr., b g, by Joe Bowers............... 2.251

*Joe Braden, b g, by Bull Gopher................... 2.201

Joe Coburn . . . . .

Joe Gates, gr g

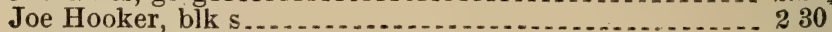

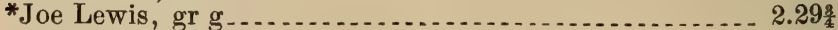

Joe Wilson, b g

John Burke, b g 
John Burnett, ch g

*John H., ch g.

John Heenan, b g, by Henry Clay (pacer)..............

John (Jim) McKinney, rn g . . . . . . . . . . . . . . . . . . . .

John McNair, b g.

John Schonchin, ch g

*Johnson, foaled 1877 by Basbaw Golddust, son of Billy Bashaw, said to be a son of Green's Bashaw. Bashaw Golddust's dam by Champion Golddust. Johnson's dam, chestnut mare by Ned Forrest; second dam, by Steele's Kentucky Hunter. Ned Forrest, by Alexander's Edwin Forrest; dam by Young Sir Henry .......

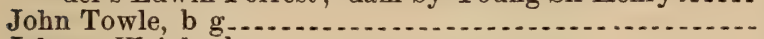
Johnny Weigle, b g.

2.25

2.23

$2.23 \frac{3}{4}$

$2.25 \frac{1}{4}$

*Jordan, ch g, by son of Scott's Hiatoga..............

Josie, br $\mathrm{m}$

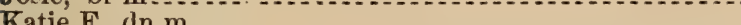

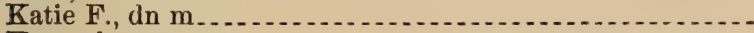

Keno, br g . .

Killbuck Tom, ch $\mathrm{s}$

*Kismet, b g, by Capt. Walker.........................

Lady Alice, $b \mathrm{~m}$... . ...........

Lady Bevins, rn m

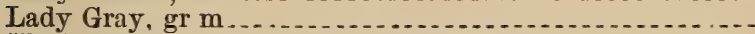

*Lady Lightfoot, br m, by Strathmore

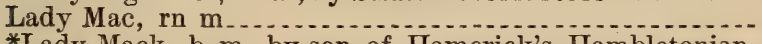

*Lady Mack, b m, by son of Hamerick's Hambletonian, dam by Mambrino Templer.

Lady Ryan, b m

2.29

(n)

Lady St. Clair, b m, by St. Clair $\ldots \ldots \ldots$

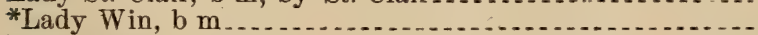

Lamplighter, ch $\mathrm{m}$

*Laura J., blk m, by Legal Tender, Jr................

Legal Tender, b s.

*Leviathan, ch $\mathrm{g}$

Limber Jack, b g, by Tom Hal

Limber Jim, ch $\mathrm{g}$.

Lincoln, ch g, by Tempest $\mathrm{Jr}$.

*Link, b g..

Little Brown Jug, br g, by Gibson's Tom Hal.

Little Ed, gr g

*Lit tle Jennie, blk m

Little Mac, $\mathrm{b} g$.

2.27

$2.26 \frac{1}{4}$

Little Mac, b g.................. 2.22

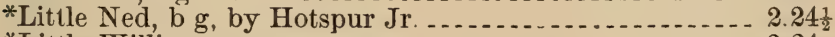

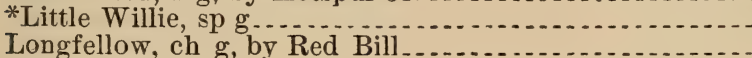

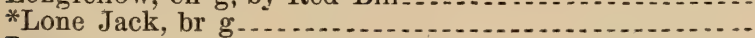

Lotta, rn m.

2.24

$2.19 \frac{1}{4}$

2.19

$2.25 \frac{1}{4}$

*Lottie P., b m, by Blue Bull (?)

Louisa, rn m. 
Lucy, gr m, by Sligo .........

Magoozler, gr g ........... 2.20

Marie Scott, b m, by Scott's Hiatoga ................. 2.24

Mattie Hunter, ch m, by Prince Pulaski . . . . . . . . . . . . 2.123

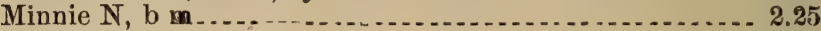

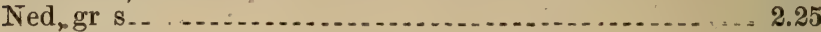

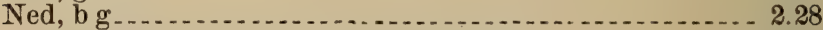

Ned Forrester, ch g, by Young Forrester ............. 2.231

*Nellie Shaw, ch m. .

Nelly Davis, b m, by Kremer's Rainbow ............... 2.24 $2.2 \frac{1}{4}$

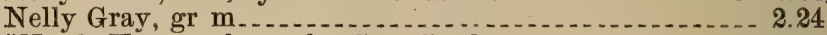

*Nettle Keenan, br m, by Geo. Gordon .............. 2.27

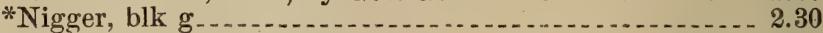

Nimrod, ch g, by Missouri Chief.

Noonday, b g _.........

Oddfellow, ch g ....

*Ohio Maid, b m

Onward, blk g, by Chieftain

Ouida, b m, by Black Hawk

Pacific, ch g

Pedro, b g

Pel, rn g-

Pete Whetstone, b g

Pocahontas, ch m, by Iron's Cadmus ................. 2.20

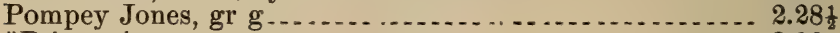

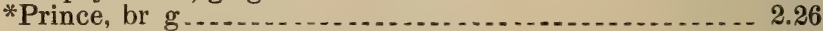

*Princess, b m, by Yocahontas Boy ................. $2.19 \frac{1}{4}$

Prussian Maid, b m, by Signal ...................... 2.19

Queen of the West, dn m ......................... 2.28

Rattling Jim, b g, by Flying Hiatoga ............... $2.23 \frac{1}{4}$

Red Bill, b g . . .

*Richball, br g, by King Pharoah, son of Seely's Ameri-

can Star, dam by Little Arthur, son of Imp. Glenco _- $2.12 \frac{1}{2}$

Roanoke, rn $\mathrm{g}$, by Old Pilot ........................ 226

*Rostrever, gr g, by Cutter's Davy Crockett............ 2.261

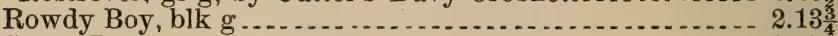

Sailor Boy, rn g, by Smuggle Jr................... 2.17

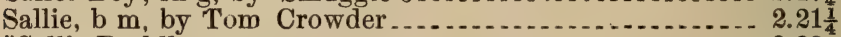

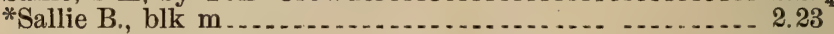

Sallie Morris, b m . . .

Sam Slick, b g . . .

Sealskin, blk $\mathrm{g}$..................

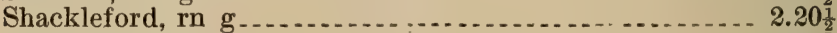

*Shaker, b g . . . . . . .

Shaker Boy, b g...................

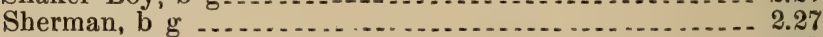

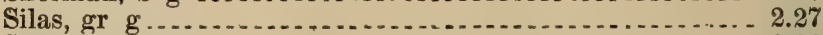

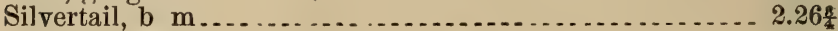

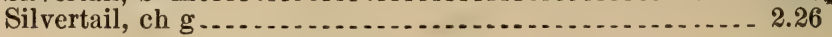




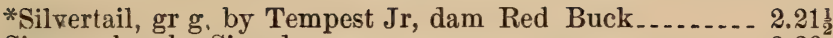

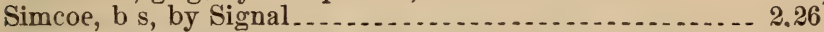

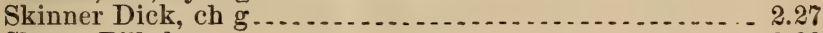

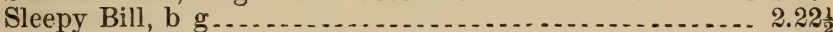

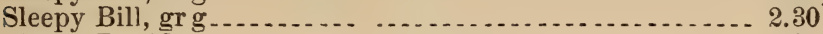

Sleepy David, rn g

Sleepy George, b g, by Belmont Bill.................. 2.15

Sleepy John, b g

Sleepy Tom, ch g, by Tom Rolf...................... 2.121

Sorrel Billy, ch g, by Scott's Hiatoga................. 2.20

Sorrel Dan, ch g, by Red Buck....................... 2.14

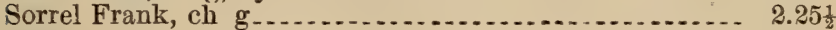

Stella ...............

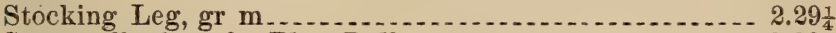

Stonewall, vh g, by Blue Bull........................ 2.28

Straightedge, gr g .....................

Sucker State, b g

Sweeper, gr g

Sweetzer, gr g, by Gosnell's Tom Crowder ........... 2.15

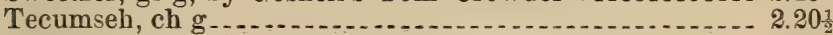

*Thunder, ch g, by Hardee...................... 2.2. $22_{4}^{3}$

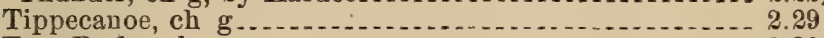

Tom Parker, br g

Tom Smiley, ch g...

Topsy, blk $\mathrm{m} . . . . .2 .25 \frac{1}{2}$

Trifle, rn g ...................................... 2.28

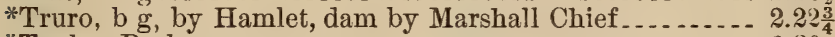

*Tucker B., b g..................................... 2.30

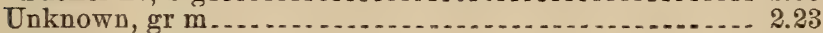

*Vasco, b g, by Copperbottom ....................... 2.263

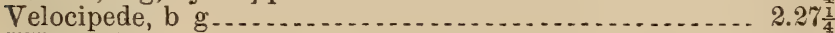

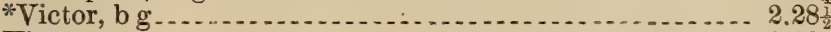

Victor, gr g

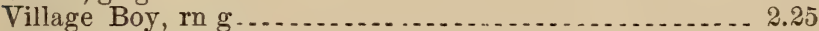

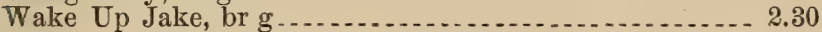

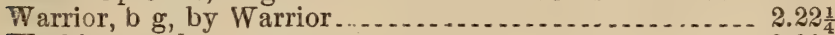

Washington, b g . . . .

Washington, blk s, by Bucephalus................. 2.261

Washington Maid, ch m ............................ 2.26

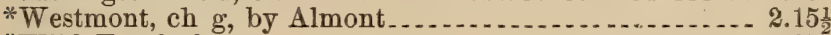

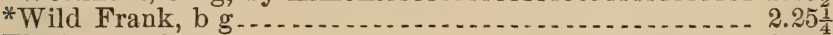

William C., b g

Winder, ch g, by Whitehall ........................ 2.21

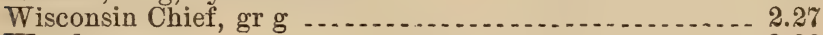

Wonder, gr g _...

Wonderful, $b \mathrm{~g}$, by Legal Tender $\mathrm{Jr}_{\ldots} \ldots \ldots . .25 \frac{1}{2}$

Wyandotte Chief, gr g

Yankee Sam, dn $\mathrm{g}$

Young America, br g, by Vt. Black Hawk........... 2.23 


\section{A. N, SIIEALI}

\section{"RECUPERATIVE"}

This preparation is designed to be administered to horses suffering from exhaustion, occasioned by violent exertion in all contests of speed. The "Recuperative" will slow the heart's action and restore the nerve force expended in trotting or pacing a fast heat. The "Recuperative" affords instant relief in cases of "Thumps" or Palpitation of the Heart, but should not be given unless the condition of the horse clearly indicates the necessity of an artificial stimulant, in which case this preparation is invaluable. Give no whisky, sherry wine, or any other stimulant with the "Recuperative."

Dose.-Twenty drops on the tongue at the termination of the heat, if necessary.

In severe attacks of Lung Fever, or Congestion of the Lungs, give the "Recuperative" in fifteen drop doses every half hour until relieved, then once in an hour, \&c. It will give relief in every case.

Put up in four ounce bottles with directions. Price, $\$ 2.00$ per bottle. Sent to any address on receipt of price.

Prepared only by

The Smeall Horse Remedy $\mathrm{C}_{0,}$ TOLEDO, OHIO. 


\section{Dr. A. N. SMEALL'S}

\section{Nerve \& Blood Tonic}

This remedy corrects every irregularity of the Digestive Organs, Liver, and Blood, arousing a healthy appetite, and assisting the stomach in digesting the food perfectly, whereby all functional troubles are expelled. This medicine is in form of powders, each box containing twelve powders, one to be given at a dose in soft feed, or bran mash.

This preparation is compounded from pure ingredients, and contains no metallic substance but Iron. Each powder has an outside wrapping of tin foil, and will retain its strength indefinitely.

No medicine has ever been offered the owners of horses equal to this for Loss of Appetite, Staring Coat, General Weakness and Emaciation, Vertigo or Staggers, Swelling of the Legs, and all forms of trouble resulting from Indigestion, Neglect, or Overwork. One box is usually sufficient.

Price, $\$ 1.00$ per box. Sent to any address on receipt of price.

Prepared by the

\section{Smeall Horse Remedy $\mathrm{C}_{0}$,}

TOLEDO, OHIO. 


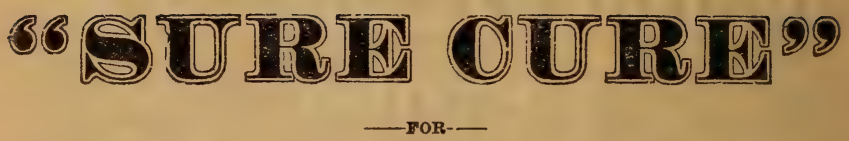

\section{Cuts, Burns, Wounds and Sores,}

Of Every Description.

\section{IMMEDIATELY RELIEVES PAIN.}

The old time theory, to heal wounds, sores, cuts, bruises, burns, skin and flesh diseases, of all descriptions, was by making salves of various ingredients, always using beef and mutton tallow, hog's lard, beeswax, and various other fatty substances. Late discovery has taught us that all above mentioned ingredients are injurious and outright poison to the human or animal flesh where wounded.

We introduce to the public the new remedy called the "SURE CURE," prepared entirely of extracts of vegetations. The "SURE CURE" will at once relieve pain, prevent inflammation, remove all soreness, and heal wounds and sores very quick. Our Agents are authorized to refund money in all cases where "SURE CURE" fails to do as recommended.

This remedy has No equal as an application to horseflesh for all cases of sore necks, sore breasts, saddle galls, or cracked heels (commonly called scratches), or any form of flesh wounds, recent or chronic.

Price, 25 and 50 cents per box. If your Druggist has not got it, order direct from us. Trial sample for human flesh sent on receipt of 2-cent stamp; sample for horse flesh sent on receipt of three 2-cent stamps. Goods sent by mail anywhere free, on receipt of price. Address

\section{SCHAEFER \& CO.,}

Sole Proprietors,

Room 5, Campbell Block,

TOLEDO, 0. 


\section{Dr. JNO. ELLIOTT, Y.S.}

\section{GRADUATE OF}

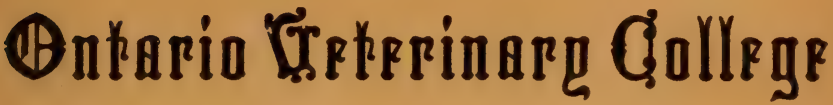

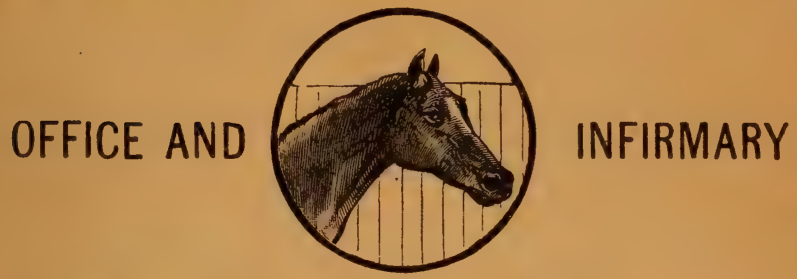

No. 83 East Wabash Street,

INDIANAPOLIS, IND.

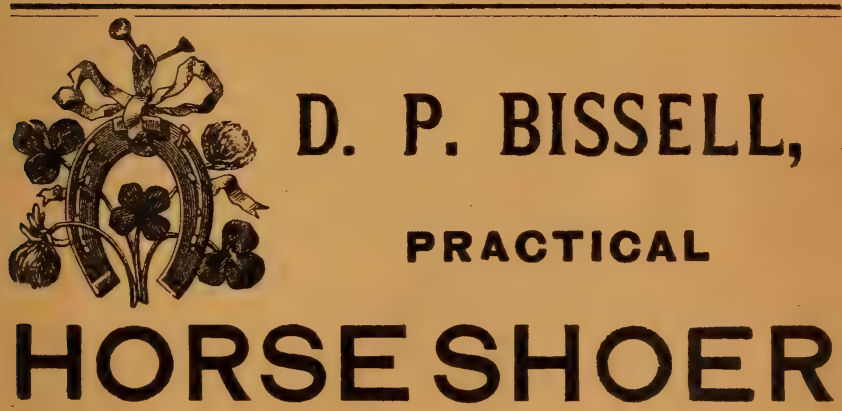

No. 26 East St. Joe Street, INDIANAPOLIS, IND.

All Track Horses shod in the most scientific manner. Having had 30 years experience with Track Horses. I am enabled to give the best of satisfaction. Shoes made from diagram of feet of any weight and sent to any point in the United States., PRICES REASONABLE. 


\section{Dr. A. N. SMEALL'S CAMPHORATED \\ Leg and Body Wash.}

This preparation must be diluted in the proportion of one ounce of the Wash to one quart of rain water, and thus diluted to be used as an ordinary wash for race horses in training. It will be found superior to any preparation designed for the same purpose, as it contains properties, which, when applied as a body wash, assists nature in opening the pores of the skin, which enables the blood to throw off its watery surplus through the pores, thereby reducing the temperature of the body and relieving the internal organs of circulation and respiration, and should always be used in assisting a horse to recover between heats of a race.

As a Leg Wash it is equally valuable. Legs inclined to inflammation and swelling from work, if bandaged with wet bandages and kept moist with the Wash while not at work, will regain their normal condition, without a "let up" in training.

Put up in Quart Bottles only, and sent by . Express to any address on receipt of price, $\$ 300$. One Quart makes Eight Gallons when diluted. .

Address orders to.

\section{SMEALL HORSE REMEDY CO.,}











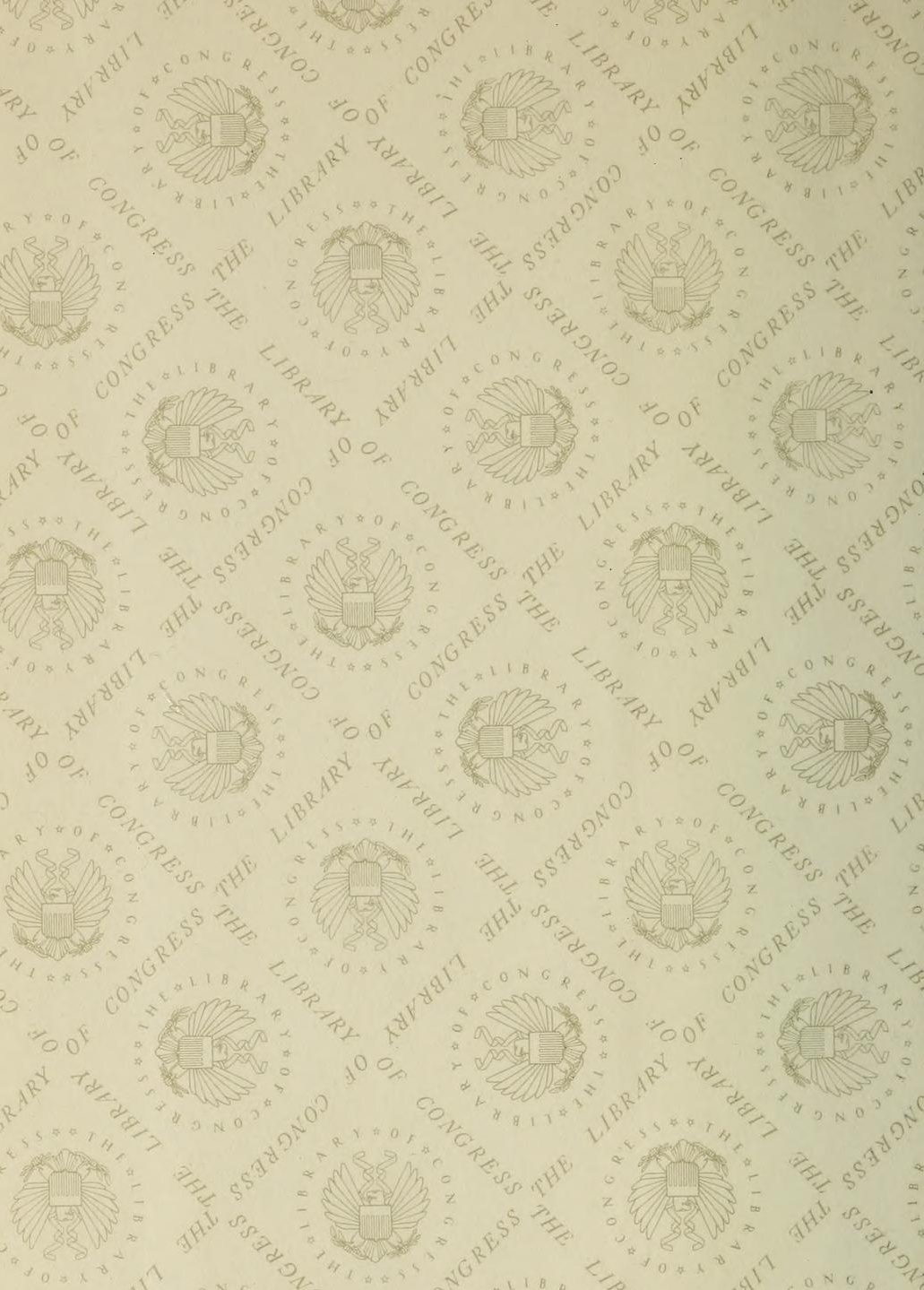

${ }_{3} 00$, 



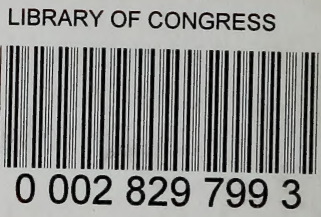

